Early Permian Vertebrates

from the Cutler Formation

of the Placerville Area

Colorado

GEOLOGIGAL SURVEY PROFESIONAL PAPER 503-G

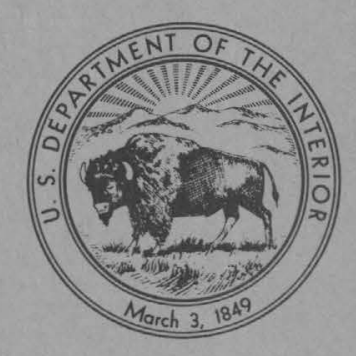





\section{Early Permian Vertebrates}

\section{from the Cutler Formation}

\section{of the Placerville Area}

Colorado

By GEORGE EDWARD LEWIS and PETER PAUL VAUGHN

With a section on Footprints from the Cutler Formation By DONALD BAIRD

C O N T R I B U T IO N S T O PA L E O N T O L O G Y

GEOLOGICAL SURVEY PROFESSIONAL PAPER 503-C

The typical Cutler Formation of Colorado correlates with classic European and with other North American Lower Permian continental formations

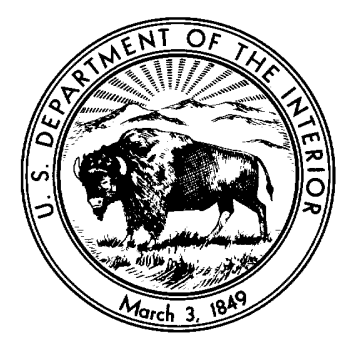


UNITED STATES DEPARTMENT OF THE INTERIOR

STEWART L. UDALL, Secretary

GEOLOGIGAL SURVEY

Thomas B. Nolan, Director 


\section{CONTENTS}

Abstract

Introduction

Early work on the Cutler Formation

Present study . . .

Acknowledgments............

Geography

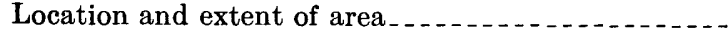

Surface features and areas of outcrop

Geology

Stratigraphy and structure of the Placerville area

Cutler Formation of Colorado.

Cutler Formation of nearby State

Vertebrate fauna

Systematic descriptions._._.

Eryops of. E. grandis (Marsh, 1878)

Platyhystrix rugosus (Case, 1910)

New (but unnamed) genus and species.......

Diadectes sanmiguelensis Lewis and Vaughn, $\mathrm{n}$.

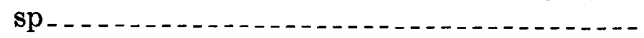

Limnoscelops longifemur Lewis and Vaughn, $\mathrm{n}$. gen., n. sp.
Page

C1

1

1

1

2

2

2

2

Vertebrate fauna-Continued

Systematic descriptions-Continued

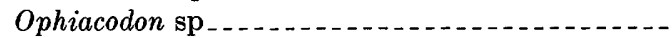

Cutleria wilmarthi Lewis and Vaughn, n. gen.,

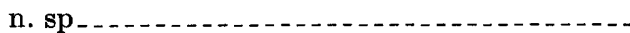

Mycterosaurus smithae Lewis and Vaughn, n. sp.

Age and correlation of the fauna

Comparison with Early Permian faunas of North

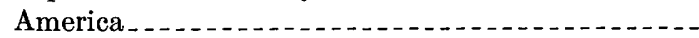

Comparison with European Early Permian faunas.

Paleogeographic considerations . . . . .

Selected references.

Footprints from the Cutler Formation, by Donald Baird

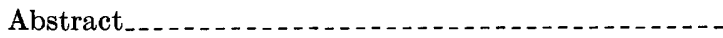

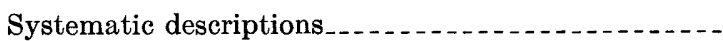

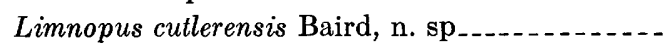

Genus indet., cf. Brachydactylopus Toepelman and Rodeck, 1936.....

Prospectus and problems.

References cited.......

Page

\section{ILLUSTRATIONS}

Figure 1. Index map of Colorado.

2. Diagrammatic section showing geologic formations of the Placerville area

3. Profile and section, Cutler Formation, Placerville area

4. Fossil vertebrate locality map, Placerville area

5-6. Photographs:

5. Platyhistrix rugosus, natural mould.

6. Platyhistrix rugosus, latex cast.

7-13. Drawings:

7. Diadectes sanmiguelensis, n. sp., type skull

8. Diadectes sanmiguelensis, n. sp., type lower jaw and lower left front leg.

9. Limnoscelops longifemur, n. gen., n. sp., elements of type and referred specimen.

10. Ophiacodon sp., vertebrae._.

11. Cutleria wilmarthi, n. gen., n. sp., type

12. Cutleria wilmarthi, n. gen., n. sp., type skull and referred snout_.

13. Mycterosaurus smithae n. sp., type

14. Sketches of footprints of Limnopus vagus, Limnopus cutlerensis, and korynichniid cf. Brachydactylopus _.....

\section{TABLE}

TABLE 1. Fossil localities 



\title{
CONTRIBUTIONS TO PALEONTOLOGY
}

\section{EARLY PERMIAN VERTEBRATES FROM THE GUTLER FORMATION OF THE PLAGERVILLE AREA, COLORADO}

\author{
By George Edward Lewis and Peter Paul Vaughn ${ }^{1}$
}

\begin{abstract}
Fossil vertebrates in the Cutler Formation of Colorado were first found in the Placerville area in the upper 885 feet of the 1,100 feet of outcrops. Total thickness of the Cutler in this area is estimated at 4,000 feet. Two genera of labyrinthodont amphibians, four genera of cotylosaurian reptiles, and three genera of pelycosaurian reptiles-in all, nine distinct generawere found.

In this assemblage only one animal, Platyhystrix rugosus, can be confidently assigned to an already known species. The species of Eryops is probably close to, if not identical to, $E$. grandis. The species of Ophiacodon may be either O. navajovicus or $O$. mirus. A seymouriid represents an unknown genus and species. A captorhinomorph is indeterminate below suborder. Two new genera, a limnoscelid and a sphenacodontid, and two new species, one of Diadectes and one of Mycterosaurus, are described and named.

The age of this fauna is Early Permian, comparable to that of part of the Dunkard Group and part of the Wichita Group (Moran, Putnam, and Admiral Formations) of the United States, and to that of the Autunian and lower Rotliegende of Europe. These American and European faunas lived in remarkably similar environments. Early Permian continental sedimentation in North America and Europe was only rarely and partially interrupted by marine transgressions that were of short duration.
\end{abstract}

\section{INTRODUCTION}

\section{EARLY WORK ON THE CUTLER FORMATION}

Most of the Permian and Triassic rocks of the Four Corners and nearby areas are red sandstone, siltstone, and shale that were laid down in continental or shallowmarine environments. These rocks were known generally as the Red Beds for about 60 years after their first geologic description. Jules Marcou (1856, p. 140 153 , map) worked in the areas of outcrop of the later named Abo, Chinle, and Wingate Formations in 1853; he correlated them with the New Red Sandstone of Europe, and included them in his Gypsum Formation of Triassic to Jurassic age. W. H. Holmes (1877a, p. 266, $267 ; 1877 \mathrm{~b} ; 1878$, p. 194) was the outstanding pioneer explorer who mapped and studied the areas of outcrop of the later named Cutler and Dolores Formations of southwestern Colorado; he called them the "JuraTrias *** Red Beds." This name was in vogue for some four more decades: for examples, Scott (1907, p. 647) wrote of "The Permian and Triassic members of the Red Beds", and Tomlinson (1916, p. 245), of "Red Beds time" in his work on "The origin of the "Red Beds."

Although correlative rocks in nearby States have yielded fossil vertebrates for many years, the Cutler Formation of Colorado had been thought to be unfossiliferous before the present study.

\section{PRESENT STUDY}

V. R. Wilmarth and R. C. Vickers of the U.S. Geological Survey (Wilmarth and Hawley, unpub. data) were the first, to our knowledge, to discover fossils in the Cutler Formation of Colorado. They collected a few weathered-out fragments from two localities. After study showed that the fragments had bony structure, G. E. Lewis went to the localities with Wilmarth and collected two partial skeletons in 1952. Further search at that time yielded more specimens of fossil vertebrates and plants. Still more fossil vertebrates were found in 1953, when A. S. Romer, S. J. Olsen, and A. D. Lewis of the Museum of Compartive Zoology at Harvard College joined G. E. Lewis of the U.S. Geological Survey for several weeks of collecting. Preparation of the collections was begun at Harvard, where G. E. Lewis and A. S. Romer made preliminary determinations of the vertebrate fauna insofar as was possible at that stage of preparation. Their preliminary report, cited in Bush and others (1959, p. 313), was necessarily inconclusive. A. S. Romer turned over his share of this joint study to P. P. Vaughn in 1958, when the latter completed preparation of the specimens and joined G. E. Lewis in the preparation of the present report. Although no other work has been done on the paleontology of the Cutler Formation of Colorado, Bush and others (1959;

\footnotetext{
1 University of California, Los Angeles.
} 
1960) have published the first two of five planned reports on the areal geology of the Placerville and four adjoining $71 / 2$-minute quadrangles which they have mapped geologically; the published scale of these quadrangles is $1: 24,000$.

\section{ACKNOWLEDGMENTS}

We gratefully acknowledge the kind help of all who contributed materially to this study: V. R. Wilmarth and R. C. Vickers not only made original discoveries and helped in the preliminary fieldwork but also gave advice on the geology of the Placerville area. Wilmarth and C. C. Hawley helpfully put unpublished information at our disposal; we have drawn on it for our paragraphs on the geology of the area. A. S. Romer, who was active in the early stages of this project, graciously gave us the results of his study and arranged for much of the technical preparation of the fossil vertebrates; his preparators, S. J. Olsen and A. D. Lewis, lent their considerable talents to both the field and laboratory work. The late Mrs. Stockton Smith and Mr. and Mrs. F. E. Lambert of Placerville all helped to make our stay in the area pleasant and successful. Figures 1 through 4 were drawn by Mrs. Mary Wagner, and the photographs of Platyhystrix rugosus were made by Mr. E. P. Krier. All other illustrations of the Cutler fauna were drawn by Mrs. H. N. Kavanau of the University of California, Los Angeles.

P. P. Vaughn's participation in this study was supported in part by National Science Foundation grants G-12456 and GB-1014.

\section{GEOGRAPHY}

\section{LOCATION AND EXTENT OF AREA}

This report describes the Placerville area where the Cutler Formation crops out in a band from $1 / 10$ to $3 / 4$ mile wide on both sides of the San Miguel River for 4 miles upstream and 4 miles downstream from the town of Placerville. The town, in San Miguel County, Colo., is at the mouth of Leopard Creek, where Colorado State Highways 62 and 145 meet 3 miles west-northwest of the intersection of $38^{\circ} \mathrm{N}$. lat and $108^{\circ} \mathrm{W}$. long (fig. 1). No common carrier serves the town, formerly a station on the abandoned Rio Grande Southern narrowgage railroad.

\section{SURFACE FEATURES AND AREAS OF OUTCROP}

Most of the country around Placerville is a high plateau having a rolling surface from 9,000 to 9,500 feet in altitude. The sheer and craggy peaks of the San
Miguel and San Juan Mountains jut high above the plateau's surface; streams that have their sources in these mountains have cut canyons a thousand or more feet deep into the plateau. Less than 20 miles from the Placerville area, where the channel of the San Miguel River has cut down to about 7,000 feet above mean sea level, there are 4 peaks whose altitudes exceed 14,000 feet, and more than 50 peaks whose altitudes exceed 13,000 feet.

At the upstream and downstream limits of the area described in this report, the contact between the base of the bright-red Dolores Formation and the top of the dark-red Cutler Formation is at river level. Between these limits, the Dolores generally ranges in thickness from 465 to 575 feet; as much as 1,100 feet of the upper part of the Cutler is exposed in outcrops as much as three-quarters of a mile wide on both sides of the river. As much as 1,300 feet of brilliant red cliffs of Permian and Triassic rocks makes up the lower slopes of the abrupt, almost inaccessible, spectacular canyons of the San Miguel and its tributaries; as much as 1,000 feet of Jurassic and Cretaceous rocks makes up the equally steep upper slopes. The difficulty of access no doubt explains the many years that passed before the discovery of the first fossil vertebrates in the Cutler, and the fossil "palmlike" forest of Sanmiguelia lewisi (Brown, 1956), the oldest known angiospermous flowering plant, in the Dolores. It is entirely probable that further systematic exploration of these cliffs from year to year would yield a rich harvest of new faunal and floral elements.

\section{GEOLOGY}

\section{STRATIGRAPHY AND STRUCTURE OF THE PLACER-} VILLE AREA

Nearly flat-lying Paleozoic and Mesozoic rocks crop out in the canyon walls of the Placerville area. Figure 2 shows all the formations in stratigraphic order, together with a diagrammatic section made near the old Fall Creek Post Office, 21/4 miles upstream from Placerville. V. R. Wilmarth (Wilmarth and Hawley, unpub. data), A. L. Bush (Bush and others, 1959, 1960), and their parties found these formations to be complexly faulted by three systems of steeply dipping faults that trend northwest, north, and northeast. They describe Tertiary(?) clastic and basalt porphyry dikes that intrude fractures parallel to the northwest-trending fault system. The river has recut its present-day channel in an old fill of Quaternary sands and gravels, remnants of which are plastered against the lower walls of the canyon. It is in these remnants that the placers that gave the town its name were mined. 


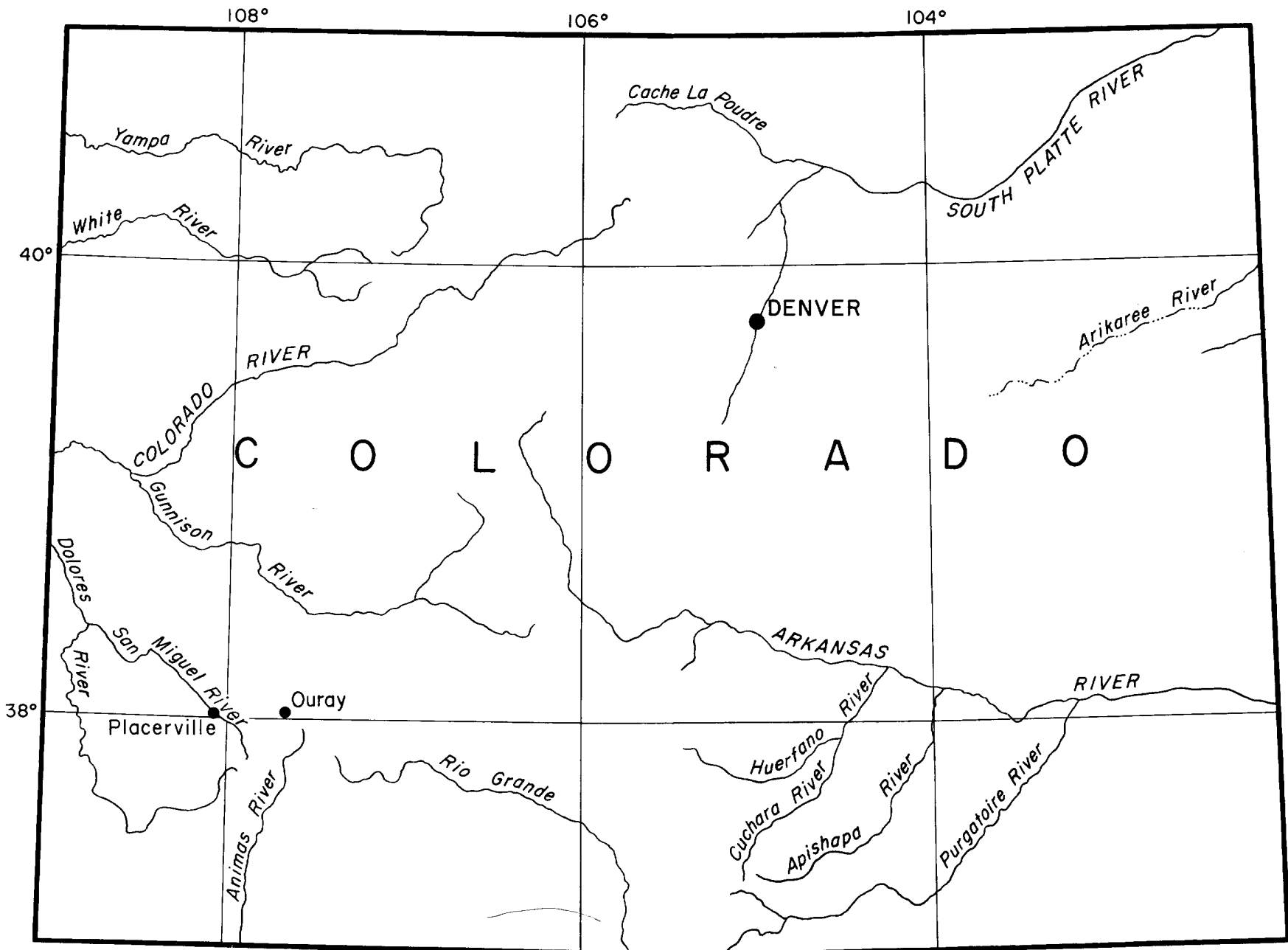

$\begin{array}{rrrr}0 & 50 & 100 & 150\end{array}$

Frgure 1.-Iocations of Placerville and Ouray.

\section{CUTLER FORMATION OF COLORADO}

The oldest rocks that crop out in the Placerville area are those of the Cutler' Formation into which the San Miguel River has cut its canyon. The base of the formation is not exposed in this area, where the thickness of outcrop ranges from about 250 to 1,100 feet downward from the top of the formation to the lowest exposures. The Upper Triassic Dolores Formation disconformably overlies the Cutler here, but the disconformity is not apparent at close range. Figure 3 is a profile made across the San Miguel Canyon, half a mile upstream from Placerville, where the greatest thickness of the Cutler Formation in the report area is exposed.

Whitman Cross and his associates named and gave us our first specific knowledge of the Cutler Formation. Cross $(1899$, p. $2-3)$ originally included these rocks as part of the Triassic Dolores Formation exposed in the
Dolores River of the Rico area, but he suspected that the more somber, seemingly unfossiliferous lower part of the formation might be a separate rock unit: "Whether or not all the beds now associated with the fossiliferous series in the Dolores Formation are really of Triassic age remains to be determined by further discoveries" (p. 2). "As known between the Animas and San Miguel Valleys, the Dolores Formation may be roughly divided into a lower, coarser-grained part *** and an upper, finer-grained portion $* * *$ often fossiliferous" (p. 3).

Later, Cross and Howe $(1905$, p. 5) found an angular unconformity between these upper and lower parts in the valley of Cutler Creek, a tributary of the Uncompahgre River only 20 miles east of Placerville. They redefined the Dolores Formation to include only the upper part and proposed the name Cutler Formation 


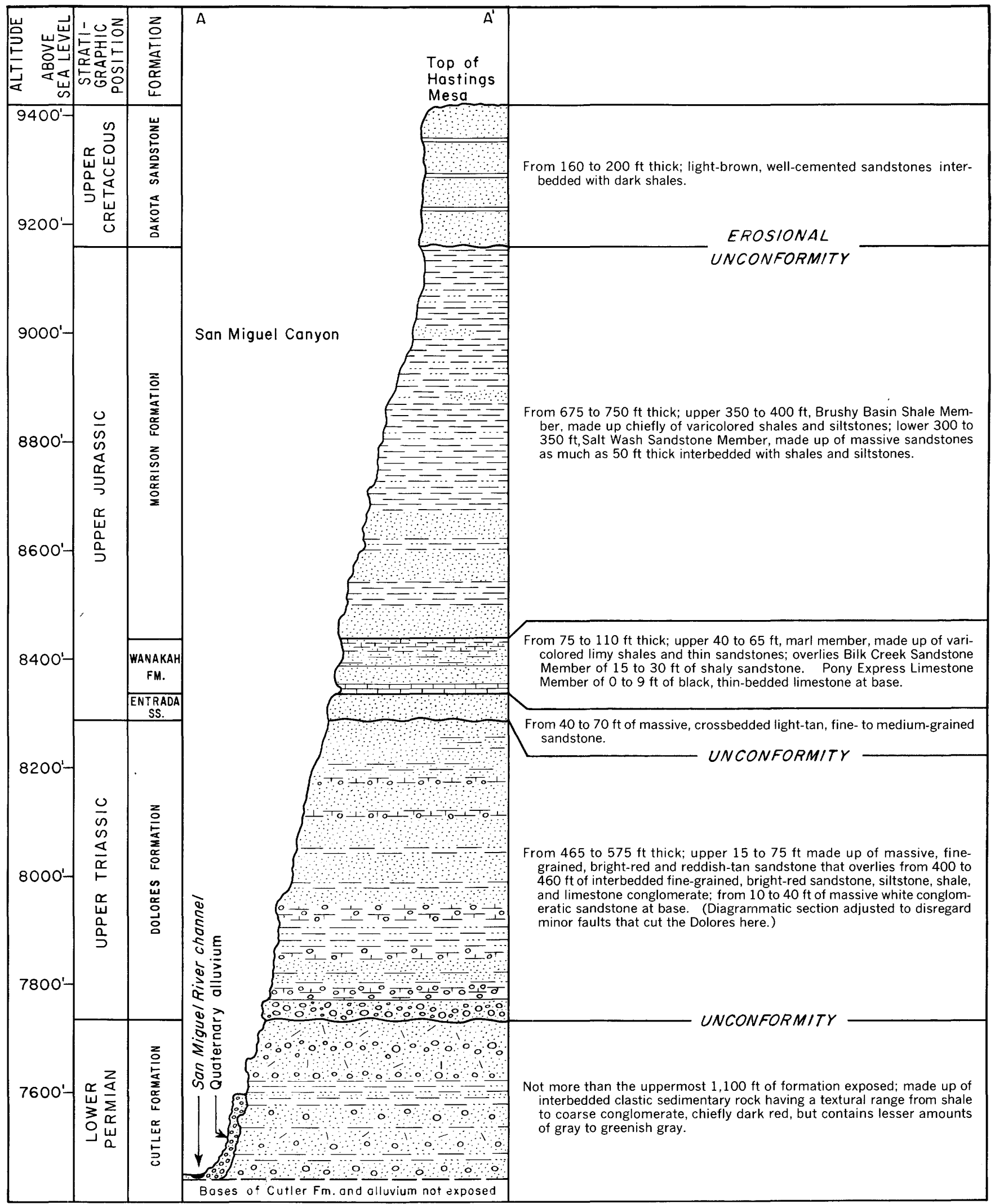

FIGURE 2.-Geologic formations of the Placerville area, and diagrammatic section $A-A^{\prime}$ near old Fall Creek Post Office. See figure 4 for location of section. 
for the lower part of the Dolores as originally defined. They provisionally referred the Cutler to the Permian, but stated that it might belong, wholly or in part, to the Pennsylvanian, and added that no fossils had been found in the Cutler, which, according to Luedke and Burbank (1962), is about 2,000 feet thick in the type area.

The Cutler Formation thickens northwest and west of the type locality, and reaches a thickness of 4,000 feet in the Placerville area (Bush, Marsh, and Taylor, 1960, p. 431). The thickest section we measured here was about 1,100 feet thick in the virt ually flat-lying outcrops in the $\mathrm{S} 1 / 2$ sec. $2, \mathrm{~T} .43 \mathrm{~N}$., R. $11 \mathrm{~W}$., above the contact with Quaternary alluvium at 7,350 feet altitude above datum as shown in figure 3. Thus, only about the upper fourth of the Cutler Formation crops out in the Placerville area, and all the vertebrate fossils described in this report found from 80 to 885 feet below the top of the Cutler come from the upper four-fifths of the outcrops. (See table of fossil localities.)

In the Placerville area, the Cutler Formation is made up of interbedded, interlensing conglomerate, sandstone, siltstone, and shale. The coarse components of the conglomerate, as large as small boulders but usually not larger than cobbles, consist of well-rounded granite, quartz, greenstone, metasedimentary rocks, and a few limestone fragments. The matrix is fine- to coarsegrained limy arkosic sandstone. Fine- to coarse-grained arkosic sandstone, in beds as much as 30 feet thick, add up to a greater aggregate thickness than do the beds of conglomerate, which make up about one-third of the total thickness of outcrop. There are some beds of quartz arenite. The coarse clastic rock outcrops are generally a dark red to maroon, but they are gray to greenish gray in some places. Bleaching has resulted in irregular gray, green, or white blotches. Crossbedding is common. Torrential deposition took place, as shown by lateral gradation, interlensing, and interbedding between sandstone and conglomerate. No individual beds of conglomerate can be traced laterally for more than a few hundred feet. Finer grained micaceous sandstone, siltstone, and shale that weather to hematite red commonly contain bleached zones from 1 to $75 \mathrm{~mm}$ in diameter; these zones seemingly have organic centers. These finer clastics yielded almost all the fossil vertebrates; they contain many mud cracks and raindrop and other impressions including footprints. (See section by Baird, p. C47-C50.)

\section{CUTLER FORMATION OF NEARBY STATES}

The Cutler Formation, as now defined by the U.S. Geological Survey, reaches southward for some 65 miles beyond the Colorado-New Mexico boundary to lat $36^{\circ}$ N., south of which the Abo Formation and the lower part of the Yeso Formation replace the Cutler by intertonguing. Lee (1909, p. 12) named the Abo and Yeso Formations from localities more than 100 miles south of the 36th parallel; he believed them to be part of the Pennsylvanian Series.

The Cutler Formation has not been subdivided in Colorado and New Mexico, but has been divided in nearby southeastern Utah and northeastern Arizona, where, from oldest to youngest, five such units are recognized: The Halgaito tongue, the Cedar Mesa Sandstone Member, the Organ Rock Tongue (all three, and the Hoskinnini Member, of Baker and Reeside, 1929, p. 1421-1422), the De Chelly Sandstone Member (of Gregory, 1917, p. 31), and the Hoskinnini Member.

\section{VERTEBRATE FAUNA}

The fossil vertebrates from the Cutler Formation of the Placerville area include several specimens of new, interesting, and important forms, but the basic aspect of the collection is that of an assemblage from beds of Early Permian age in a new geographic area. Figure 4 is a map that shows 14 numbered localities where vertebrate fossils were found; one of these locality numbers is listed for each specimen described below. Table 1 gives additional data on fossil localities. The following systematic faunal list includes only the animals that are determinable at least to suborder, but the collection also includes indeterminate fragments of which some may represent additional genera and species.

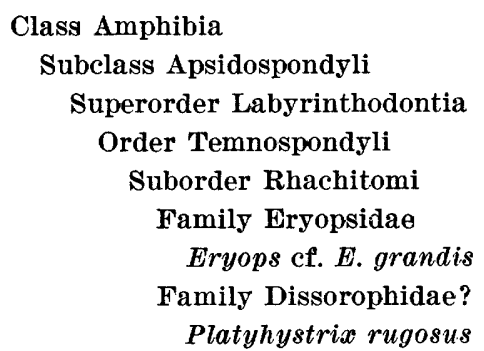




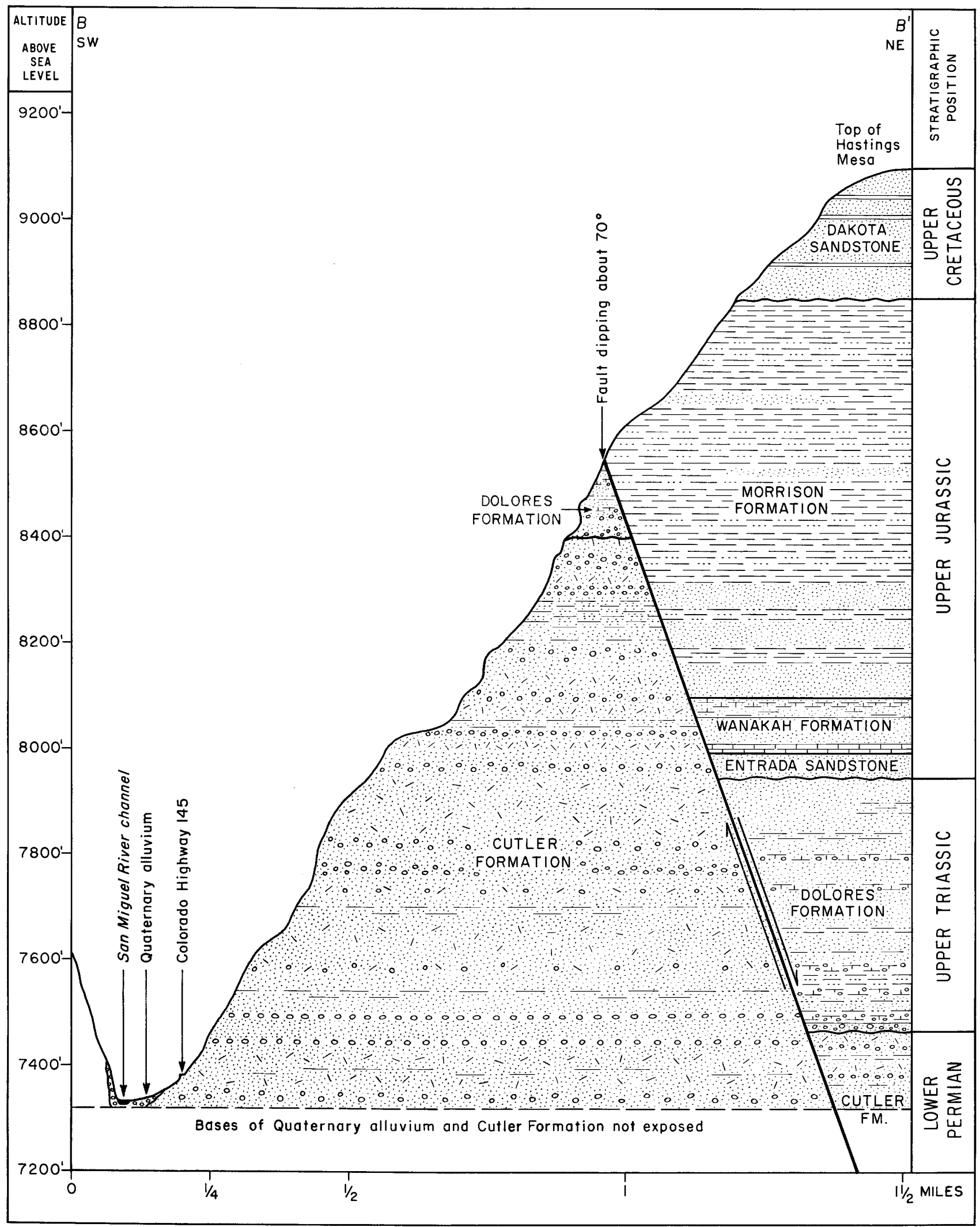

Figure 3.-Profile and section $B-B^{\prime}$ near greatest exposed thickness of Cutler Formation in Placerville area. See figure 4 for location of section. 
Class Reptilia-Continued

Subclass Synapsida

Order Pelycosauria

Suborder Ophiacodontia

Family Ophiacodontidae Ophiacodon sp.

Suborder Sphenacodontia

Family Sphenacodontidae

Subfamily Haptodontinae

New genus and species

Suborder Edaphosauria

Family Nitosauridae

New species of Mycterosaurus

SYSTEMATIC DESCRIPTIONS

The following abbreviations are, used in this section of the text to refer to collections of vertebrate fossils: AMNH, American Museum of Natural History; CNHM, Chicago Natural History Museum; MCZ, Museum of Comparative Zoology at Harvard College; UMMP, University of Michigan Museum of Paleontology; and USNM, United States National Museum.

TABLE 1.-Fossil localities

[All localities are on north wall of San Miguel Canyon. Localities 15 (about $8 / 4$ mile south by east of Placerville) and 16 (about $5 / 8$ mile south of Placerville) correspond to those of $\mathrm{MCZ}$ field Nos, 12 and 11 respectively; both 15 and 16 are imprecisely located and are on the south wall of San Miguel Canyon]

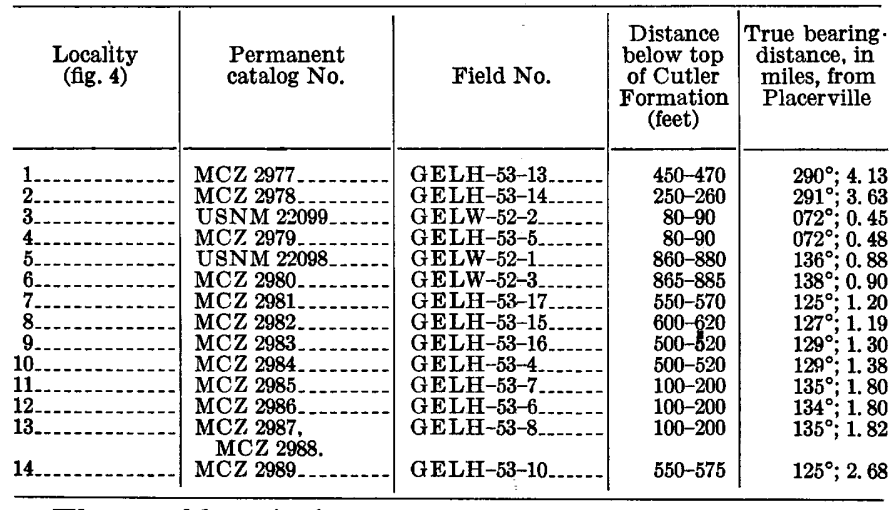

These abbreviations are used in figures $7,8,12$, and 13:

ACET, acetabulum

ANG, angular

$\mathbf{A R}$, articular

C, centrale, coronoid

$\mathrm{D}$, dentary

DC1, distal carpal 1

$F$, frontal

FCHT, foramen for chorda tympani

FOBT, obturator foramen

FSGL, supraglenoid

foramen

GLEN, glenoid cavity

I, intermedium

IT, intertemporal

J, jugal

L, lacrimal

LLJ, left lower jaw

MX, maxilla

$\mathbf{N}$, nasal
$\mathrm{P}$, parietal, pisiform

PF, postfrontal

PM, premaxilla

PO, postorbital

PP, postparietal

PRA, prearticular

PRF, prefrontal

QJ, quadratojugal

$R$, radius

$R L$, radiale

SANG, surangular

SM, septomaxilla

SP, splenial

SQ, squamosal

T, tabular

"membrane"

To, unerupted tooth

$\mathrm{U}$, ulna

$\mathbf{X}$, indeterminate element
ST, supratemporal

TM, tympanic

\section{Class AMPHIBIA \\ Subclass APSIDOSPONDYII \\ Superorder LABYRINTHODONTIA \\ Order TEMNOSPONDYII \\ Suborder RHACHITOMI \\ Family ERYOPSIDAE}

Eryops cf. E. grandis (Marsh, 1878)

Specimen MCZ 2980 (from loc. 6), which consists of a partial skull and mandible, a series of several vertebrae, and fragments of a pectoral girdle, is tentatively referred to Eryops grandis (Marsh, 1878).

The cranial skeleton is well-enough preserved to show, roughly, the proportions characteristic of Eryops. Most of the roof and palate are missing, and what is left is poorly preserved. It is possible to measure, approximately, the longitudinal distance from the tip of the snout to the angle of the lower jaw : about $255 \mathrm{~mm}$. This is very close to what the corresponding distance must have been in a specimen of $E$. grandis, from the Cutler Formation of northern New Mexico, of which Langston (1953, fig. 11) has figured the lower jaw. Few details can be made out on the skull, but it is interesting that a part of the shagreen of denticles on the coronoid bones of the lower jaw can be seen.

The series of several vertebrae is fairly well preserved; these vertebrae are of the construction characteristic of Eryops. The height of the neural spine above the zygapophyses is about $52 \mathrm{~mm}$, perhaps morethe best preserved spine is not complete. Langston (1953, fig. 11e) has figured a neural spine having a height of $44 \mathrm{~mm}$ above the zygapophyses, but this spine is from a different specimen than the lower jaw figured by him. There are no diagnostic features in the fragments of the pectoral girdle from locality 6 .

There is very little basis for determination of species of Eryops. Eryops specimens from Texas are generally included in the genotypic species $E$. megacephalus Cope, and the New Mexican forms are somewhat arbitrarily included in $E$. grandis. It is possible that several species will eventually be distinguished in both these areas (Langston, 1953, p. 380; Romer, 1947, p. 131), but at present no good diagnostic character is known to separate the Texan and New Mexican forms, and Romer (1952, p. 63-64) assigns even the forms from the Dunkard of eastern North America to $E$. megacephalus. The New Mexican animals tend to be smaller than the typical Texas specimens of E. megacephalus (Langston, 1953, p. 377-379). This difference, of course, may be due to the equivalence in age of the New Mexican Cutler to the lower part of the Lower Permian Wichita of north-central Texas: in Texas, the specimens of E. megacephalus low in the Wichita Group are smaller than those higher in the 
group. (See Romer, 1952, p. 62). For the present, it is perhaps best to refer tentatively the specimen from Placerville to $E$. grandis, because of the nearness of its geographic occurrence to that of typical $E$. grandis of New Mexico and because of its morphological similarity to the specimen figured by Langston (1953).

\section{Order TEMNOSPONDYLL \\ Suborder RHACHITOMI \\ Family DISSOROPHIDAE?}

Platyhystrix rugosus (Case, 1910)

Figures 5 and 6

The important specimen MCZ 2982 (from loc. 8) is referred to the long-spined rhachitomous amphibian Platyhystrix rugosus (Case, 1910), known heretofore only from the Cutler ("Abo") Formation of northern New Mexico. When better specimens are known, perhaps the Coloradan and New Mexican animals will prove to be specifically distinct, but the materials on hand offer no basis for separation.

The complicated taxonomic history of Platyhystrix rugosus has been summarized by Langston (1953, p. 403-404):

Long flat sculptured neural spines of the Platyhystrix type seem to have been recorded first by Cope (1881), who included them together with vertebrae of another form in the type of Zatrachys apicalis. Case (1910) separated Cope's material, designating part as type of Aspidosaurus apicalis (Cope); the elongate spines were referred to the pelycosaur Ctenosaurus Huene and served as type of Case's C. rugosus. Williston (1911 a, b) recognized their generic distinctness from Ctenosaurus and proposed the name Platyhystrix to receive the long ornamented spines. Like Case he at first regarded them as pelycosaurian in nature, but in 1916 he correctly recognized the amphibian affinities of the material. His basis for this conclusion was, however, erroneous, since he mistook a skull of Zatrachys found associated with characteristic Platyhystrix neural spines in New Mexico for that of the latter. As a result, statements that Zatrachys and Platyhystrix are closely related are common in subsequent literature. Several vertebrae associated with Zatrachys skulls in the Welles quarry [in northern New Mexico] are of the usual rather low-spined normal rhachitomous construction, and there is no suggestion of sculpture or ornamented apices.

Morphologically, the specimen in every way resembles comparable material of Platyhystrix rugosus. Comparisons have been made with a number of specimens of $P$. rugosus: UMMP 9770 , a neural spine; UMMP 9771, a proximal part of a rib; and CNHM UC 742, parts of neural spines and ribs mixed with skull fragments referable to Zatrachys. The figures and description published by Langston (1953) have been especially useful.

The new material consists mostly of the impressions, and some few bony remnants, of a series of 10 neural spines, on slab and counterslab. Most of these spines are incomplete proximally, but the seventh and eighth have connected to them impressions of the neural arches and zygapophyses. When the slab and counterslab were parted, many bony fragments of the spines were found, but the bone was badly leached away and the tubercular ornamentation had been lost from the spines; fairly good pieces of bone are included with the impressions of the seventh and eighth spines, but the tubercles are not complete even on these. The size and pattern of the tubercles can readily be made out in the impressions (fig. 5) and on a latex cast (fig. 6) taken from them. Also included are an impression of the proximal part of a rib and fragments of other bones, but these bones too are very poorly preserved.

The neural spines are undoubtedly from the dorsal region. They and the pattern of their tubercles are like those described and figured by Langsto: Williston (1911b), and the complete description need not be repeated here. The neural arch, as noted by Langston (1953, p. 402), is of rhachitomous structure. There is no sign of transverse barbs of the kind figured by Langston $(1953$, fig. $21 b, c)$, on a presumed middorsal spine, just above the junction between the smooth proximal part of the spine and the much longer tubercular part. The only spines in MCZ 2982 that have preserved proximal parts seem to be from a region posterior to the middorsal region. A presumed anterior dorsal spine figured by Langston (fig. 21a) has no transverse barbs.

The preservation of two attached impressions of neural arches allows anteroposterior orientation, and we now see, in this first known series of spines of $P$. rugosus, that Langston's hypothetical assignation of specific spines to specific vertebral regions is correct. To quote Langston (1953, p. 402) : "Presumed anterior dorsal spines arched gently forward, expand gradually upward toward broad platelike summit, which is sharply truncated with upper edge slanting strongly downward anteriorly. Presumed middorsal spines longer, straighter, more nearly parallel-sided, with summits more or less expanded anteroposteriorly and rounded above from front to back *** Presumed anterior caudal spines acutely bent backward distally *** very broad and platelike distally, narrower below." We would narrow Langston's diagnosis only to this extent: the "presumed anterior caudal spines" seem really to be spines from the region immediately anterior to the sacrum; Langston himself (1953, fig. 21d) labels one of his specimens as a "posterior dorsal or anterior caudal $* * *$ spine" (italics ours). The first spine of the series, as may be seen in the photograph, is displaced from its original position with respect to the others. The fourth of the series is the tallest and straightest; the tenth spine of the series is a recurved spine of the kind thought by Langston to be a possible anterior caudal spine. 


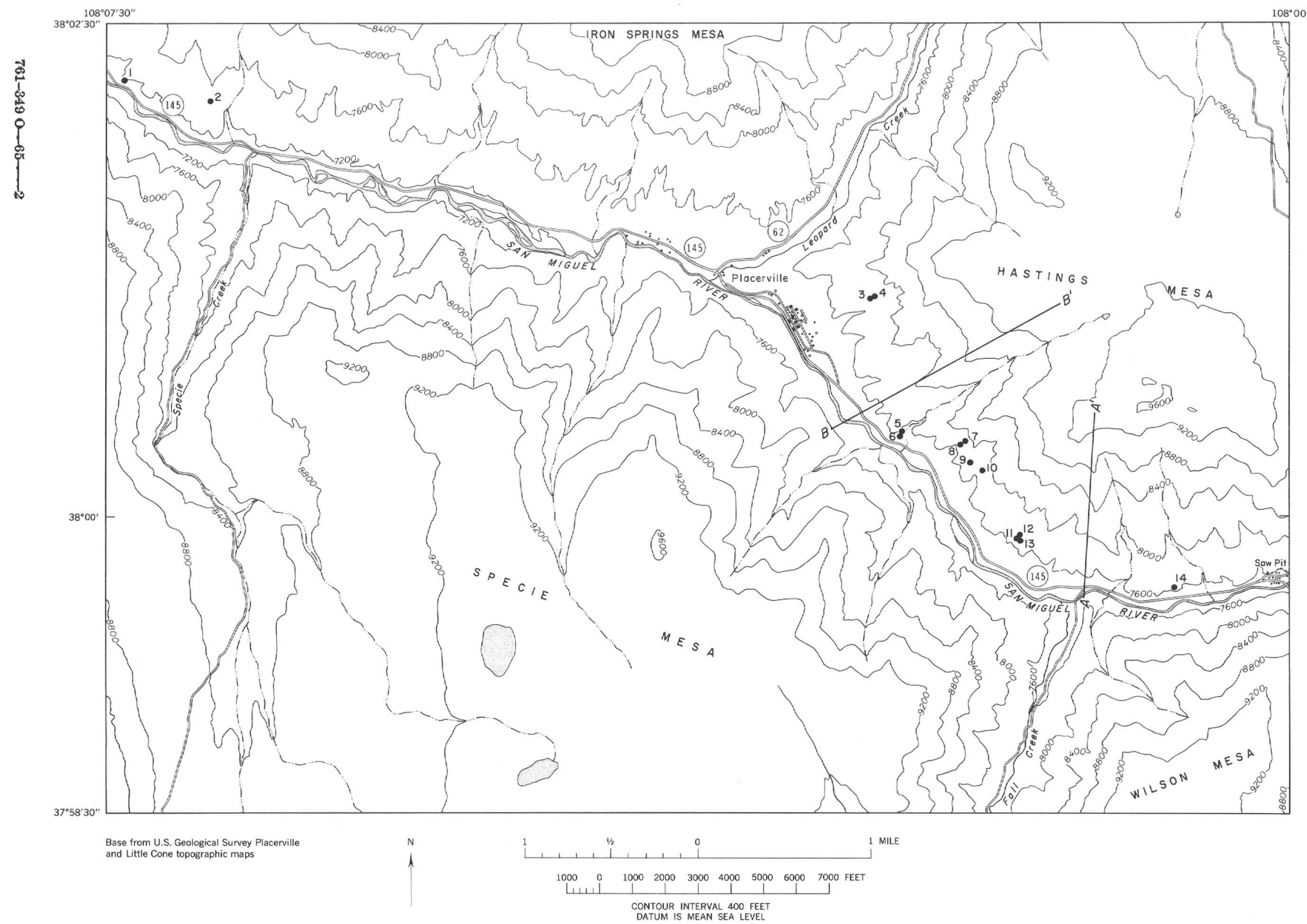

资

FTGURe 4.-Fossil vertebrate localities in Placerville area and positions of sections $A-A^{\prime}$ and $B-B^{\prime}$. 


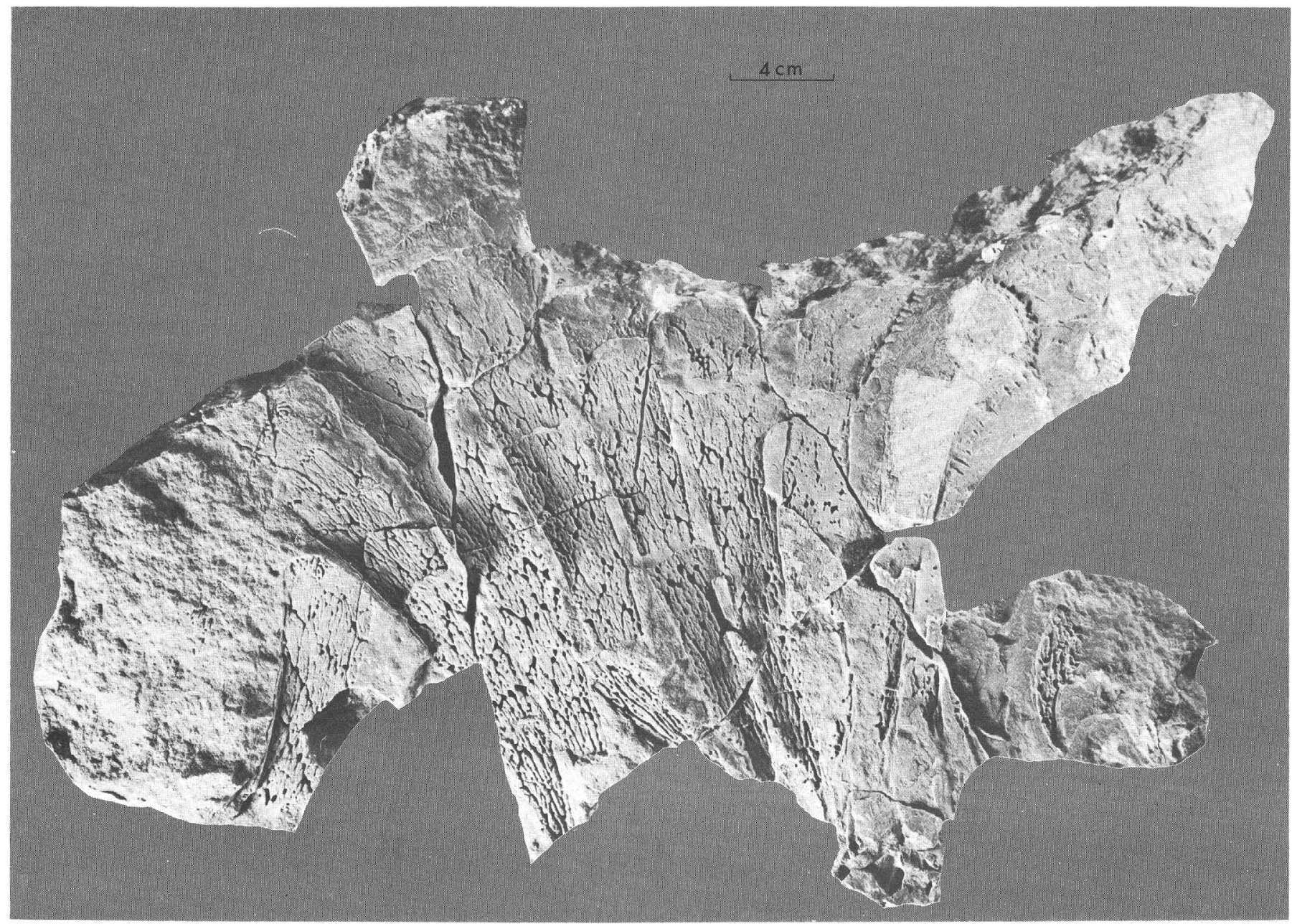

FIgURE 5.-A natural mould of a series of neural spines of the rhachitomous amphibian Phatyhystrix rugosus. The anterior end lies to the left. Fragments of bone are visible in places.

The dimensions of the eighth spine in the series are: height of spine from top of prezygapophysis, $222 \mathrm{~mm}$; anteroposterior length at summit, about $40 \mathrm{~mm}$ (estimated; the distalmost part is not complete) ; anteroposterior diameter at base, about $12 \mathrm{~mm}$. These dimensions are very close to those of an anterior dorsal spine measured by Langston (1953, table 5), for which the respective figures are $217 \mathrm{~mm}, 43 \mathrm{~mm}$, and $11 \mathrm{~mm}$. The first spine in the series has an anteroposterior length at the summit of about $37.5 \mathrm{~mm}$, the fourth, and largest, $52.5 \mathrm{~mm}$. These figures may be compared with the range of $24 \mathrm{~mm}$ to $55 \mathrm{~mm}$ for this measurement in the specimens studied by Langston (table 5). Clearly, the animal from Placerville is of about the same size as the New Mexican animal.

A latex cast taken from the impression of a proximal part of a rib shows that this rib was similar to a tuberculated rib figured by Langston (1953, fig. 22b). The fragments of bone other than spines are poorly preserved and, most unfortunately, give no indication of the structure of the skull in Platyhystrix rugosus.
Langston (1953, p. 405) has said that Platyhystrix probably represents an unnamed family related to the eryopsoids. We suggest that either such an unnamed family within the Eryopsoidea would be closely related to the family Dissorophidae, or that Platyhystrix may even be a dissorophid. The earliest dissorophid amphibians are recorded from rocks of late Des Moines age (= late Westphalian) at Mazon Creek, Ill., (Gregory, 1950) in the form of Amphibamus (Miobatrachus); this early genus was unarmored. In the Early Permian there was a variety of armored dissorophids: Alegeinosaurus, Aspidosaurus, Broitiellus, Cacops, Dissorophus, and possibly others.

The evolution of dermal armor in the dissorophids seems to have followed at least two diverging paths. By using known forms, two morphological, although not chronological, series can be constructed using Aspidosaurus as a central genus. Aspidosaurus chiton, from the Clear Fork Group of the Lower Permian of 'Texas, bears at the distal ends of its neural spines small roofshaped caps of sculptured bone (Case, 1911b, fig. 13); 


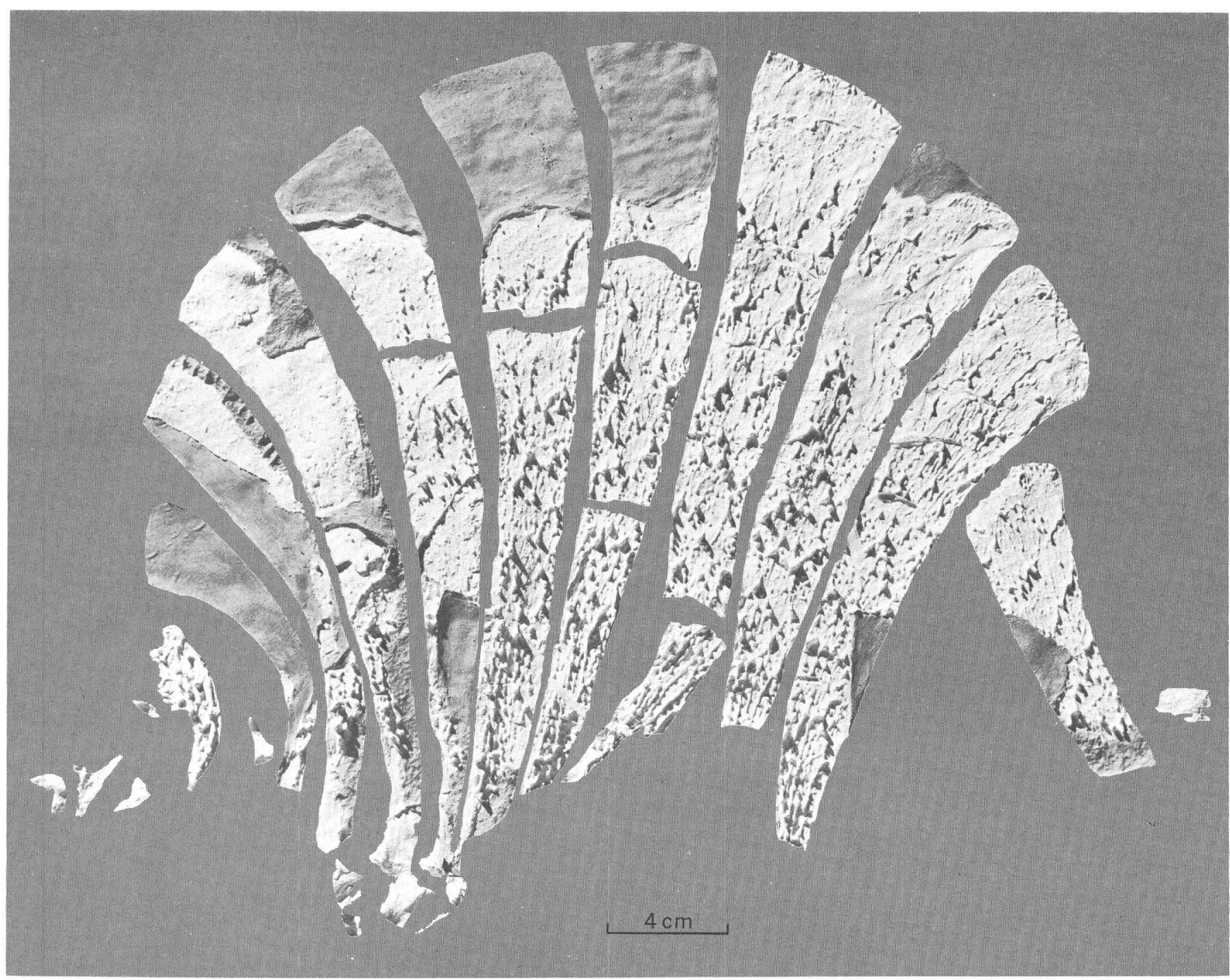

Figure 6.-A latex cast taken from MCZ 2982, the specimen of Platyhystrix rugosus shown on figure 5. The anterior end lies to the right. The white areas represent casts of bone impressions in the specimen; the gray areas represent restoration.

these caps are not separate from the neural spines, but the fact that they are separate in other members of the family would seem to indicate a dermal origin for the armor of $A$. chiton. From such a stage may have been derived the condition seen in Dissorophus (also from the Clear Fork), where the armor plates, free from, but resting on, the distally widened neural spines, are greatly expanded toward both sides to form, collectively, a broad dorsal cuirass. (See Case, 1911b, fig. 45.)

The morphological series from Aspidosaurus chiton to Dissorophus is characterized by transverse expansion and freeing of the dermal armor. Cacops, in which the armor plates are free but not significantly expanded, would serve as a morphologically intermediate form in this series; Cacops occurs higher in the Clear Fork
Group than the preceding genera. (See Olson, 1954.) If such a series does represent a truly related group of dissorophids, it would seem that Alegeinosaurus (Clear Fork) and Broiliellus (Wichita) also belong to this group, but that other species of Aspidosaumus were on a different evolutionary path: A. omicifer, from the Wichita Group of the Texas Lower Permian, shows a definite tendency toward dorsalward elongation of the dermal armor.

A neural spine of A. crucifer figured by Case (1911b, fig. $15 C$ ) is only slightly elongated, but another in the collections of the University of Texas (UT 40030-13) is so elongated that it resembles one of the shorter spines in Platyhystrix rugosus. There is a transverse barb just above the junction of the proximal, smooth part of the neural spine and the distal, sculptured part of the 
spine as in one of the spines of $P$. rugosus figured by Langston (1953, fig. 21b), and the anterior and posterior edges of the flattened part of the spine bear longitudinal ridges, probably for the insertion of interspinous ligaments.

A difference from $P$. rugosus lies in the pattern of the sculpture in $A$. crucifer, where there are large pits, separated by anastomosing ridges, instead of the tubercular ornamentation seen in $P$. rugosus. However, on a part of a spine in the materials (CNHM UC 742) of $P$. rugosus, the sculpture on the proximal part of the dermal part of the spine comes as close to pitting as it does to tuberculation. Possibly, the greater elongation of the spine of $A$. crucifer in the University of Texas collections, as compared with the spine figured by Case, is due to a more anterior or posterior position in the vertebral column. Spines of $A$. crucifer of this kind are probably the basis for Langston's statement (1953, p. 405 ) that "somewhat differently sculptured spines from Texas mentioned by several authors under various names probably belong to other species of Platyhystrix."

Whether or not $A$. crucifer really belongs in the genus Aspidosaurus, its close relationship to the other dissorophids seems fairly clear, and its resemblance to Platyhystrix rugosus would seem to indicate that Platyhystrix is at least related to the dissorophids. P. rugosus, then, may be an advanced member of a group of dissorophids-or derivatives of the dissorophids-in which the evolution of dermal armor proceeded in the direction of dorsalward elongation rather than lateralward expansion.

It must be emphasized that the grouping of dissorophids used here is based strictly on the patterns of the dermal armor and has no demonstrated basis in relative ages of the members of the morphological series. In fact, there are at the U.S. National Museum fragments (USNM 21861) of the spines of a large Platyhystrixlike animal from the Pennsylvanian Conemaugh of Ohio. These fragments indicate spines much more robust than those in P. rugosus, and the ornamentation is more complicated; tubercles are alined in vertical rows proximally and anastomose in a vermiculate pattern distally. A gross longitudinal fluting is superimposed on the tuberculate ornamentation, so that two or more bilaterally symmetrical grooves, more obvious distally than proximally, lie along either either side of the spine. The edges of the spines bear ridges for the insertion of interspinous ligaments. The Platyhystrix-like amphibians may prove to have been a fairly long-lived and varied group.

The importance of the evident connection of Platyhystrix to the dissorophids lies in the evidence thus presented for the dermal origin of the ornamented part of the neural spine. The superficial resemblance of the neural spines of Platyhystrix to those of some of the long-spined pelycosaurian reptiles is remarkable, especially when one considers such pelycosaurs as Edaphosaurus pogonias and Ctenospondylus casei, in which some of the spines are expanded anteroposteriorly and are flattened from side to side. To be sure, the transverse bars in Edaphosaurus are more numerous and are more extensively distributed along the spine. Convergence in elongation of spines would seem to indicate similar adaptations, and this is not unlikely: the dissorophid amphibians were apparently well adapted to a terrestrial existence and probably had little to do with the water (Romer, 1947, p. 159). Langston (1953, p. 405) has pointed out that, whatever the primary function of the elongated neural spines may have been, quite possibly they could have been turned, through preadaptation, to some other use, such as camouflage. In the same way, a fin originally developed in response to selection for protective function could have become preadapted to use in temperature regulation, which function Romer (1948) has suggested for the fin of the long-spined pelycosaurs.

Whatever the function of the fin, its appearance in both rhachitomous amphibians and pelycosaurian reptiles is an extraordinary example of convergence, and interesting in that the pelycosaurian spine was purely endochondral in origin whereas that of Platyhystrix combined endochondral and dermal elements.

\section{Class REPTILIA \\ Subclass ANAPSIDA \\ Order COTYLOSAURIA \\ Suborder SEYMOURIAMORPHA \\ Family SEYMOURIIDAE}

New (but unnamed) genus and species

A single, fairly well preserved vertebra (MCZ 2983 from loc. 9) lacking the intercentrum is so similar to the vertebrae in Seymouria baylorensis that the animal it represents surely belongs to the same family.

The dimensions of the vertebra are: length of centrum, $8 \mathrm{~mm}$; anterior width of centrum, $11.5 \mathrm{~mm}$; distance between base of neural spine and posterior ventral edge of centrum, $24.5 \mathrm{~mm}$; distance between most lateral points of postzygapophyses, $30.5 \mathrm{~mm}$. By comparison with the vertebrae in Seymouria baylorensis figured by White (1939, figs. 12, 14), this vertebra seems quite definitely to be from the dorsal series. It is about ninetenths as large as those figured by White.

The following description of MCZ 2983 would, with the exceptions noted, fit equally well a vertebra of Seymouria baylorensis. The centrum is abruptly constricted along a longitudinal line at the junction of its dorsal two-thirds and its ventral third. This constriction is not carried into the anterior and posterior rims, so that the ventral third of the centrum, viewed from below, has something of an hourglass shape. The ratio 
of the distance between the most lateral points of the postzygapophyses to the width of the centrum is $2.65: 1$. The length of the neural arch measured along the midline is $8 \mathrm{~mm}$, the same as the length of the centrum. Even on casual inspection, the neural arches in Seymouria baylorensis seem longer along the midline than are their respective centra; from White's illustrations (1939, fig. 12), the ratio is about 1.5:1 for vertebrae selected from several positions along the dorsal series.

The articular surfaces of the zygapophyses in MCZ 2983 are tilted at a small angle to the horizontal; although no tilt can be seen in White's illustrations, it may occur in some specimens of Seymouria baylorensis. (See Romer, 1956, fig. 129A.) Only the base of the diapophysis is preserved, but this is sufficient to show that the diapophysis was expanded behind the prezygapophysis, and was connected, via a constricted area, with an anteroventral extension that passed to the anterior point of junction of the centrum and neural arch. This pattern marks this vertebra as an anterior dorsal. In the anterior dorsals of Seymouria baylorensis, too (White, 1939, fig. 12), the diapophyses are extended anteroventrally, but not so far as in MCZ 2983, and there is no marked constriction in the diapophysis.

On either side of the dorsal surface of the neural arch, a raised ridge, gently rounded medially but more prominent laterally, passes from a point above the anterior end of the neural arch backward and outward to the most lateral point of the postzygapophysis. The articular surfaces of the postzygapophyses are continuous medially with the ventrally and somewhat laterally facing surfaces of a broad wedge of the neural arch that terminates at the dorsal border of the neural canal; this wedge is present also in a vertebra of Seymouria baylorensis at hand but in which the apex of the wedge lies nearer to the plane of the articular surfaces of the zygapophyses than it does in MCZ 2983 . The neural spine of MCZ 2983 is $4 \mathrm{~mm}$ wide at its base; it is incomplete dorsally but was at least $21 / 2 \mathrm{~mm}$ high. This spine is similar to that of the vertebra of Seymouria baylorensis at hand.

The great similarity to the vertebrae in Seymouria baylorensis makes it seem quite certain that we are dealing with a seymouriid, but there are also differences from Seymouria baylorensis, as noted. The differences in configuration of the diapophyses and of the wedge on the posterior aspect of the neural arch are, perhaps, not too important, but the greater ratio of the midline length of the neural arch to the length of the centrum in Seymouria baylorensis does seem significant. White (1939, p. 388) has suggested that the broad zygapophyses in Seymouria are "an adaptive feature rather than a primitive character. The breadth of the zygapophyses would permit the vertebral column to undulate laterally but would prevent any torsion. The absence of torsion in the column would compensate for the weak ilio-femoralis (gluteal) muscles which prevent the body from slumping on one side when that foot is lifted off of the ground $* * *$ the nature of the vertebrae seems to be an adaptation to facilitate terrestrial progression rather than a primitive character." Gephyrostegus, a seymouriamorph from the European Upper Pennsylvanian, does not have greatly expanded neural arches (Romer, 1956, p. 480-481).

It would seem that the neural arches became "swollen" within the Seymouriamorpha, probably as a better adaptation to land life. Perhaps increase in midline length of the neural arch was part of the general phenomenon of "swelling." If so, the lesser length in MCZ 2983, as compared with Seymouria baylorensis, may be a mark of relative primitiveness. This would be consonant with the difference in age that we infer: Although Seymouria occurs in the Belle Plains, Admiral, and Putnam Formations of the Wichita Group (Romer, 1947, p. 282), Seymouria baylorensis is known only from the Arroyo Formation at the base of the Clear Fork Group of the Lower Permian of north-central Texas. The seymouriid from the Cutler Formation at Placerville is associated with other fossils that are probably equivalent in age to the fauna from the lower part of the Wichita Group, which underlies the Clear Fork, but we have had no opportunity to compare it with the inadequately known Seymouria from the formations of the Wichita Group.

It seems unwise to us to establish a new genus or species on the basis of this lone vertebra. The interest in this specimen lies in its indication of the existence of a more primitive seymouriid than Seymouria baylorensis in the Early Permian, and in its being the first record of any seymouriid from west of the north-central Texas area.

\section{Order COTYLOSAURIA Suborder DIADECTOMORPHA Family DIADECTIDAE}

Diadectes sanmiguelensis Lewis and Vaughn, n. sp.

Figures 7 and 8

We name Diadectes sanmiguelensis and hereby designate MCZ 2989 from locality 14 as the holotype of a new species of Diadectes Cope, 1878. The diagnostic characters of this new species are: the shallowness of the lower jaw, where the greatest depth, at the region of the coronoid elevation, is only one-third as great as the length of the jaw; the lowness of the flange of the dentary on the labial side of the cheek teeth, all of which are exposed to lateral view; and the simple pattern of the cheek teeth, each of which has only one prominent cusp. All these characters are described more fully below. The generic determination has been so 
made for a number of reasons: (1) the new species is obviously a diadectid; (2) it resembles the known species of Diadectes more closely than it does any other known reptiles; (3) the holotype is immature, and it would be difficult to say positively that its distinctive characters are not due to this immaturity; and (4) the nomenclatorial history of Diadectes is already sufficiently complicated.

Romer (1956, p. 486) lists eight synonyms for $D i$ adectes, and Desmatodon may be a ninth. Specimens referable to Diadectes show great variation; as Olson (1947, p. 11) has summed it: "Most confusing, especially to one not thoroughly familiar with the genus [Diadectes], is the remarkable variation of characters that would seem at first glance to be of specific or even generic rank. On examination, however, it becomes apparent that there is no clear pattern of variation and that the variations at present offer little or no basis for taxonomic work." Case (1911a, p. 26) set up a new genus, Diadectoides, using as genoholotype an immature specimen that has since proved to be referable to $D i$ adectes (Olson, 1947, p. 7). Considering the present lack of understanding of the variations within the genus Diadectes, we believe that it would be ill advised to set up a new genus on the basis of an immature specimen when a strong case can be made for referral to Diadectes.

It may be assumed that Diadectes sanmiguelensis is closely related to Diadectes lentus (Marsh), 1878, the only clear-cut species of Diadectes definitely known heretofore from the Cutler Formation of northern New Mexico-if, as Olson (1947, p. 9) believes, Diasparactus zenos Case, 1910, represents a distinct genus. Diadectes [Animasaums] carinatus (Case and Williston), 1912 , is not clearly different from D. lentus. (See Olson, 1947, p. 9.) Olson gave the locality as "Las Animas," but Las Animas is in eastern Colorado, and it is unlikely that the specimen came from there. There are outcrops of upper Paleozoic rocks on both sides of the Animas River beginning about 2 miles northeast of Animas (Larsen and Cross, 1956, p. 48, pl. 1). Diadectes sanmiguelensis, notwithstanding that it is based on an immature specimen, is kept separate from $D$. lentus, because (1) we believe that, although a mature individual of $D$. sanmiguelensis would probably have looked more like specimens of known species of Diadectes than MCZ 2989 does, it would still not have fitted into the specific pattern of $D$. lentus and (2) a geographic separation in the occurrences of $D$. sanmiguelensis and $D$. lentus exists, at least as known at present.

The type includes a complete skull with mandible; several cervical vertebrae; a few incomplete ribs; a partial pectoral girdle consisting of left and right clavicles, the interclavicle, the left cleithrum, and the left scapu- locoracoid; and the left humerus, epipodium, and manus.

The best indication of the immaturity of the specimen is the nature of the carpus, where ossification is only incipient, and there are rudimentary centers for only the radiale, ?intermedium, ?ulnare, ?pisiform, a centrale, and the first distal carpal. Other indications are the unfinished appearance of both ends of the humerus and the separation of scapula and coracoid. Less dependable criteria are the smoothness of the bones of the skull roof and the fact that many of the sutures in the skull are open; in larger individuals referable to Diadectes, the skull is rugose, and the sutures are difficult to find. Though the preservation of the proximal part of the ulna is not good enough to permit a positive statement, the olecranon seems not to have been ossified, and this lack too would indicate immaturity. The shallowness of the lower jaw, the lowness of the flange of the dentary labial to the cheek teeth, and the simple pattern of the teeth may also be attributable to immaturity, but this deduction is unsure. At first sight, the orbits of D. sanmiguelensis seem to be proportionately larger than is usual in Diadectes, but in fact they are of nearly the same size in relation to total skull length as the orbits are in a specimen of $D$. lentus at hand.

If the referral to Diadectes is correct, the small size of the specimen would, of course, in itself seem to be sufficient evidence of immaturity, although early geological age may explain the specimen's small sizethere seems to have been a fairly steady increase in size of the species of Diadectes during the Early Permian (Romer, 1944, p. 142).

The type skull of D. sanmiguelensis is about $85 \mathrm{~mm}$ long from the tip of the snout to the posterior edge of the postparietal bones. It has been distorted in such a way that the left cheek forms a right angle, and the right cheek an obtuse angle, with the table of the skull. The bones of the dermal roof are badly fractured, so that it is difficult in some places to distinguish sutures from cracks. The accompanying figure has been drawn to show not only the sutures but also the conspicuous cracks, including those that presented difficulty in interpretation.

The type skull is about one-half as long as the skull in the composite restoration given by Olson (1947), which was based on specimens of both Diadectes sideropelicus from the Wichita Group and D. tenuitectus from the Clear Fork Group of Texas. It is about three-fifths as large as CNHM UC 675, a skull of $D$. lentus described by Case and Williston (1912) from the Cutler ("Abo") Formation of northern New Mexico. The proportions of the dermal roof of D. sanmiguelensis are those figured for Diadectes generally. It may be noted that $D$. sanmiguelensis and $D$. lentus resemble each other more closely than they do the species of Diadectes from Texas 

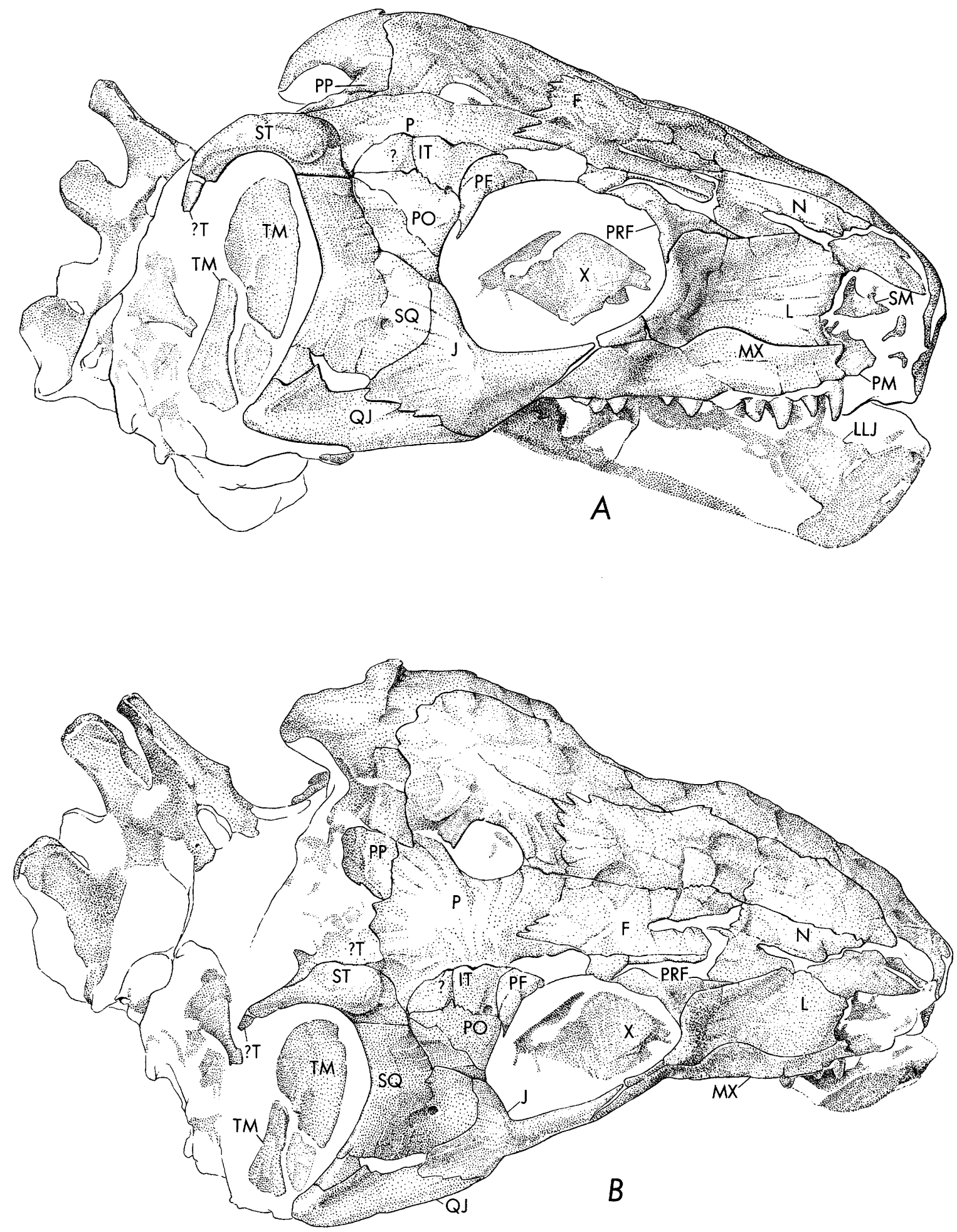

FIguRE 7.-Skull of type specimen of Diadectes sanmiguelensis n. sp., MCZ 2989. A, Lateral view; $B$, dorsolateral view. Parts of several neural spines also are visible. Unshaded areas represent matrix. $\times$ 1.25. 

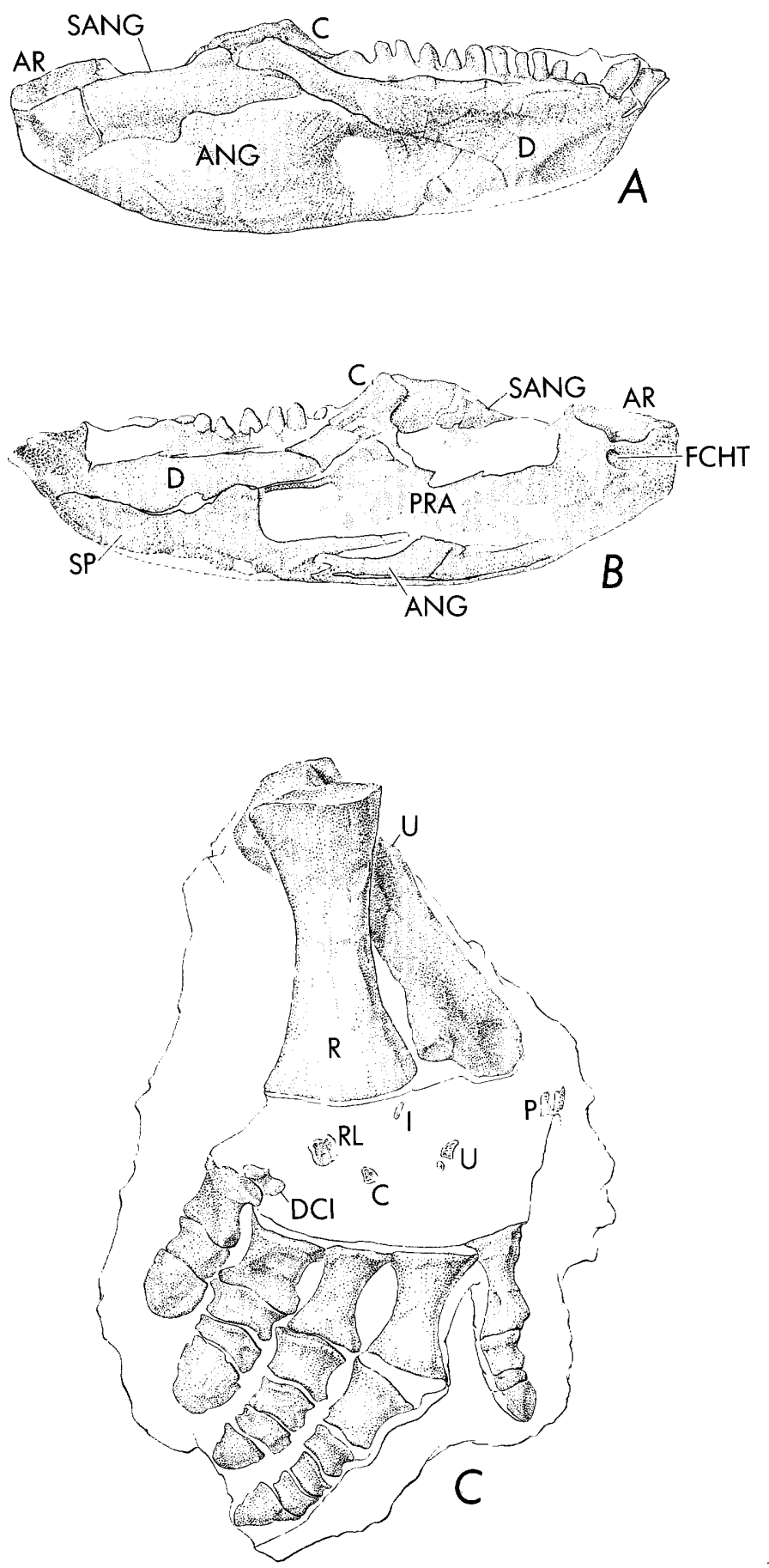

Figure 8.-Diadects sanmiguelensis n. sp. $A$, Latheral, and $B$, medial views of the right lower jaw of the type specimen, MCZ $2989 ; C$, dorsal view of the left radius, ulna, and manus of the type specimen. Unshaded areas represented matrix. $\times 0.88$.

in that both Cutler species have the orbit placed slightly farther posteriorly than in the Texan forms; this position may be taxonomically significant.

Reference may be made here to the recent restorations of the skull of Diadectes (Olson, 1947, p. 12, 13; Wat- son, 1954, p. 382, 383; and Romer, 1956, p. 89). There would be little value in a detailed description of the interorbital region, the region anterior to the orbit, the jugal region, or the quadratojugal region of $D$. sanmiguelensis, for in these regions the patterns of the sutures are like those described by Olson, Watson, and Romer, but it may be worthwhile to point out that although the pattern is not clear above the right orbit it is obvious on the left side that the frontal does not enter the orbital margin. As in other specimens referable to Diadectes, there is a large parietal foramen.

The cheek and temporal regions deserve special attention because of the conflict of opinion on the presence of an intertemporal bone in Diadectes. Olson (1947) has drawn in an intertemporal and (1950) has discussed its variations in outline and in fusion with neighboring elements. Watson (1954) has drawn an extension of the parietal, a parietal lappet, in the position of Olson's intertemporal. Romer (1956, p. 86) has taken a neutral position pending further information. The question of the presence of an intertemporal in Diadectes is of considerable theoretical importance: Parrington (1958) bases his theory of the derivation of all the amniotes from a stock other than of the typical labyrinthodont amphibians partly on the assumption that the place of the intertemporal is taken by a parietal lappet in Diadectes as well as in all other primitive reptiles. We hoped that this immature specimen, MCZ 2989, with its open sutures, would throw light on this problem. Perhaps it does, but the evidence is inconclusive because of the imperfect preservation of the temporal region. The left temporal region is too badly cracked to be of use here; description will be based on the right side.

The supratemporal of $D$. sanmiguelensis is a large bone, about $22 \mathrm{~mm}$ long, occupying the posterolateral corner of the roof of the skull. Its posterior five-sixths is raised as a boss above the level of the anterolateral one-sixth. The anterolateral part meets the dorsal extension of the squamosal in a short, straight, horizontal suture, about $8 \mathrm{~mm}$ long, that passes forward to touch the postorbital, and thereby barely excludes the parietal and the ?intertemporal (or ?parietal lappet) from contact with the squamosal. This short suture between supratemporal and squamosal resembles that in Romer's reconstruction but is unlike that drawn by either Olson or Watson, in which the dorsal extension of the squamosal has a much longer upper edge. The postorbital is a large element whose upper edge is longer than that of the squamosal-again a feature in agreement with Romer's reconstruction; anterior to the postorbital lies the postfrontal, which occupies the posterodorsal part of the orbital margin. 
Between what we may call the undisputed part of the postorbital and the undisputed part of the parietal lies a bone-or fragment of bone - that meets the postfrontal in front, and that may have met the supratemporal behind in a restricted contact (the bone narrows posteriorly and a small part of it seems to have been broken away in this region). The contact of this bone with the parietal (or ?main body of the parietal) seems to be sutural; its contact with the (?main body of the) postorbital seems also to be sutural, but not so clearly as its contact with the parietal. Is this bone the intertemporal? Its relationships are those of an intertemporal: it meets the parietal above and the postorbital below; it meets the postfrontal in front and may have met the supratemporal behind, and it would be part of the longitudinal series, postfrontal-intertemporal-supratemporal. Its restricted contact-or the bare miss of a contact-with the supratemporal might indicate a stage of reduction of the intertemporal.

The alternatives to calling this bone the intertemporal are to regard it as a part of the parietal or to regard it as a part of the postorbital. If it is a part of the parietal, it forms the usual parietal lappet, intervening between postfrontal and supratemporal. But the contact of this bone with the parietal (or ?main body of the parietal) seems clearly to be sutural, and, if the bone is not the intertemporal, it would seem more likely, on this evidence, that it is a part of the postorbital. This latter interpretation would postulate a great reduction in the size of the parietal lappet to a small wedge between postorbital and supratemporal, and this size would be in conflict with the usual pattern of relationships of the lappet. (See discussion of parietal lappet in Watson, 1954.) It would seem that the bone in question is the intertemporal.

Further study, including perhaps the grinding of the bones found in this region of MCZ 2989, is indicated, and the present report must be regarded as preliminary. It needs to be stressed that the bones in the temporal region are checkered with cracks; it may be, for example, that a crack running vertically through a constricted part of the ?intertemporal about midway in that bone's length is a suture, and that only the anterior part of the bone is to be regarded as the (even more reduced) intertemporal.

The position of the tabular of $D$. sanmiguelensis is obscure. In lateral view, it is perhaps represented by a small fragment of bone ventral to the posterior tip of the right supratemporal. In dorsal view, there may be seen on the right side a fragmented area of bone immediately posterior to the posterolateral part of the parietal and medial to the supratemporal, from which it is demarcated by what seems to be a suture; this frag- mented bone is probably part of the tabular. A small wedge of the parietal intervenes between the anterior parts of the tabular and supratemporal.

A single postparietal is usually restored for Diadectes (Olson, 1947; Watson, 1954; Romer, 1956), but D. sanmiguelensis seems to have a pair of postparietals. The paired postparietals may be a sign of primitiveness and may be taxonomically significant, but possibly they are only another indication of the immaturity of the type specimen.

Within the type skull's right otic notch, external to the quadrate, lie several fragments of a thin film of bone whose posterior edge extends farther medially than its anterior edge. This film of bone is so similar to the remarkable ossified tympanic membrane described in Diadectes by Watson $(1954$, p. 388$)$ that it must be the same structure. As Watson (p. 390) points out, we cannot at this time say whether this structure is the tympanic membrane itself or some extracolumellar part that was inserted into the membrane. The ossified membrane in the type skull of $D$. sanmiguelensis has been displaced somewhat ventrally and slightly posteriorly from its attachments as described by Watson. That this film of bone is not part of the quadrate has been determined by grinding through the matrix surrounding the borders of the membrane until the right quadrate, which has apparently been rotated about its long axis so that its posterior edge has been moved laterally, was reached; anteriorly at least, a layer of matrix about $2 \mathrm{~mm}$ thick separates the ossified film from the quadrate. The presence of an ossified tympanic membrane in $D$. sanmiguelensis is interesting in that it shows, assuming that the specimen is immature, that this ossification was not necessarily a feature of advanced age in Diadectes.

The quadrate, whose posterior surface can be seen on the left side, looks like that of other specimens referable to Diadectes, even to the large facet near its ventromedial corner that Olson $(1947$, p. 21) feels may have served as a place of attachment for a cartilaginous process of the stapes.

The lower jaw of D. sanmiguelensis, in its patterns of sutures and foramina, fits the general picture of Diadectes, but it is different from this picture in the details of its overall proportions and in the degree of development of the dorsal edge of its dentary. The following comparisons are based on the excellent figure of a lower jaw of $D$. lentus published by Welles (1941, p. 426), and on a specimen of Diadectes lentus (CNHM UC 675) that includes a well-preserved lower jaw, which has obscure sutures.

The immediately obvious difference is the relative shallowness of the lower jaw in D. sanmiguelensis, which 
is $88 \mathrm{~mm}$ in its greatest length. This is only about fiveninths as long as the jaw figured by Welles, and only about two-thirds as long as that of a particularly small specimen of D. Tentus (CNHM UC 675). The ratio of the greatest depth of the jaw to the length, measured from the highest point of the coronoid elevation, is about $1: 3$ for MCZ 2989 and $1: 2$ for CNHM UC 675 and for the reconstruction of the lower jaw figured by Romer (1956, fig. $107 C$ ). The measurements were taken along the medial surface of the jaw to avoid the complication of the flange of the dentary described below. In both MCZ 2989 and CNHM UC 675 the center of the coronoid elevation lies about three-fifths of the way back in the length of the jaw. The difference in depth of the jaws is not a matter only of relative elevation of the coronoid process: the ratio of the depth of the jaw midway between the anterior end and the coronoid elevation to the length of the jaw is about $1: 5$ for MCZ 2989 and 1:3.5 for CNHM UC 675. These ratios show that the jaw of $D$. lentus is relatively deeper throughout its length than that of $D$. sanmiguelensis.

The other obvious difference between the jaws of these two species is the much greater development in D. lentus of the bony flange that extends upward, labial to the cheek teeeth, from the lateral wall of the dentary. This flange is highest directly in front of the coronoid elevation and slopes forward and downward to be nonexistent in the region of the "incisors"; there is a trench between the teeth and the flange. The flange completely hides the posterior five teeth from lateral view, and three teeth anterior to these are partially hidden; in the lower jaw figured by Welles, even more teeth are hidden. In contrast, in D. sanmiguelensis although there is a shallow trench between flange and teeth, the flange is very low and all of the teeth are exposed to lateral view.

The individual bones of the lower jaw in D. sanmiguelensis, as seen in lateral view, are disposed generally as in Diadectes (see figures by Romer and Welles, referred to above), except for differences in proportions of the elements associated with the relative shallowness of the jaw. Two interesting features may be pointed out: (1) The suture separating the dentary from the surangular and angular in the right lower jaw of D. sanmiguelensis seems to have its ventral termination at a point much farther forward (about two-ninths of the way back in the length of the jaw) than in the left lower jaw of D. sanmiguelensis and in Diadectes generally, where it lies about one-third of the way back. The lateral surface of the right jaw in MCZ 2989 is checkered with cracks, and it is possible that the suture has been incorrectly identified, but if the identification is correct, we are provided with a good example of varia- tion in sutural pattern. (2) As in Welles' specimen, there is a vertical line of separation running through the surangular about one-third of the way forward in the length of this bone; this line seems to be present in CNHM UC 675 too, and this feature may have more significance than has been suspected.

The type of $D$. sanmiguelensis has many features in common with other species of Diadectes: the depth of the surangular is less than that of the angular, and the coronoid is exposed laterally above the junction of surangular and dentary. The splenial is imperfectly preserved ventrally and is lacking on the inside of the right jaw, but this element is well preserved in the left jaw, where it is exposed laterally as a narrow strip lying below the dentary and passing posteriorly to a point shortly behind the ventral end of the suture between dentary and angular. A foramen on the medial surface of the articular presumably is for the $N$. chorda tympani. The junction between articular and prearticular cannot be made out.

Because the prearticular bone has been badly crushed and the angular has been split along its ventral edge, the relations of the angular with the splenial are not certain, but the general features of the medial aspect of the lower jaw can be readily made out. There are two Meckelian fenestrae (called "anterior fenestra" and "medial fenestra" by Welles) as in typical Diadectes. The anterior one is small and bounded by the dentary above and the splenial below; the main posterior Meckelian fenestra is large and bounded by the splenial anteriorly, by a straplike process of the prearticular above, and by the main body of the prearticular posteriorly.

Differences from the general pattern in Diadectes are: the splenial in $D$. sanmiguelensis forms the entire ventral boundary of this fenestra, excluding the angular from the fenestral border; this exclusion is accomplished by a process of the splenial that passes posteriorly along the dorsal edge of the angular to touch the prearticular. The anterior border of this main Meckelian fenestra lies about one-third of the way back and relatively higher in the jaw of $D$. sanmiguelensis than in Diadectes generally, where it is only one-quarter of the way back. The collective depth of the dentary and prearticular in D. sanmiguelensis is less than onehalf as great as the distance from the lower edge of the jaw to the upper fenestral border, but in Welles' specimen of D. lentus and in CNHM UC 675 the collective depth of the parts of the dentary and prearticular directly above the fenestra is about three-quarters as great as the distance from the lower edge of the jaw to the upper border of the fenestra. The dentary in $D$. sanmiguelensis bulges medially over the main 
Meckelian fenestra much more than in CNHM UC 675, so that the process of the prearticular above the fenestra faces ventrally more than it does medially.

The medial outline of the adductor fossa in $D$. sanmiguelensis, as would be expected from the relative shallowness of the jaw, is much longer than it is deep; in Diadectes generally the length and depth are nearly equal. There is a roughly vertical fissure running through the coronoid bone, but this is probably only a crack. There is no good reason to believe that more than one coronoid was present. The articular bulges medialward but not so markedly as in Diadectes generally.

It has not been possible to study the marginal dentition in as much detail as would be desirable, because of the extreme friability of the teeth and the refractory nature of the matrix, but its general features can be made out.

The premaxillary seems to have held three teeth, and all of these seem to have been "incisors;" Diadectes (see Romer, 1956, fig. 43A) normally has four premaxillary teeth, all "incisors." Only the first and third "incisors" are preserved on the left side of the type of $D$. sanmiguelensis; none are preserved on the right side. The "incisors" seem to have been procumbent, as in Diadectes generally.

Diadectes sanmiguelensis shows a relatively simple pattern of the nine cheek teeth preserved in the maxilla, which has empty spaces for two more, bringing to fourteen the number of teeth in each upper jaw. Sixteen teeth in the upper jaw are shown in one reconstruction of Diadectes by Romer (1956, fig. 43A) and 15 in another (fig. 44A) ; CNHM UC 675 also seems to have had 15. The first left maxillary tooth in the type of Diadectes sanmiguelensis is only about one-half as long as the incisor in front of it and is not, or is only slightly, procumbent. The right side lacks the fifth and eighth maxillary teeth. The seventh right maxillary tooth seems to be fairly young, but advanced to such a degree that the tooth it was replacing had been completely lost. Along the lingual sides of the bases of several of the maxillary teeth of the type of $D$. sanmiguelensis there are circularly outlined basal notches of the type found in Diadectes generally (Welles, 1941, p. 427); these basal notches had to do with resorption of the teeth preliminary to replacement. There is a single row of small palatal teeth as in typical Diadectes.

In the lower jaw, there are two obvious procumbent "incisors." The basal part of the second right "incisor" shows clearly the longitudinal striae so characteristic of the bases of the teeth in Diadectes. The tooth immediately posterior to the second right "incisor" is very short and may possibly be in an early stage of replacement of a third; there are no others. Posterior to these three teeth there are eleven more, the last of which is very poorly preserved. There are thus fourteen teeth in the lower jaw, and this may be compared with the condition in Diadectes lentus, where, according to Welles (1941, p. 427), the number varies from 14 to 18 . Preparation in this region of the type lower jaw of $D$. sanmiguelensis is even more difficult than in the upper jaw, but a lingual basal notch has been demonstrated alongside at least one of the cheek teeth.

As pointed out earlier, there is a shallow trench between the cheek teeth and the low flange of the dentary labial to the teeth. Welles (1941, p. 424) has suggested that this flange may have supported a horny beak; if it did, such a beak probably would have been less developed in D. sanmiguelensis than in other species of Diadectes. The alveolar margin of the dentary in D. sanmiguelensis (MCZ 2989) is appreciably less swollen from side to side than is the margin in $D$. lentus (CNHM UC 675); this is undoubtedly correlated with the lesser development of the cheek teeth in $D$. sanmiguelensis.

The general pattern of the teeth midway in the upper and lower series can be described even though the cheek teeth are not well preserved. In the maxillary series, the longer axis of the crown, the transverse axis, is set at an angle of about $60^{\circ}$ to the lateral surface of the maxilla, and the lateral end of the tooth is farther forward than the medial end. The largest teeth of the maxillary series lie somewhat posterior to the middle of the series; they have a maximum height of about $7.2 \mathrm{~mm}$ (measured from the lingual basal notch), are about $5.2 \mathrm{~mm}$ wide along their transverse axes, and are about $2.8 \mathrm{~mm}$ long along their anteroposterior axes (measured near the base). A typical large maxillary cheek tooth has a prominent cusp set off to the lateral side of the center of the crown; lateral to the cusp, and lower, there is a poorly defined, broadly rounded shoulder; medial to the cusp the surface of the crown slopes in a gently concave arc to a prominent medial shoulder, which is placed lower than the lateral shoulder. Posterior to the largest maxillary teeth, the teeth are smaller and the shoulders less pronounced. The shoulders are gradually lost anterior to the largest maxillary teeth and the cusp becomes more prominent until, in the anteriormost maxillary teeth, only the cusp remains. The state of preservation makes it difficult to analyze the pattern of attrition, but wear seems to have been most severe in the region between the cusp and the medial shoulder.

The largest cheek teeth in the lower jaw occlude with the largest in the maxillary series. As in the maxillary teeth, the transverse axis is the longer. A difference 
from the upper dentition lies in the placement of the transverse axis of the lower teeth at nearly a right angle to the longitudinal axis of the dentary. The largest cheek teeth of the lower jaw have a maximum height of about $5.8 \mathrm{~mm}$ (measured from the lingual basal notch), are about $4.3 \mathrm{~mm}$ wide along their transverse axes, and are about $2.8 \mathrm{~mm}$ long along their anteroposterior axes (measured near the base). The cusp and shoulders of the crowns of the lower cheek teeth are oriented contrary to those of the upper teeth: in the lower teeth the cusp is set off to the medial side of the center of the crown, the higher shoulder is at the medial end of the tooth, and the lower shoulder is at the lateral end. Further, in the lower teeth it is the lateral sides that show more wear.

The cusp of the typical large cheek tooth in D. sanmiguelensis obviously corresponds to the central cusp of the typical cheek tooth in Diadectes generally; Romer (1952, p. 86) calls this cusp the primary cusp. The shoulders of the cheek teeth in D. sanmiguelensis correspond to the secondary and tertiary cusps of Romer's terminology. The pattern of wear in D. sanmiguelensis, mostly on the medial side above and on the lateral side below, also corresponds generally to the pattern in Diadectes, as does the fact that the upper teeth are wider than the lower teeth.

The simple crown of the cheek tooth of Diadectes sanmiguelensis resembles that figured by Case (1908, figs. 4, $5 C$ ) for Desmatodon hollandi, from the Conemaugh Group of Pennsylvania, except that in Diadectes sanmiguelensis the slope from cusp to lower shoulder is gently concave, whereas in Desmatodon hollandi the cusp is sharply demarcated from the shoulder. There are more differences: The tooth figured by Case has a transverse width of about $10 \mathrm{~mm}$. Romer $(1952$, p. 86, pl. 1, fig. 3) has shown that other cheek teeth in Case's specimen of Desmatodon hollandi have a transverse width of as much as $11 \mathrm{~mm}$, are closer to the pattern normal for Diadectes, and have greater development of the secondary and tertiary cusps; he believes that the toothed fragment described by Case is part of a dentary. The teeth of Desmatodon hollandi are about two and one-half times as large as the teeth of MCZ 2989, and are as large as some in heretofore known specimens referable to Diadectes: the largest tooth in the dentary of CNHM UC 675 (D. lentus) has a transverse width of only $11.7 \mathrm{~mm}$. We do not feel that the simple pattern and small size of the teeth of $D$. sanmiguelensis warrant keeping this species out of the genus Diadectes.

For one thing, the type seems to be immature, and it is more than likely that the teeth of the mature animal would have been larger, and possibly more complicated. The cheek teeth in Diadectes sanmiguelensis, even in this presumably immature stage, do closely resemble at least the anterior cheek teeth of Desmatodon hollandi and are not too greatly different from the more posterior cheek teeth in that species. Olson $(1947$, p. 9) feels that "The known characters [of Desmatodon hollandi] are insufficient to permit a morphological differentiation from Diadectes. The principal interest in the specimen is that it indicates the presence of the diadectids in the eastern part of North America. Because of the geographic isolation of the type specimen the genus and species may be tentatively retained."

It is of interest here that Romer $(1952, p .87)$ has described a battery of very small lower cheek teeth of a diadectid from the Conemaugh. These teeth, eight in a length of $11 \mathrm{~mm}$, have each only a single cusp and no shoulders. Romer has suggested that these teeth may represent either an otherwise unknown primitive diadectid or, not impossibly, a young individual referable to Desmatodon.

The first five vertebrae are fragmented in the type of D. sanmiguelensis. The neural spines are of about the proportions figured in the reconstruction by Romer (1944, fig. 1). The spines of the third and fifth vertebrae are clearly quadrangular in cross section, as they are in diadectids generally. The spine of the fourth vertebra is not complete. That of the axis is not well preserved but seems to have been more bladelike than the others. Owing to the state of preservation of the materials, it has not been possible to confirm the presumed presence of episphenes and hyposphenes. Parts of a few ribs are present, but these parts are of no diagnostic value.

The cleithrum, clavicle, and interclavicle are like those usually described for Diadectes (Case, 1911a, p. 79) except, of course, that they are smaller; the length of the interclavicle posterior to the suture between the clavicles is $57 \mathrm{~mm}$. There is nothing unusual about the scapula and coracoid, which resemble those figured by Romer (1956, fig. 143B). As is usual for Diadectes, there is a good-sized foramen in the supraglenoid buttress. The scapula and coracoid have come apart anterior to the glenoid cavity, and this feature may be taken as another indication of the immaturity of the specimen.

The.humerus is about $56.5 \mathrm{~mm}$ in its greatest length; this is about one-half the size of a humerus of Diadectes sp. figured by Case (1911a, fig. 28) and about one-fourth the size of a humerus of $D$. tenuitectus described by Romer (1944, p: 142). The ends of the humerus, as would be expected in an immature specimen, are unfinished: the ectepicondyle and capitellum were not ossified. As is usual in Diadectes, the humerus has the tetrahedral shape characteristic of primitive tetrapods; 
the proximal half is twisted at a right angle to the distal half. The entepicondylar foramen has the same shape and relations as generally in Diadectes. The humerus can be used to distinguish $D$. sanmiguelensis, and all other species of Diadectes, from Diasparactus zenos Case, 1910.

Diasparactus zenos is an incompletely known diadectid from the Cutler Formation of northern New Mexico. Nothing is known of the top of its skull, and the palate and lower jaw are imperfectly known. Case and Williston (1913) have presented a fairly complete postcranial osteology, but it is still not clear whether or not episphenes and hyposphenes were present in the vertebral column. Olson $(1947$, p. 9) regards Diasparactus as a distinct genus. Case and Williston (1913, p. 21) have pointed out the remarkable fact that the humerus in Diasparactus zenos lacks a supinator process, or, at best, has only a poorly developed one. In their words, "there is no such process; the shaft of the left humerus is perfectly smooth at the position of the process, but on the right humerus there is a slightly elevated rugosity." The figure of their specimen of Diasparactus zenos (fig. 10) shows a humerus about 124 $\mathrm{mm}$ in length from the proximal articular surface to the distal end of the capitellum, and there seems to be no supinator process.

In Diadectes the supinator process generally arises from the preaxial side of the humerus about midway between the proximal articular surface and the distal end of the ectepicondyle. In the type of $D$. sanmiguelensis, the supinator process is definitely present and prominent although not perfectly preserved, and it arises, preaxially, about midway in the length of the humerus. Since the ectepicondyle was not ossified, it may be seen that the supinator process lay somewhat father proximally than it did in Diadectes generally.

There is nothing distinctive about the radius. The state of preservation of the proximal end of the ulna is not good enough to permit a positive statement, but the fact that the olecranon seems not to have been ossified is additional evidence of immaturity. In Diadectes there is generally a prominent olecranon. (See Case, 1911a, fig. 27.) Ossification of the carpus is only incipient and there are rudimentary centers for the radiale, the first distal carpal, a centrale, and what may be the intermedium, ulnare, and pisiform; the carpus is far less ossified than the carpus figured for Diasparactus zenos by Case and Williston (1913, fig. 12). Romer $(1956$, p. 381) points out that the diadectid carpus is generally poorly ossified. There is nothing unusual about the metacarpus, and the phalangeal formula is the usual $2-3-4-5-3$. The digits are much like those figured for Diasparactus zenos (Romer, 1956, p. 381).

\section{Order COTYLOSAURIA \\ Suborder CAPTORHINOMORPHA \\ Family IMMNOSCELIDAE}

Limnoscelops longifemur Lewis and Vaughn, n. gen. and n. sp.

Figure 9 A-G

The type of Limnoscelops longifemur (MCZ 2984 from loc. 10) consists of a small jaw fragment, the tips of two teeth, seven incomplete vertebrae, a partial pelvic girdle, proximal and distal parts of a femur, the proximal part of an ulna, and other fragments. These parts were found as associated loose scrap. The similarity of the vertebrae to one another, the fitness in size of these vertebrae to the rest of the elements, and the size of the head of the femur relative to the dimensions of the acetabulum all indicate that these bones are the remains of one animal. This specimen clearly represents a new species of a new genus of cotylosaurian reptile.

The combined generic and specific diagnosis is : Vertebrae similar to those of Limnoscelis and Limnosceloides. Posterior part of pubic symphysis thick. Large, circular depression in anterior face of conjoined internal ridges of pubes. Femur similar to femora of Captorhinus and Labidosaurus. The outstanding demonstrable feature of Limnoscelops longifemur is the combination of limnoscelidlike vertebrae with a captorhinidlike femur.

The fragment of the lower jaw is so small-about $1 \mathrm{~cm} \times 2 \mathrm{~cm}$-and so poorly preserved that it is uninformative. The distal tips of two teeth about $11 / 2 \mathrm{~mm}$ long, and impressions of two more tips, occur in the matrix adhering to this fragment. The better preserved of the two tips is round in cross section; its diameter at its proximal end is $3 \mathrm{~mm}$, and it tapers to a blunt point. A ground section shows no sign of labyrinthodonty.

Of the parts of vertebrae present, only a single dorsal vertebra approaches completeness, and even in this the zygapophyses, the neural spine, and the ventral half of the centrum are missing. The centrum is notochordal, has a canal of the typical hour-glass shape, and must have been roughly circular in anterior or posterior aspect. The greatest width of the centrum, measured at the anterior end, is $25 \mathrm{~mm}$. The centrum is about 16.5 $\mathrm{mm}$ long, measured along the lateral side on the level of the notochordal canal. This centrum is similar in both proportions and absolute size to a dorsal centrum of Limnosceloides dunkardensis measured by Romer (1952, p. 89), in which the corresponding dimensions are $26 \mathrm{~mm}$ and $16 \mathrm{~mm}$. The dimensions of a dorsal centrum in a specimen of Limnoscelis paludis figured by Williston $(1912$, p. 462$)$ are about $25 \mathrm{~mm}$ by $18 \mathrm{~mm}$ (calculated from Williston's figure). The ratio of the width of the centrum to the distance between the centrum and 

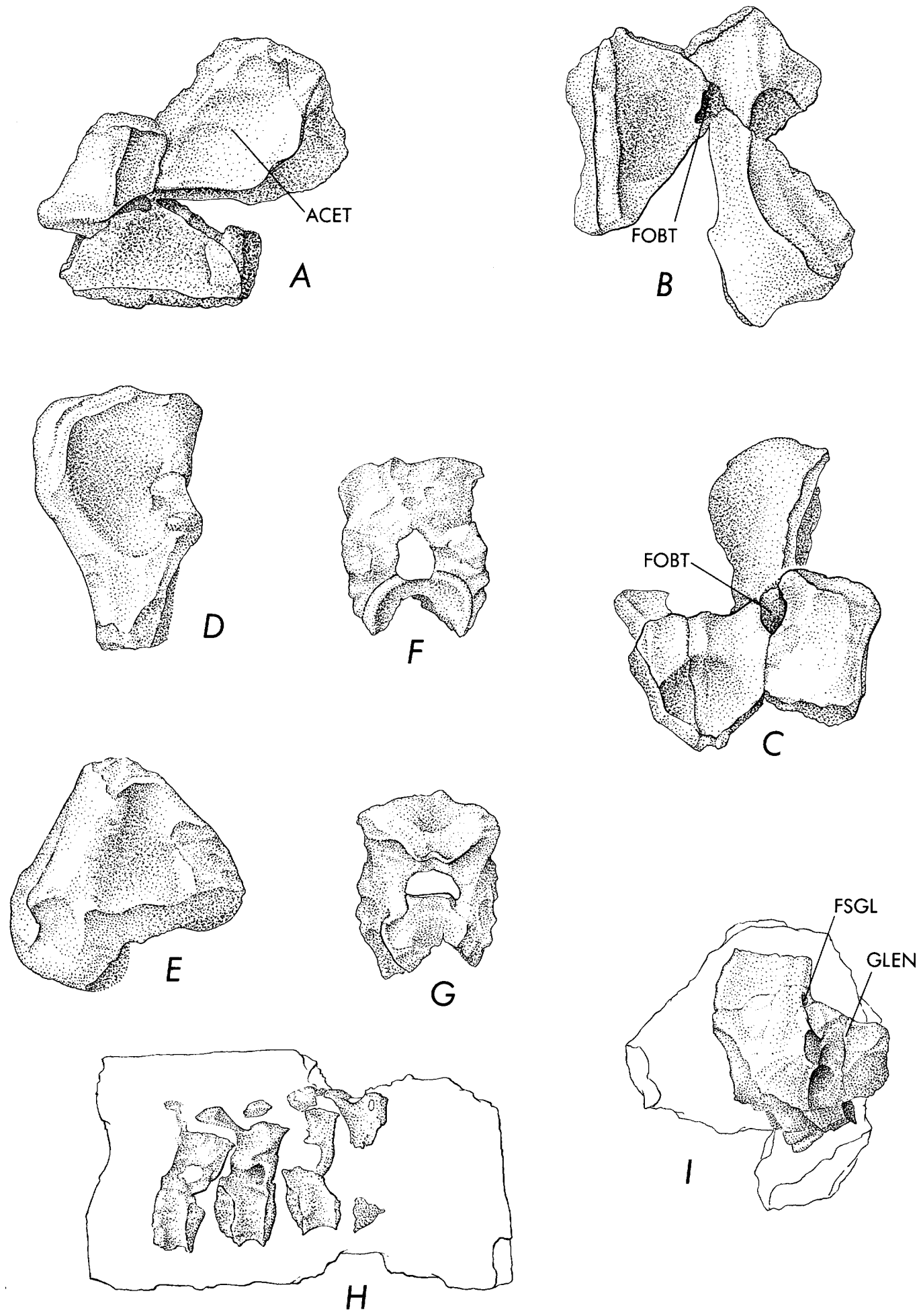

Figure 9.-Limnoscelops longifemur, n. gen., n. sp., elements of the type specimen, MCZ 2984. $A, B, C$, Lateral, ventral, and anterior views of the preserved part of the innominate bone; $D, E$, ventral views of the proximal and distal parts of the left femur; $F, G$, anterior and posterior views of a dorsal vertebra; $H, \mathrm{MCZ} 2979$, a series of articulated vertebrae referred to Limnoscelops longifemur; I, MCZ 2981, a part of the left scapulocoracoid of an undetermined captorhinomorph. Unshaded areas represent matrix. All $\times \mathbf{0 . 6 7}$. 
the base of the neural spine, measured along the posterior surface, is about 1.1: 1 in both MCZ 2984 and the specimen of Limnoscelis paludis figured by Williston.

The vertebrae of Limnoscelops longifemur are typical of limnoscelids in general; they resemble most closely those of Limnosceloides dunkardensis. The neurocentral sutures in the vertebrae are not visible, in contrast to the lumbar vertebrae of Limnosceloides dunkardensis figured by Romer (1952, fig. 10). The neural arch in Limnoscelops longifemur has the "swollen" appearance of such typical cotylosaurs as Limnoscelis and Limnosceloides. A broad, wedge-shaped process projects downward to end at the dorsal border of the neural canal on the posterior surface of the neural arch. The ventral end of this process, whose two ventrolaterally facing surfaces are continuous with the articular surfaces of the postzygapophyses, is notched in the midline. Such a process is found also in Limnoscelis paludis (Williston, 1912, fig. 15), and we have found it on vertebrae of the only known specimen of Limnosceloides dunkardensis (USNM 12166). The hyposphenes are connected to a similar process in Diadectes, but Limnoscelops, Limnoscelis, and Limnosceloides lack hyposphenes. Captorhinus, Captorhinikos, and Labidosaurus lack such a process, and it probably did not occur in any of the Captorhinidae.

Because the lateral parts of the zygapophyseal processes and their articular surfaces are missing, it is not possible to measure the greatest width of the neural arch on this specimen, but a referred specimen (see below) shows that the zygapophyses were widely separated and the articular surfaces were in a nearly horizontal plane as in Limnoscelis and Limnosceloides. The costal articular surface is not well preserved, but there seems to have been a ridge passing from about midway on the anterior edge of the centrum upward to the diapophyseal area behind the prezygapophysis as in Limnoscelis. A small notch occurs between the areas for the capitular and tubercular parts of the rib. There is a dimple about $4-5 \mathrm{~mm}$ in diameter behind the costal ridge and immediately dorsal to the probable line of the neurocentral suture. This depression is not as deep on the best preserved vertebra as it is on a fragment of another vertebra. Such dimples occur also in a series of four articulated vertebrae of Limnosceloides dunkardensis (see Romer, 1952, fig. 10) where the dimples are deeper in the posterior than in the anterior vertebrae (personal examination).

Probably the best preserved vertebra is a more anterior one than the more deeply dimpled fragment that articulates with a partial vertebra that includes part of the centrum. The ventral surface of this centrum is flattened in a longitudinal strip about $5 \mathrm{~mm}$ wide. Wil- liston (1911a, p. 387) has described such a flattened surface on the centrum in Limnoscelis paludis, in which it apparently is not a constant feature (Williston, 1912, p. 458). There are several partial caudal vertebrae similar to those figured for Limnosceloides dunkardensis by Romer (1952, fig. 10).

The preserved part of the left innominate bone consists of the acetabular parts of the pubis and ischium and a bit of the posterior acetabular part of the ilium, and of the thickened, symphyseal parts of the pubis and ischium below the acetabulum on both sides. The blade of the ilium, which in Diadectes and Limnoscelis contains the external shelf apparently characteristic of the most primitive cotylosaurs, is totally lacking as it is in the specimen of Limnosceloides dunkardensis. Maturity is indicated by the lack of visible sutures between the pelvic elements. The length of the acetabulum is $43 \mathrm{~mm}$, measured from the anteroventral corner to a point midway on the rim of the acetabular part of the ischium, about equal to the corresponding distance in the specimen of Limnosceloides dunkardensis (calculated from Romer, 1952, fig. 11) and about two-thirds as great as in the specimen of Limnoscelis paludis figured by Williston (1911a, fig. 6).

Limnoscelops longifemur, Limnoscelis paludis, Limnosceloides dunkardensis, and the captorhinid cotylosaurs (see Romer, 1956, fig. 150-I for Labidosaumus) all have a thickened ridge passing from the internal surface of the acetabular part of the pubis to end at the thickest part of the pubic symphysis, which is greatly thinned anterior to this ridge. In Limnoscelis paludis and Limnosceloides dunkardensis, the pubic symphysis is considerably thinned posterior to this ridge also. (See Romer, 1956, fig. 150-H; 1952, fig. 11.) In Limnoscelops longifemur there is some thinning posterior to the ridge, but it is much less pronounced than in the other two animals. The thickest part of the pubic symphysis is about $29 \mathrm{~mm}$; this is about twice the thickness of Limnosceloides dunkardensis and slightly less than that of the specimen of Limnoscelis paludis figured by Williston (1911a, fig. 6). Two $\mathrm{cm}$ posterior to this thickest part the depth of the symphysis has decreased only to $22 \mathrm{~mm}$; and $3 \mathrm{~cm}$ posterior to the thickest part the depth of the (probably ischiadic) symphysis has decreased only to about $17 \mathrm{~mm}$. The acetabular length is about two-thirds that of the same specimen of Limnoscelis paludis.

Limnoscelops longifemur has a conspicuous circular depression, about $18 \mathrm{~mm}$ in diameter and about $4 \mathrm{~mm}$ deep at the center, on the anterior face of the thickest part of the pubic symphysis, the anterior surface of the conjoined internal ridges of the pubes. This feature is unmatched in any other known cotylosaur. The 
depression on the anterior face of the conjoined internal ridges of the pubes in Limnoscelops longifemur makes this face more nearly vertical than it is in Limnoscelis or Limnosceloides. In this, Limnoscelops is more like the captorhinids than are the other two genera.

The external opening of the obturator foramen is similarly placed in Limnoscelops, Limnoscelis, and Limnosceloides. In Limnoscelis, as in Labidosaurus, the internal opening of the foramen lies anterior to the internal ridge of the pubis, but in Limnosceloides, the opening lies at the upper end of the ridge (Romer, 1952, p. 90). Limnoscelops longifemur shows a somewhat intermediate condition in that the opening lies immediately anterior to a crest above the greatest depth of the ridge, but the position of the opening is more like that in Limnosceloides than it is like that in Limnoscelis.

The proximal fragment of an ulna is about fivesevenths the size of the corresponding part of Limnoscelis paludis figured by Williston (1912, fig. 27), but the two are morphologically indistinguishable.

The hind led of Limnoscelops longifemur is represented in the type by only the proximal and distal ends of the left femur; they are very similar to those of Labidosaurus, but what is left of its stumps seems to indicate that the shaft was more slender and more like that of Captorhinus. The relative slenderness in Limnoscelops is a significant difference from Labidosaurus, a much smaller reptile by comparison of the proximal and distal ends. (See Case, 1911a, fig. 48.)

The complete femur may have been at least $130 \mathrm{~mm}$ long from the most proximal point on the head to the end of the posterior condyle, and at least $122 \mathrm{~mm}$ long from the most proximal point on the head to the center of the intercondylar notch. This calculated distance from head to intercondylar notch is about one and onefourth times the comparable length in Limnosceloides dunkardensis (USNM 12166). The pelves are about the same size in these two; therefore, Limnoscelops longifemur had proportionally much longer femora, and probably also had proportionally longer hind legs and slenderer shaft than Limnosceloides dunkardensis: The stump of the shaft on the proximal fragment of Limnoscelops longifemur is about $17 \mathrm{~mm}$ thick (measured in the plane of the head of the femur) as compared to about $25 \mathrm{~mm}$ in Limnosceloides dunkardensis (calculated from Romer, 1952, fig. 12). The proximal and distal ends of the femur in Limnosceloides are not so wide in comparison with the shaft as in Limnoscelis whose femur is short, stoutly built, and in general comparable to the femur in Seymouria. (See Romer, 1952, fig. $12 ; 1956$, figs. $171 A, B, C, F$.)

The trochanteric crest is set off from the head by a distinct notch as in Labidosaurus (Romer, 1956, fig. $171 \mathrm{G}$ ), but in contrast to Limnoscelis, makes almost a right angle with the head, and does not flare widely at the front. The trochanteric crest in Labidosaurus and Limnoscelis is directed anteriorly as well as ventrally, so that it makes an obtuse ventral angle with the head; only the base of the crest is preserved in Limnosceloides dunkardensis (USNM 12166). There is a prominent excavation on the posterior side of the posterior condyle as in Labidosaurus and Limnoscelis, but in contrast to Limnosceloides.

To sum up the significant morphologic features of Limnoscelops longifemur: The vertebrae are typically limnoscelid, the preserved parts of the pelvis are much like those in Limnosceloides except for the thicker symphysis, and for the almost vertical, captorhinomorphlike face of the conjoined internal ridges of the pubes.

Romer (1956) recognizes three families of captorhinomorph cotylosaurs : the Limnoscelidae, the Romeriidae, and the Captorhinidae. The consensus seems to be that vertebral structure is more conservative than the structure of the appendages, as illustrated by the currently accepted classification of labyrinthodont amphibians; thus, the classification of Limnoscelops must depend more on its vertebrae than on the other materials available to us. We therefore tentatively assign Limnoscelops to the family Limnoscelidae. Romer's assignment of Limnosceloides to this same family was also only tentative. Limnoscelis, known only from the Cutler (El Cobre Canyon) of New Mexico, has heretofore been the only unquestioned representative of this family. Limnoscelops, for the time being, is best thought of as a limnoscelid advanced in the direction of the captorhinids.

The romeriids and captorhinids are closely related, the captorhinids having apparently been derived from the romeriids. The postcranial skeleton of the romeriids is, unfortunately, still unknown. Protorothyris and Romeria of the romeriids are known from the lower part of the Wichita Group in Texas, Melanothyris is known from the lower part of the Dunkard Group in the eastern United States, and Cephalerpeton may be a romeriid from the Allegheny Formation of Illinois. The Wichita Group has yielded only a few primitive captorhinids, but the advanced Captorhinus and $L a$ bidosaurus are common in the over-lying Clear Fork Group.

The known limnoscelids could not have been the actual ancestors of the romeriids or captorhinids if we consider their respective ages. The phylogenetic divergence must therefore have occurred no later than Middle Pennsylvanian time. 
Limnoscelops longifemur Lewis and Vaughn, referred specimen Figure $9 H$

We refer an articulated series of four vertebrae ( $\mathrm{MCZ}$ 2979 from loc. 4) to the new cotylosurian species Limnoscelops longifemur Lewis and Vaughn. It has not been possible to prepare fully these vertebrae owing to an extremely difficult matrix, but diagnostic characters are clearly evident.

The second vertebra in the series has a centrum 12.5 $\mathrm{mm}$ in length. This is considerably less than the length, $16.5 \mathrm{~mm}$, of the centrum of the best preserved, apparently dorsal, vertebra of the holotype. In the specimen of Limnosceloides dunkardensis, the centra increase in length passing posteriorly, from $16 \mathrm{~mm}$ in a dorsal vertebra to about $19 \mathrm{~mm}$ in the five vertebrae immediately anterior to the sacrum. There is a similar increase in the holotype of Limnoscelops longifemur: In one of the vertebrae determined as posterior to the best preserved vertebra (on the basis of a more pronunced dimple above the junction of centrum and neural arch), the centrum is about $18 \mathrm{~mm}$ long. The dimples on the referred vertebrae are deeper than any in the holotype and are very much like those in the specimen of Limnosceloides dunkardensis; if the correlation, derived from the materials of the latter animal, of farther posterior position with deeper dimples is correct, the referred vertebrae are from a posterior position. The small size of the centra may be due to immaturity: traces of a persistent neurocentral suture can be seen immediately below the dimple on several of the vertebrae.

The centrum of the second vertebra in the series has a transverse width of approximately $15 \mathrm{~mm}$ at the anterior end. The ratio of width to length for this centrum, $1.2: 1$, is not greatly different from the same ratio for the posterior vertebra of the holotype whose length was measured as $18 \mathrm{~mm}$ and whose width is about $20 \mathrm{~mm}$, $1.1: 1$. It will be noted that this posterior centrum of the holotype is narrower than the holotype's dorsal centrum. In the specimen of Limnosceloides dunkardensis too, the centra not only become longer posteriorly, but they also decrease somewhat in width, although not as markedly as in the materials of Limnoscelops longifemur. The decrease observable in the holotype of Limnoscelops longifemur is $5 \mathrm{~mm}$ (from $25 \mathrm{~mm}$ to 20 $\mathrm{mm}$ ) ; Romer (1952, p. 89) records a maximum decrease of $3 \mathrm{~mm}$ (from $26 \mathrm{~mm}$ to $23 \mathrm{~mm}$ ) passing posteriorly in Limnosceloides dunkardensis.

In the first vertebra of the referred series, the distance between the most lateral points of the postzygapophyses is about $33 \mathrm{~mm}$. The ratio of this distance to the width of the centrum is about $2.2: 1$, assuming that the first and second centra have the same width; this ratio is greater than the ratio $2: 1$ calculated for Limnoscelis paludis from Williston's illustration (1912, fig. 15). The transverse distance across the waist of the neural arch of the referred first vertebra is $25 \mathrm{~mm}$. This distance is $28 \mathrm{~mm}$ in the best preserved vertebra of the holotype. The zygapophyses lie in a nearly horizontal plane. The costal facets of the vertebrae are too poorly preserved to add to the description of the holotype.

This referred specimen might have been made the type of a new species assigned to Limnosceloides if the holotype of Limnoscelops longifemur were not known, but the geographic proximity of this specimen to the latter makes it highly probable that the referral to Limnoscelops longifemur is correct.

\section{Order COTYLOSAURIA \\ Suborder CAPTORHINOMORPHA Family CAPTORHINIDAE?}

Genus and species indeterminate

Figure $9 I$

Almost an entire scapulocoracoid (MCZ 2981 from loc. 7) is questionably referred to the Captorhinidae. It consists of the parts in the vicinity of the glenoid cavity, including the scapular blade up to a short distance above the supraglenoid buttress, and a large part of the coracoid plate. This specimen probably came from a mature animal, as indicated by the lack of visible sutures.

The glenoid cavity has the screw-shaped articular surface common in cotylosaurs. The supraglenoid buttress has the outline of an isosceles triangle; the sides are slightly shorter than the base along the dorsal border of the glenoid cavity. The buttress faces more posteriorly than it does laterally. The supraglenoid foramen pierces the buttress immediately below the apex of the triangle, nearer the blade of the scapula than the posterior border of the buttress. There is a large supracoracoid foramen. The coracoid plate is incomplete posterior to the glenoid cavity; hence, it is not possible to say whether there was a process for the coracoid head of the triceps muscle as in pelycosaurs.

The scapulocoracoid is very close in size to that of a specimen of Captorhinikos chozaensis (USNM 21275) which it closely resembles, especially in details of the supraglenoid area. In both, the supraglenoid buttress has the isosceles outline described, and the supraglenoid foramen lies near the scapular blade. Both specimens resemble Labidosaurus in this characteristic (Romer, 1956, fig. 143-C) ; in Captorhinus, the foramen lies even farther forward, almost on the blade. The resemblance to the scapulocoracoid in Captorhinikos is so close that this bone from the Cutler (MCZ 2981) probably repre- 
sents a captorhinomorph cotylosaur, if not actually a captorhinid.

If we may attempt a comparison with other known cotylosaurian components of the fauna described in this paper, we see at once that MCZ 2981 could not have belonged to the seymouriid (MCZ 2983) assumed to have had a pectoral girdle like that in Seymouria baylorensis (White, 1939, fig. 17) : the glenoid cavity in Seymouria is too narrow from top to bottom and is not well developed as a screw-shaped socket. The scapulocoracoid of the holotype of Diadectes sanmiguelensis is of roughly the same size but has the supraglenoid foramen nearer the glenoid cavity, and a supraglenoid buttress that passes smoothly into the posterior edge of the scapular blade without an abrupt decrease in thickness.

It is doubtful that MCZ 2981 could have belonged to the limnoscelid Limnoscelops longifemur, represented by MCZ 2984 and MCZ 2979, assuming that Limnoscelops longifemur had a pectoral girdle whose size relative to its pelvic girdle was roughly similar to the ratio of the pectoral to pelvic girdle in Limnoscelis paludis. The individual of Limnoscelops longifemur represented by MCZ 2984 is estimated to have had a glenoid cavity in which the straight-line distance between the most anterior and most posterior points on the rim was about $33 \mathrm{~mm}$ based on the ratio of the length of the acetabulum to the length of the glenoid cavity in Limnoscelis palu$d i s$, as calculated from Williston (1911a, figs. 4, 6), and on the acetabular length of $43 \mathrm{~mm}$ in MCZ 2984. This is considerably larger than the distance of $20 \mathrm{~mm}$ seen in MCZ 2981.

We conclude that this scapulocoracoid represents a captorhinomorph cotylosaur, possibly a captorhinid.

\section{SUBCLASS SYNAPSIDA \\ Order PELYCOSAURIA \\ Suborder OPHIACODONTIA \\ Family OPHIACODONTIDAE}

Ophiacodon sp.

Figure 10

An articulated string of three whole and two half vertebrae and intercentra (MCZ 2977 from loc. 1) represents a species of Ophiacodon Marsh, 1878. None of the neural spines are completely preserved. These vertebrae are from the posterior dorsal region as shown by the narrow separation of parapophysis and diapophysis and by the presence on the ventral side of the centrum of a flattened area bounded by a pair of longitudinal ridges. The vertebrae fit Ophiacoden in that: (1) The neural arches are not excavated on the lateral sides of their laminae; (2) the centra lack a sharp ventral keel in these posterior dorsal vertebrae; (3) the neural canal sends a narrowed extension far ventrally, almost to the notochordal canal, as seen in a cross section of the centrum ground to approximately the plane of minimal area of the notochordal canal-such an extension is found in ophiacodonts and edaphosaurs, but not in sphenacodonts (Romer and Price, 1940, fig. 17); and (4) the sides of the centrum converge ventrally toward the ridges bounding the narrow, ventral flattened area, with only the slightest suggestion of concavity.

The only genus of ophiacodontids that fits the above description is Ophiacodon. The margins of the ventral surface of the centrum are rounded in Clepsydrops and Varanosaurus (Romer and Price, 1940, p. 214).

The nomenclatorial history of the genus Ophiacodon is complicated, having seven synonyms; Romer and Price (1940, p. 225) have reviewed this history. The two species of Ophiacodon known from the Cutler Formation of northern New Mexico are $O$. navajovicus (Case, 1907) and O. mirus Marsh, 1878. Ophiacodon mirus is very similar to $O$. uniformis from Texas, and it is difficult to distinguish the postcranial skeleton of $O$. mirus from that of $O$. navajovicus except that $O$. navajovicus is a somewhat smaller animal (Romer and Price, 1940 , p. 233, 237).

The greatest length of each of the complete centra is $16.5 \mathrm{~mm}$. This may be compared with the known lengths of posterior dorsal vertebrae in Ophiacodon navajovicus, $12-18 \mathrm{~mm}$; O. mirus, $18-22 \mathrm{~mm}$; and $O$. uniformis, 15-19 mm. (See Romer and Price, 1940, table 3 ; these authors also list a questionable specimen of O. uniformis, which has a "lumbar" vertebra $13 \mathrm{~mm}$ long.) The ratio of the length of the centrum to the width of the posterior end of the centrum is $1.1: 1$; in both $O$. navajovicus and $O$. mirus this ratio varies from $0.9: 1$ to $1.2: 1$ for posterior dorsal vertebrae. The height from the bottom edge of the centrum to the top of the posterior zygapophysis is $25.5 \mathrm{~mm}$; this height would fit $O$. navajovicus, in which the range, for mid-dorsals through "lumbars," is about $22-26 \mathrm{~mm}$; $O$. mirus, in which the same range is about $26-31 \mathrm{~mm}$; or $O$. uniformis, in which the range is about $26-31 \mathrm{~mm}$, according to Romer and Price (1940) The least height recorded for $O$. retroversus, from Texas, is $36 \mathrm{~mm}$, and $O$. major, also from Texas, is an even larger animal.

The facts of similarity in size, similarity in geographic location, and presence in the same geological formation would seem to indicate that the species represented may be either $O$.navajovicus or $O$. mirus. The size actually fits into the size range of $O$. navajovicus, but we feel that it misses fitting into the range of $O$. mirus by too narrow a margin to allow a choice between the species on the basis of these vertebrae alone. 


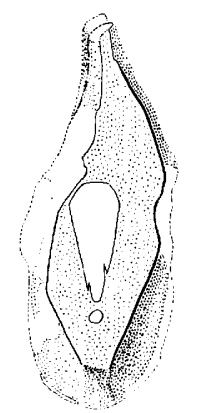

A

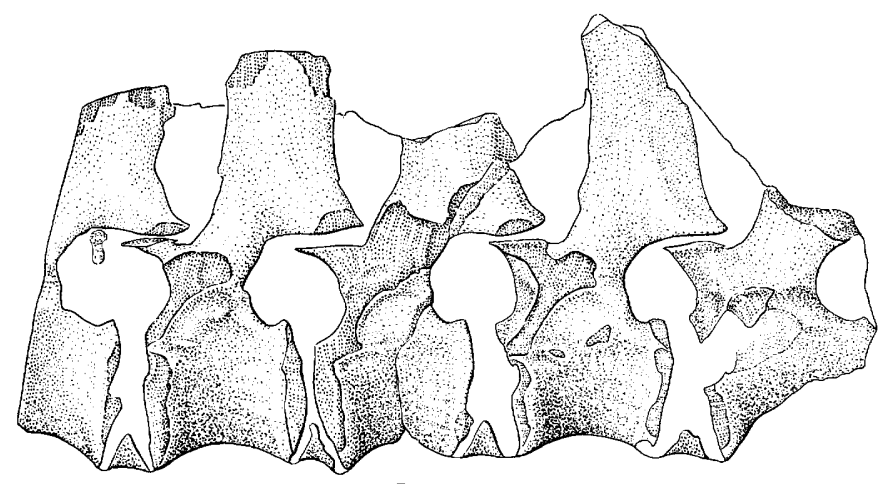

B

FIgURE 10.-Ophiacodon sp., MCZ 2977. A, Ground transverse section through the first vertebra in the string; $B$, the string of vertebrae in lateral view. Unshaded areas represent matrix. $\times 1$.

\section{Order PELYCOSAURIA \\ Suborder OPHIACODONTIA?}

Genus and species undetermined

A left tibia and an articulated fragment of a femur (MCZ 2991 from loc. 16) are thought to be those of an ophiacodont. The dimensions of the tibia are: length, $90 \mathrm{~mm}$; estimated proximal width, $36 \mathrm{~mm}$ (the posterior condyle is incomplete); distal width, $22 \mathrm{~mm}$; diameter of narrowest part of shaft, about $11.5 \mathrm{~mm}$. The tibia is obviously pelycosaurian. Because it does not have the stocky shape of the edaphosaurian tibia, comparisons may be restricted to specimens of ophiacodonts and sphenacodonts having tibiae of roughly comparable length.

The ratio of the length of the tibia to the narrowest part of the shaft is $7.8: 1$, greater than in some species of ophiacodonts. For example, in Varanosaurus acutirostris it is $6: 1$; in Ophiacodon navajovicus, $6: 1$; in 0 . uniformis, $7.7: 1$. The ratio may be the same as in O. mirus, or it may be greater as in Clepsydrops collettii where it is $8.8: 1$. This ratio is greater in sphenacodonts: Varanops brevirostris, 9.5:1; Dimetrodon natalis, $9.4: 1 ;$ D. milleri, $11.5: 1$ (approximate figures based on Romer and Price, 1940, fig. 38). The figures for the ratio of the length to the proximal width overlap when ophiacodonts are compared with sphenacodonts, and in both these groups are found tibiae from 61 to $114 \mathrm{~mm}$ in length where the ratio (based on Romer and Price, 1940, table 4) is very close to that for MCZ 2991.

These pelycosaurian limb bones may be part of an ophiacodont, considering the ratio of the tibial length to the narrowest part of the shaft. The ratio of the length of the tibia to the length of posterior dorsal vertebrae has a considerable range in the two known ophiacodonts from the Cutler Formation of northern New Mexico: for Ophiacodon navajovicus, $4.9: 1$ to $7: 1$, for 0. mirus, $4.5: 1$ to $5.6: 1$ (based on Romer and Price, 1940 , tables 3 and 4). The length of the tibia of MCZ 2991 is 5.5 times as great as the length of each of the posterior dorsal vertebrae in $\mathrm{MCZ} 2977$, described on page $\mathrm{C} 26$ as belonging to Ophiacodon sp.; this ratio fits easily into the range of the ratio of the length of the tibia to the length of posterior dorsal vertebrae for the New Mexican ophiacodonts. Possibly, MCZ 2991 belongs to the species of Ophiacodon represented by $\mathrm{MCZ}$ 2977.

\section{Order PELYCOSAURIA \\ Suborder SPHENACODONTIA Family SPHENACODONTIDAE Subfamily HAPTODONTINAE}

Cutleria wilmarthi Lewis and Vaughn, n. gen. and n. sp.

Figures 11, 12A

We here name Cutleria wilmarthi, a new species of a new genus of haptodontine pelycosaurs, and designate as the type USNM 22099 from locality 3 : a fractured skull that is fairly complete except for parts of the bones of the snout, the mandible, the first 12 vertebrae, several additional presacral and caudal vertebrae, parts of the rib cage, the pectoral girdle, the incomplete left humerus, the right epipodials, and the right carpus. The specific name is given in honor of V. R. Wilmarth, who found the holotype and who was the first, to our knowledge, to discover fossils in the Cutler Formation of Colorado.

Because Cutleria wilmarthi is the only known species of the new genus, the following diagnosis does not differentiate between generic and specific characters : Skull has the diagnostic characters of the Sphenacodontidae (Romer and Price, 1940, p. 283-284), including a flange on the angular bone, and having the proportions of the nonsecondontosaurine sphenacodontids. Temporal fe- 


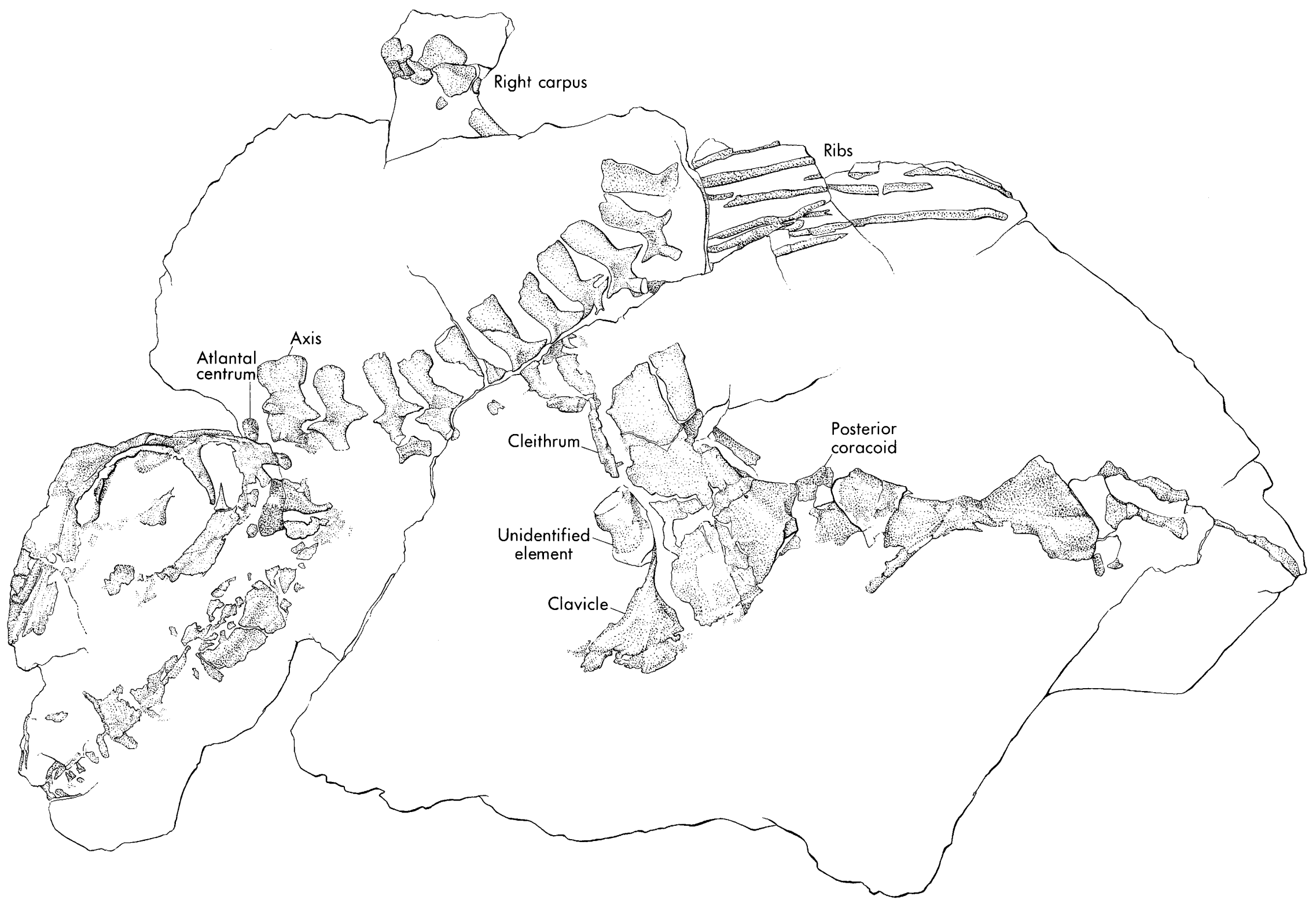




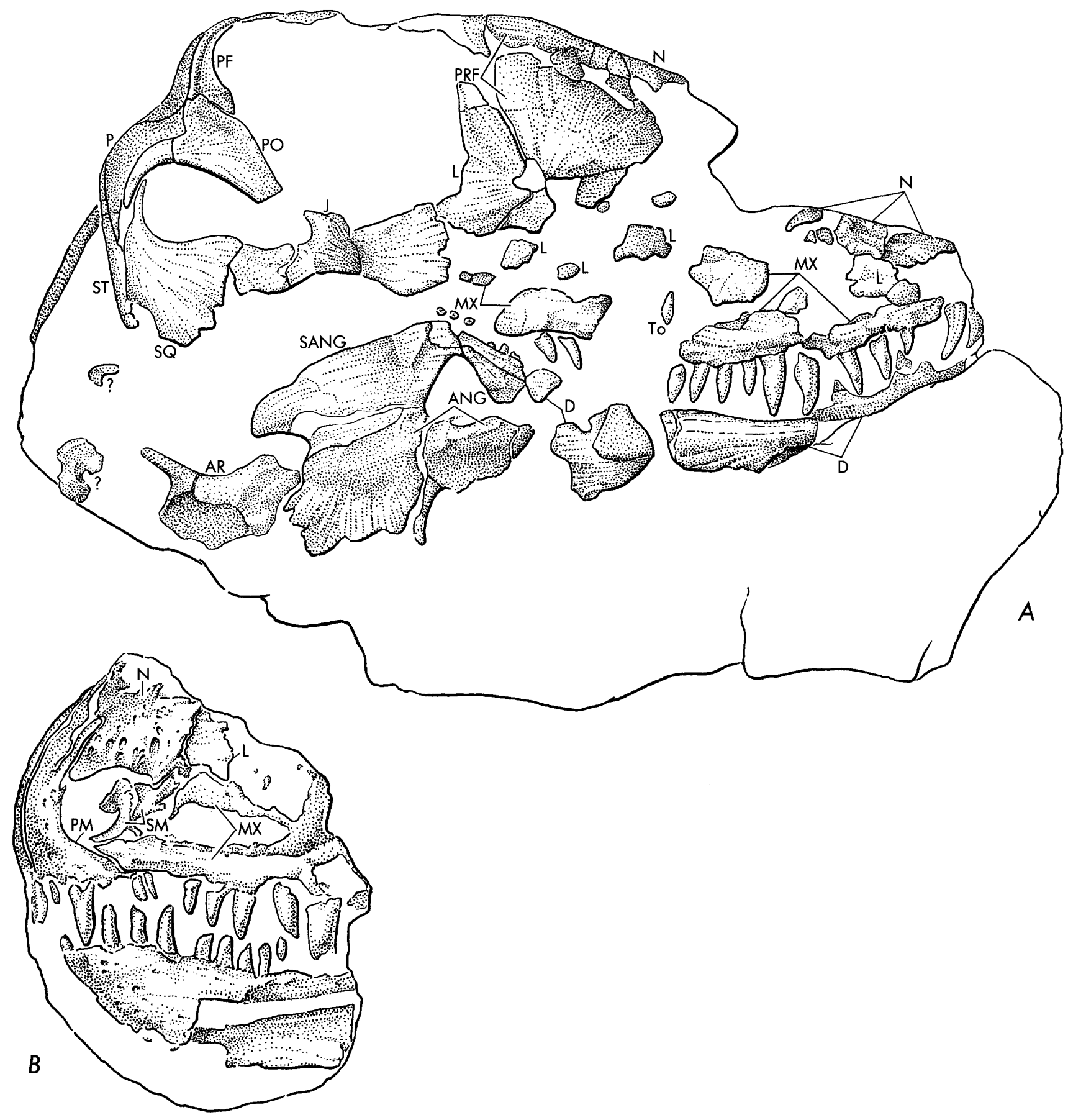

FIgURE 12.-Cutleria wilmarthi n. gen., n. sp. A, right lateral view of the skull of the type specimen, USNM 22099; B, MCZ 2987, a snout fragment referred to Cutleria wilmarthi. Unshaded areas represent matrix. Both $\times 1.125$.

nestra is narrow from front to back, elongated vertically, narrower ventrally than dorsally, and has its long axis steeply inclined to the horizontal axis of the skull. The largest maxillary teeth lie about one-third of the way back in the length of the maxilla and are not markedly developed as canines. No "step" in the anterior part of the alveolar border of the maxilla.
Known postcranial skeleton of same general proportions as that of the varanopsid Varanops brevirostris, except that the limbs of $C$. wilmarth $i$ are proportionately somewhat longer and the postcranial skeleton of $C$. wilmarthi is closer in some respects to the sphenacodontid pattern than it is to the varanopsid pattern, as in the more posterior position of the supraglenoid foramen and the 
absence of an incisure in the anterior border of the coracoid plate.

The sphenacodontid characters of the skull will distinguish $C$. wilmarthi from all nonsphenacodontid pelycosaurs in this diagnosis. The "normal" proportions of the skull will distinguish $C$. wilmarthi from the species of Secodontosaurus within the Sphenacodontidae. The lack of pronounced canines, the lack of a "step" in the maxilla, and the varanopsidlike proportions of the postcranial skeleton will distinguish it from the members of the Sphenacodontinae; and the shape of the temporal fenestra will distinguish it from other known members of the Haptodontinae.

Romer and Price (1940, p. 260) listed the following characteristic sphenacodontian features: (1) The posterior region of the skull is broad. (2) The dorsal and lateral surfaces of the skull are sharply demarcated in the preorbital and temporal regions; the temporal opening is barely visible in dorsal view. (3) The posterodorsal corner of the orbit, where the postfrontal and postorbital bones meet, projects lateralward as a boss that distinctly sets off this region of the lateral margin of the dorsal surface of the skull from the more posterior part of the margin. (4) The articular surface of the quadrate is well posterior to the occipital condyle as shown by the position of the first vertebra; the occiput is concave in dorsal view. (5) The cervical and anterior dorsal vertebrae have sharp ventral edges, and a cross section of a dorsal vertebra shows no extension of the neural canal reaching toward the notochordal canal. (Such an extension does exist in ophiacodonts and edaphosaurs; see Romer and Price, 1940, fig. 17.) (6) The lateral surfaces of the neural arches are excavated between the transverse processes and the base of the neural spine. (7) The clavicles are expanded ventrally. (8) The scapula is tall and narrow. (9) The supraglenoid foramen lies anterior to the supraglenoid buttress of the scapula. (10) The supraglenoid buttress faces as much sideward as it does rearward. (11) There is an open suture between the posterior coracoid and the anterior elements of the primary shoulder girdle; it is characteristic of the sphenacodonts that the coracoid ossified slowly.

Cutleria wilmarthi clearly belongs to the suborder Sphenacodontia because this new genus and species shows all eleven of the preceding easily observable characters; within the suborder, it is a sphenacodontid easily distinguished from the more primitive varanopsid Sphenacodontia. We place it in the family Sphenacodontidae on the basis of the presence of a well-developed, posteroventrally directed flange that forms the ventral and posterior edges of the angular bone and has a posterior notch somewhat like that of therapsid reptiles. The Sphenacodontidae, alone among pelycosaurs, have such a flange (Romer and Price, 1940, p. 284). Cutleria is a primitive haptodontine sphenacodontid. It lacks the secodontosaurine elongation of the snout, the sphenacodontine enlargement of the canine teeth, and the formation of a "step" in the anterior part of the alveolar border of the maxilla. The lacrimal bone probably reached the narial border in primitive style as suggested by the arrangement of the fragments of bone in the anterior region of the snout; this arrangement would distinguish $C$. wilmarthi from both the secodontosaurine and the sphenacodontine pelycosaurs. The lack of lacrimal entry into the narial border in Secodontosaurus may be related to the extreme length of the snout. The shortness of the lacrimal in the sphenacodontines may be related to great dorsalward enlargement of the maxillary bone associated with the development of large "canine" teeth.

Cutleria differs from the advanced sphenacodontids in these cranial features as well as in the rest of its osteology, particularly the lack of elongation of the neural spines, but resembles Haptodus, the only known genus of the primitive subfamily Haptodontinae. Cutleria is therefore assigned to this subfamily that contains its nearest relatives, the species of Haptodus from the European Autunian and Rotliegende.

The following description of $C$. wilmarth $i$ will not repeat many of the characters already described except for elaboration on some points. The comparisons of $C u t$ leria with Haptodus are based on the revised description of this latter genus by Romer and Price (1940, p. 297309) who consider the five Autunian-Rotliegende forms, Haptodus, "Palaeohatteria," "Pantelosaurus," "Callibrachion," and "Datheosaurus" as congeneric.

The skull was crushed in such a way that the posterior half of the right side has been forced upward and somewhat forward, and the posterior half of the left side has been forced downward and somewhat backward. In this way, the left maxilla has been torn away from the more dorsal part of the snout, and the right orbit has been narrowed dorsoventrally. The snout was crushed in such a way that a line drawn along the dorsal surface of the anterior part of the nasal bones may be projected into the center of the orbit, while the posterior parts of the nasal bones remain in their original position anterodorsal to the orbits.

The parts of the premaxillae anterior to the nares are lacking. The length of the skull, as preserved, measured along the left side from the most anterior point of the specimen to the posterior end of the quadrate, is $137.5 \mathrm{~mm}$. The right quadrate is not present, but if the right and left quadrates were similarly located, the same measurement on the right side would 
give a length of about $125 \mathrm{~mm}$. If we take the average of these measurements and add $5 \mathrm{~mm}$ for the approximate length of the missing part of the premaxilla (and the preserved cross sections of the anteriormost premaxillary teeth indicate that this is a safe approximation), we arrive at a skull length of about $136 \mathrm{~mm}$. This skull length is very close to that of a specimen of Dimetrodon natalis $(138 \mathrm{~mm})$ figured by Romer and Price (1940, fig. $5 B$ ). This comparison accentuates the nonsphenacodontine appearance of the dentition of $C$. wilmarthi; $D$. natalis has a relatively enormous "canine" tooth.

The left orbit of USNM 22099 seems to have preserved its original, nearly circular outline. It is 42.5 $\mathrm{mm}$ in greatest length and $38.4 \mathrm{~mm}$ in greatest height. Crushing has reduced the height of the right orbit to about $30 \mathrm{~mm}$. The orbits, whose centers lie about seventh-tenths of the way back in the length of the skull, bulge above the general plane of the interorbital region. The temporal fenestra, which has a narrow, rounded triangular shape and its anteroventral apex lying anterior to its anterodorsal angle, is about $11 \mathrm{~mm}$ long along its dorsal base and about $21 \mathrm{~mm}$ long along its slanted long axis.

The ventral edge of the lateral surface of the skull is concave in the region below the orbit and temporal fenestra as in all sphenacodontids. As in Haptodus, the alveolar border of the maxilla is gently convex, but not so convex as in Dimetrodon and Sphenacodon, where the convexity is accentuated by a "step" into which the large anterior teeth of the dentary fit in the anterior part of the maxilla.

The pattern of sutures in the skull in $C$. wilmarthi is mostly like that of the sphenacodontids generally and deserves little attention here. Figure $12 \mathrm{~A}$ shows our identifications of the bones and fragments. The nature of the specimen will not permit a statement as to whether or not the frontal bone enters the orbital margin. The preserved part of the jugal ends anteriorly somewhat behind the anterior edge of the orbit, but this is probably due to postmortem loss of the anterior part; the jugal seems to have overlapped the lacrimal and probably terminated in an anterior angle wedged between lacrimal and maxilla, as in other sphenacodontids.

Bones of the lateral surface of the snout are present only on the right side, except for the maxilla. The area of the lacrimal bone is worthy of special attention. We have identified a large, somewhat crescent-shaped fragment of bone at the anterior edge of the orbit as the posterior part of the lacrimal. Anterior and dorsal to this lies another fragment that we have identified as the major part of the prefrontal. The prefrontal has a longitudinal fissure running through it in the specimen, but the bone can be traced around the junction of the lateral and dorsal surfaces of the skull onto the dorsal surface, where it meets the nasal and frontal. The prefrontal hides the junction of nasal and frontal from lateral view, as it does also in at least Sphenacodon ferox and Dimetrodon milleri among other sphenacodontids. (See Romer and Price, 1940, figs. $4 E, 5 A$.) The rather limited entry of the prefrontal into the orbital margin in the specimen, as compared to the much more extensive entry of the lacrimal, is probably due to the same crushing that decreased the height of the right orbit; the prefrontal probably formed a larger part of the orbital margin in life than it does in the fossil. The distortion that displaced the prefrontal was probably also the cause of the longitudinal fissure in this bone.

Directly anterior to the described fragments of lacrimal and prefrontal lie several smaller fragments. The more ventral of these, and probably a fragment anteroventral to the body of the prefrontal, are probably parts of the lacrimal; the pelycosaurian lacrimal characteristically expands a short distance anterior to the orbit. A larger fragment anterior to these, above and immediately behind the part of the maxilla that bears the largest teeth, is probably part of the maxilla, although it is broken away from the rest of this bone; this is shown by the presence behind this fragment of a part of an unerupted replacement tooth. The maxilla apparently was shallow below the orbit, expanded to a depth of about 18-19 $\mathrm{mm}$ in the region of the largest teeth, and became shallow again as it approached the naris. Immediately behind the naris, entering the narial margin and bordered by maxilla below and nasal above, lies an incompletely broken fragment of bone that we have identified as the anteriormost part of the lacrimal. Crushing destroyed the connecting piece between this anteriormost part and the large orbital part of the lacrimal, caused the proximity of the nasal to the deepest part of the maxilla, and greatly altered the proportions of the snout in the specimen.

Well-preserved teeth are visible only on the right side. The premaxillary bone is not preserved except for very small fragments, but its teeth are present, although the anteriormost are not complete. There are two recurved teeth in the premaxilla, each about $6 \mathrm{~mm}$ long from alveolar border to tip. Behind these, there is a cross section of a much smaller tooth that probably also belonged to the premaxillary series. The first maxillary tooth lies posterior to a diastema of about $3.5 \mathrm{~mm}$; this tooth is $4 \mathrm{~mm}$ long. The teeth gradually increase in size for about one-third of the way back in the maxilla; the two largest teeth are here, as in Haptodus. 
Romer and Price, 1940, figs. $4 C, 4 D$.) The posterior one, fairly well preserved, has a length of about $9.5 \mathrm{~mm}$ and an anteroposterior diameter, measured at the alveolar border, of $4 \mathrm{~mm}$. The anterior one, whose tip has been broken away, may have been slightly longer. These two largest teeth, like all the maxillary teeth, are gently recurved and somewhat flattened from side to side; posterior to them the maxillary teeth gradually decrease to a least diameter of only about $1.5 \mathrm{~mm}$ near their bases.

Crushing, with the loss of parts of the maxilla, makes it impossible to state accurately the number of maxillary teeth, but a rough estimate would be $20-22$; a space immediately anterior to the largest teeth may represent a missing tooth, so that the largest teeth are either the fourth and fifth or the fifth and sixth in this series. This estimate may be compared with estimates of 22 maxillary teeth (including empty sockets) for Haptodus longicaudatus, skull length $70 \mathrm{~mm}$; and 18 for Haptodus saxonicus, skull length $180 \mathrm{~mm}$. The two largest teeth are the sixth and seventh in the maxillary series in both $H$. longicaudatus and $H$. saxonicus. $H$. longicaudatus is pictured having three premaxillary teeth, the third about half the length of the anterior two, and $H$. saxonicus is pictured having five premaxillary teeth, the last somewhat shorter than the others (Romer and Price, 1940, fig. $4 C, D$ ).

The depth of the mandible is greatest below the orbit in the region of the coronoid elevation, just behind the posterior termination of the dentary bone. Anterior to this, it becomes slimmer. Posteriorly, owing to the presence of the angular flange, the depth remains about the same as in the coronoid region until the articular area is reached. The flange on the angular bone and the posterior notch generally look like these structures in sphenacodontids; excavation of the matrix medial to the flange has demonstrated the platelike structure of the angular in this region. The surangular seems to play a somewhat more direct role in the dorsal border of the notch than it does in the sphenacodontines; in this, $C$. wilmarthi resembles the condition figured for Haptodus saxonicus by Romer and Price (1940, fig. $4 D)$. The articular bone has been displaced posteriorward. Poor preservation of the bone makes analysis of the articular area difficult, but the articular seems to have carried away with it a lateral dermal cover probably consisting of the inturned part of the angular and the turned-out part of the prearticular. A large opening in the right mandible, bounded by surangular, dentary and angular, is probably not a true fenestra but is more likely a postmortem effect of crushing. Of the mandibular dentition, only a few small posterior teeth are visible.
The first 12 vertebrae, a few additional presacral vertebrae, and a few caudal vertebrae are preserved. Diagnostic sphenacodontid characters-a sharp ventral edge on the centrum, lack of extension of the neural canal towards the notochordal canal, and excavation of the lateral surfaces of the neural arches-have already been noted.

The fourth vertebra has a length, measured along the ventral edge in a straight line, of about $12 \mathrm{~mm}$. The transverse diameter of the posterior end of the centrum is $11.9 \mathrm{~mm}$. The height of the neural spine, measured from the zygapophyses, is about $23.5 \mathrm{~mm}$. By Romer's system of linear units, where the unit, based on the radius of the centrum, is equal to $r^{2 / 3}$ (Romer and Price, 1940, p. 8 ), the spine has a length of about 7.2 units. The posterior diameter of the centrum of the ninth vertebra is about $12 \mathrm{~mm}$, and the height of the neural spine of this vertebra is about $26 \mathrm{~mm}$; in linear units, the height of this neural spine is 7.9. The spines of vertebrae 10,11, and 12 are of about the same height as that of vertebra 9 ; rearward, there seems to be no trend to increase in elongation. The 12th vertebra, as shown by its position relative to the pectoral girdle and by the attachment to it of a long rib, is part of the dorsal series and well posterior to the cervical region, as is the 12th vertebra in all pelycosaurs. We may, therefore, take the length of 7.9 units as approximately that of the tallest spines, and this measurement may be compared with lengths in other pelycosaurs.

According to Romer and Price (1940, p. 104), "Leaving aside $* * *$ genera in which these structures are unusually elongated, the spine in many ophiacodonts and sphenacodonts tends to have a length (measured from the zygapophyses) of 8 to 10 units. In some edaphosaurs, the spines appear to have been but half this height." The neural spine length is about 8 units in the primitive sphenacodont Varanops. (Romer and Price, 1940, p. 274). Exact data on the sizes of adult vertebrae in Haptodus are not available, but a comparison of reconstructions of Varanops brevirostris and Haptodus saxonicus (Romer and Price, 1940, figs. 55, 58) shows that the proportionate lengths of the spines in these animals must have been much the same. Immature specimens referable to Haptodus have shorter spines (Romer and Price, 1940, p. 306). Among the sphenacodontines, the length of the spines in Sphenacodon ranges from 14 to 20 units and in Dimetrodon from 91 to 157 units (Romer and Price, 1940, p. 325, 333). The length is not known with certainty for $\mathrm{Se}$ codontosaurus, but Romer and Price (p. 313) think it probable that this genus paralleled Dimetrodon in the development of its spines.

Cutleria wilmarthi has thus retained, in the length of 
its neural spines, a primitive feature in which it resembles the varanopsids; this feature is consonant with the other haptodotine features of this species. The neural spines in $C$. wilmarthi are longer from front to back at the top than they are at the base. They resemble the spines of Varanops brevirostris in lateral outline and length but are thicker from side to side (about $5 \mathrm{~mm}$ ) than those of $V$. brevirostris (CNHM UR 348, about $2 \mathrm{~mm})$.

The atlantal centrum is similar to that in Dimetrodon limbatus. (See Romer and Price, 1940, pl. 23E.) There is no line of junction with any underlying element on the anterior face, and the depth is about equal to that of the axial centrum; therefore, the atlantal centrum seems to have reached the ventral line of the vertebral column as in other sphenacodonts, but is unlike the condition in ophiacodontids where the axial intercentrum underlies the atlantal centrum. The neural spine of the axis is longer from front to back than in the more posterior vertebrae. The anterior edge of the forward-projecting part of the axial neural spine is vertical as in Varanops brevirostris (Williston, 1911b, pl. I-2) and Dimetrodon limbatus (Romer and Price, 1940, pl. 23B). The spine is not continued dorsally above this forward projection in Cutleria or in Varanops, but is in Dimetrodon. In Ophiacodon (Romer and Price, 1940, fig. 44A), the anterior and dorsal edges of the axial neural spine meet at an acute angle. In the rest of its structure, including the zygapophyses and diapophyses, the axis of $C$. wilmarthi is much like that of $D$. limbatus.

Few proximal ends of ribs are preserved. Well-developed capitular and tubercular processes are both present; however, the separation of these processes is imperfect, and the condition is therefore intermediate between holocephaly and dichocephaly. The capitular and tubercular processes are thickened; the bone between them is thin and has a broadly concave notch at its proximal edge. The ribs, in their general configuration as well as in their proximal ends, resemble those of Varanops brevirostris figured by Williston (1911b, pl. I-1). The proximal ends of the ribs are not well known in Haptodus. The stage of development of the ribs in $C$. wilmarthi is that which would be expected in a primitive sphenacodontid.

There is nothing distinctive about the cleithrum. The ventral part of the clavicle is broadly expanded as in all sphenacodonts. The general character of the scapulocoracoid has already been described. The supraglenoid foramen is small and on the blade of the scapula, but very near the supraglenoid buttress, as in other sphenacodontids such as Sphenacodon ferox and Dimetrodon limbatus. This position contrasts with Varanops brevirostris, in which the foramen is far forward on the blade (Williston, 1911b, pl. V-1. Note: Williston has labeled all his figures of Varanops brevirostris as "Varanosaurus brevirostris," because of mistaken referral of the species). The foramen also lies far forward in Aerosaurus greenleorum (Romer and Price, 1940, fig. $22)$; this position is a useful distinction, because $A$. greenleorum, a probable varanopsid, occurs in the Cutler Formation of northern New Mexico, and, being of about the same size as $C$. wilmarthi, might be confused in isolated postcranial elements with this species. We have examined a cast of a skull of Aerosaurus sp., taken from a specimen at the University of California at Berkeley, and it is obvious that this animal is, in its cranial structure, quite different from $C$. wilmarthi. V. brevirostris has a large incisure in the anterior border of its coracoid plate; no such incisure is present in $C$. wilmarthi or in other sphenacodontids for which this part of the girdle is known (Romer and Price, 1940, fig. 23).

The left humerus is present, but its ends are poorly preserved. It is about $82 \mathrm{~mm}$ long. The right radius and ulna are each about $67 \mathrm{~mm}$ long. The fact that the olecranon is missing probably indicates immaturity; it is interesting here that the only known specimens of Varanops brevirostris are also immature (Romer and Price, 1940, p. 270) and that they show little development of the olecranon.

Cutleria wilmarthi was of about the same size as Varanops brevirostris: the skull length is about 136 $\mathrm{mm}$ as compared to $140 \mathrm{~mm}$ in a specimen of $V$. brevirostris listed by Romer and Price (1940, table 1$)$. The average lengths of the humerus, radius, and ulna in $V$. brevirostris are, respectively, $73 \mathrm{~mm}, 62 \mathrm{~mm}$, and $57 \mathrm{~mm}$ (Romer and Price, 1940, table 5). The limbs of $C u t$ leria wilmarthi are thus proportionately longer than those of $V$. brevirostris. In this respect Cutleria fits a sphenacodontid rather than a varanopsid pattern. (See Romer and Price, 1940, p. 268, 284.)

The incompletely preserved right carpus consists of a fragment of the pisiform, the ulnare, a part of the intermedium, both centralia, and traces of the third and fourth distal carpalia. Both centralia are in contact with the third distal carpal, and the preaxial centrale overlaps the third distal carpal as in Dimetrodon but in contradistinction to the condition in Ophiacodon (Romer and Price, 1940, fig. 40); this overlap may be associated with the narrowing of the carpus characteristic of sphenacodontids. (See Romer and Price, 1940, p. 284.) The ulnare is about $21 \mathrm{~mm}$ long, somewhat more than 1.5 times as long as that of a specimen of $V$. brevirostris figured by Williston (1911b, pl. VIII); this measurement is in keeping with the sphenacodontid elongation of the limb. 
Cutleria wilmarthi Lewis and Vaughn, referred specimen

FTgure 12B

We also refer a skull fragment (MCZ 2987 from loc. 13) to the new species Cutleria wilmarthi Lewis and Vaughn. The specimen includes right and left premaxillae, the anteriormost parts of the left nasal and lacrimal bones, the anterior part of the left maxilla, the left septomaxilla, the anterior part of the left mandible, the left premaxillary dentition, and the anterior parts of the left maxillary and mandibular dentitions.

The premaxillae of the two sides are in contact throughout their entire height. The dorsal process of the premaxilla fits into a rectangular indentation in the anterior and medial part of the nasal; it ends posteriorly at a point above the middle of the naris. The premaxilla is overlapped by the maxilla below the naris. The nasal occupies almost the entire dorsal border of the naris. The anterior part of the lacrimal lies posterior to the fragment of the nasal bone. The suture between lacrimal and nasal is easily seen in the ventral part of the junction of the two fragments; although it is not so clearly evident dorsally, a ground section of the dorsal part of the junction proves that the two fragments are from distinct elements. The lacrimal overlaps the nasal in this ground section; this relationship is also seen ventrally, where the thin lacrimal occupies a plane a fraction of a millimeter lateral to the planes of the nasal and maxilla.

The lacrimal probably reached the naris in life but now misses the narial border by about $5 \mathrm{~mm}$; considerable breakage in this area also affects the maxilla. If the referral to $C$. wilmarthi is correct, and it seems to us to be clearly justified, this specimen offers additional evidence for the entry of the lacrimal into the narial border in this species of pelycosaur. The overlap of the lacrimal on the maxilla is obvious. The maxilla forms the posterior half of the ventral border of the naris and the posteroventral corner externally, and apparently took part in most of the posterior border of the naris underlapping the lacrimal.

The septomaxilla is well preserved and divides the naris into an anterior main opening and a smaller posterior septomaxillary foramen as in Dimetrodon limbatus (Romer and Price, 1940, pl. 16A-D). The foot of the septomaxilla rests on the premaxilla and maxilla where these two elements meet; its posterior arm reaches the nasal and maxilla and probably underlaps the lacrimal.

There are four premaxillary teeth. The first is small, about $4 \mathrm{~mm}$ long and $1.5 \mathrm{~mm}$ thick at the base, but it is set in a large socket, almost $3 \mathrm{~mm}$ wide, and probably represents the tip of a partially erupted replacement tooth. The second is about $9 \mathrm{~mm}$ long and $4.5 \mathrm{~mm}$ thick at the base. The third and fourth lie posterior to a disastema of $4.5 \mathrm{~mm}$, and each is about $4.5 \mathrm{~mm}$ long. These two teeth, set in a posterior prolongation of the premaxilla under the maxilla and pressed closely together, must have functioned as a single tooth.

The first maxillary tooth, posterior to a diastema of $4.5 \mathrm{~mm}$, is about $5 \mathrm{~mm}$ long and $2.7 \mathrm{~mm}$ thick at its base; behind it the teeth gradually increase in size to the fifth maxillary tooth (the most posterior tooth preserved). This tooth, whose tip has been lost, was at least $10.5 \mathrm{~mm}$ long and is $5.1 \mathrm{~mm}$ thick at its base. The tooth immediately anterior to it is $6.1 \mathrm{~mm}$ long (from projected alveolar border to tip; part of the root is exposed in the specimen). The first of the largest teeth in the type is either the fourth or the fifth maxillary tooth. Nine teeth of the mandibular dentition, fairly uniform in appearance, are visible.

The last two premaxillary and the first four maxillary teeth are recurved, as are these teeth in the type. Recurvature is not evident in the anterior premaxillary teeth or in the fifth maxillary tooth. The recurvature of the premaxillary teeth in the type may have been accentuated by the crushing of the anterior part of the snout. Further, the recurvature of the first of the largest maxillary teeth in the type is less than that of the other teeth; the tooth has been broken in such a way that it seems more recurved than it probably actually was. Thus, the apparent small differences in dentition between the type and the referred specimen may not be real; they are very much alike. The larger size of the dentition of MCZ 2987 indicates an individual of more advanced age than the type.

\section{Order PELYCOSAURIA \\ Suborder EDAPHOSAURIA \\ Family NITOSAURIDAE}

Mycterosaurus smithae Lewis and Vaughn, n. sp.

Figure 13

We name a new species of Mycterosaurus Williston, 1915, Mycterosaurus smithae, and designate MCZ 2985 from locality 11 as the type. The type consists of the most of a skull, lacking the snout; a string of five poorly preserved vertebrae and their ribs; the proximal half of a femur; the proximal half of a tibia; and other, poorly preserved fragments.

This new species is best diagnosed by comparison with the genotype, Mycterosaums longiceps Williston, 1915, as follows: Skull and postcranial skeleton of same size as those in $M$. longiceps; temporal fenestra of only three-tenths as much area as that in $M$. longiceps; zygomatic arch more than twice as deep, and distance from posterior border of temporal fenestra to 

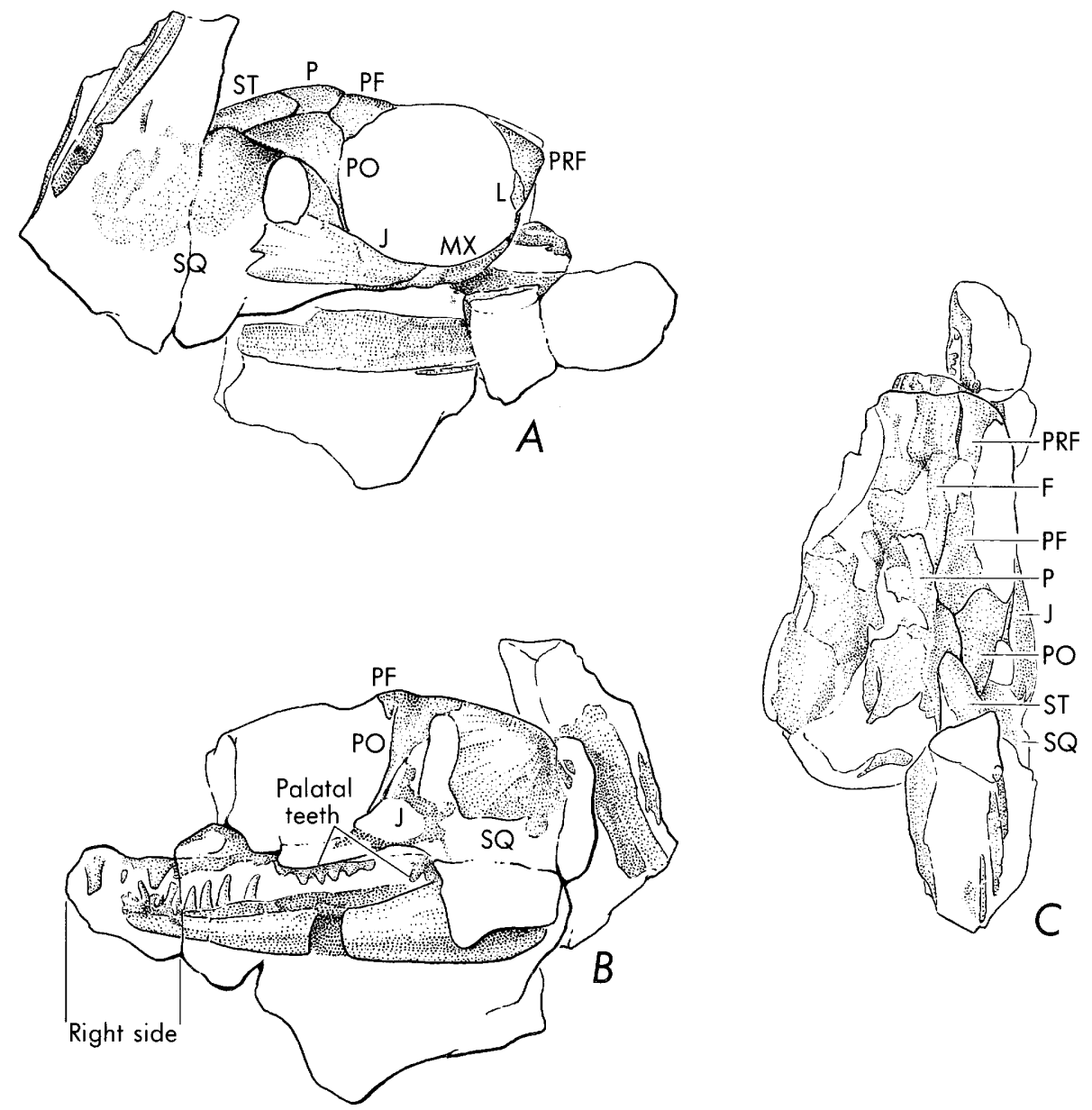

FIGURE 13.-Skull of type specimen of Mycterosaurus smithae n. sp., MCZ 2985 . A, Right lateral; $B$, left lateral; $C$, dorsal views. Fragments of a limb bone and of ribs are visible behind the skull. Unshaded areas represent matrix. $\times 1$.

posterior border of squamosal about one and one-half times as long as in $M$. longiceps; largest maxillary teeth about two-thirds as thick at base as in $M$. longiceps. This new species is named in honor of the late Mrs. Stockton Smith, of Placerville, Colo., from whose property and with whose generous cooperation many of the fossils described here were collected.

Mycterosaurus longiceps Williston, 1915, is known only from the Mitchell Creek nodular deposit of the Clyde Formation of north-central Texas (the synonym Eumatthevia bolli Broom, 1930, is based on a specimen, AMNH 7002, that probably came from the same locality). (See discussion in Romer and Price, 1940, p. 409.) Romer and Price (1940, p. 408-412) give a full description of the osteology of $M$. longiceps. Their description is based not only on Williston's type (CNHM UC 692) but also on Broom's materials and on additional specimens (CNHM UR 90 and CNHM UC 169). The holotype of $M$. longiceps consists of a skull and a few postcranial fragments. The greater part of the description of the postcranial skeleton is based on CNHM UR 90 and UC 169, which include no cranial materials. There is some reason to suspect that CNHM UR 90 and UC 169 might really belong to Glaucosaurus megalops Williston, 1915, a species based on a skull found in the same Mitchell Creek nodular deposit: Glaucosaurus megalops seems to have affinities with the caseid pelycosaurs; Romer and Price (1940, p. 421) consider G. megalops as "probably representing an early stage in the evolution of the caseids."

One of us, in discussing the origin of the family Caseidae, commented on the possible caseid connections of $G$. megalops but noted that, unlike the caseids, the dermal roof of the skull in $G$. megalops was not pitted (Vaughn, 1958b, p. 988); this statement was based on published descriptions of $G$. megalops (for example, Romer and Price, 1940, p. 422). Since that time, an examination of the type of $G$. megalops (CNHM UC 691) has demonstrated that this small pelycosaur does have a markedly pitted skull roof that heightens its 
resemblance to the caseids. The postcranial materials assigned to Mycterosaurus longiceps have a definitely caseidlike appearance, as noted by Romer and Price $(1940$, p. 412$)$. The pelvis, with its remarkably long anterior extension of the iliac blade, is particularly caseidlike. The skull in G. megalops is only about threefifths as long as the skull in $M$. longiceps. The ratio of the size of the skull to the size of the postcranial skeleton in the reconstruction of $M$. longiceps by Romer and Price would seem to be a ratio proper for the "normally" proportioned pelycosaurs. 'To put the skull of G. megalops onto this postcranial skeleton would seem to produce a pelycosaur having a disproportionately small head; but exactly this deviation from the "normal" pelycosaurian proportions is characteristic of the caseids-and we are left with our problem.

Unfortunately, the holotype of $M$. smithae does not include really helpful evidence. The vertebrae and ribs are too poorly preserved to be useful here. The preserved parts of femur and tibia are near in size and proportions to those assigned to $M$. longiceps, but it is not possible to say whether or not the femur in $M$. smithae had the unusually prominent adductor crest seen in the femur assigned to $M$. longiceps. (See Romer and Price, 1940, p. 412.) The most that can be said of the type of $M$. smithae is that there is no evidence to dispute the reconstruction given by Romer and Price. Probably the best evidence for the correctness of their reconstruction is the similarity between the scapulocoracoid included in CNHM UC 169 and the scapulocoracoid associated with Broom's skull of M. longiceps ("Eumatthevia bolli"). We note that there is no trace of a supraglenoid foramen in either of these scapulocoracoids. The caseids also lack the supraglenoid foramen; this may further confuse or may indicate, as Romer and Price believe, that both Mycterosaurus and Glaucosaurus are related to the caseids.

This problem may be resolved in the future, because it is now possible to compare the skulls of $M$. smithae and $M$. longiceps and so contribute to our knowledge of the skull of Mycterosaurus.

The similarity of $M$. smithae to $M$. longiceps convinces us that MCZ 2985 represents a species of Mycterosaurus. All the snout anterior to the orbit is lacking, but measurements taken posterior to the anterior border of the orbit, including distance from anterior border of orbit to posteroventral corner of cheek, dimensions of orbit, height of temporal region, interorbital width, and width of parietal region, are so much like the corresponding measurements taken on the type of $M$. long $i$ ceps that the small discrepancies cannot be distinguished from possible slight changes due to distortion, and the estimated total length of the skull for $M$. longiceps (about $89 \mathrm{~mm}$, Romer and Price, 1940, p. 433) corresponds to the estimate for the total length of the skull in $M$. smithae, assuming that the snout in $M$. smithae was as long as that in $M$. longiceps.

There is little possibility that $M$. smithae may belong to any other known genus of pelycosaurs. Bayloria morei Olson, 1941, Tetraceratops insignis Matthew, 1908, Elliotsmithia longiceps Broom, 1937, Anningia megalops Broom, 1927, Haptodus longicaudatus (Credner, 1888), Casea broilii Williston, 1910, Eothymis parkeyi Romer, 1937, Colobomycter pholeter Vaughn, 1958, Glaucosaurus megalops Williston, 1915, Basicranodon fortsillensis Vaughn, 1958, and Nitosaurus jacksonorum Romer, 1937, are other small pelycosaurs with which $M$. smithae has been compared by examination of specimens or published descriptions. All these are significantly different from $M$. smithae in known features of the skull except for Basicranodon fortsillensis and Nitosaurus jacksonorum.

Basicranodon fortsillensis is known only from a fragment of the brain case and may prove to belong to Mycterosaurus when better known. The parts that are known of the skull of Nitosaurus jacksonorum (Romer and Price, 1940, p. 406), the premaxilla, maxilla, and dentary, with a dentition, are about the size and character of that in $M$. smithae; therefore, we could expect the skulls of both to be about equal in size. The postcranial elements found in the same nodule with the skull of MCZ 2985 are, however, of about the same size as the corresponding postcranial elements assigned to $M$. longiceps - the femur and tibia seem to be of the same dimensions, and the central lengths of the vertebrae are about the same-whereas both the central lengths of the vertebrae and the length of the tibia in $N$. jacksonorum are about one and one-half times those in $M$. longiceps (Romer and Price, 1940, table 5). The skull in $N$. jacksonorum therefore seems to have been much smaller in proportion to total body size than was the skull in M. smithae.

Postmortem crushing has somewhat distorted the skull, especially in the region of the left cheek where forward displacement of the squamosal has shortened the anteroposterior length of the temporal fenestra; the fenestra of the right side seems to have been preserved unaltered. The large orbits bulged above the general level of the roof of the skull, as in Mycterosaurus longiceps. The interorbital region is narrow as in $M$. longiceps, and the roof widens gradually as it passes into the parietal region, without the abrupt postorbital widening seen in Varanosaurus and more markedly in Varanops. It is not possible to say whether or not the frontal entered the orbital margin. There is a large parietal foramen as in $M$. longiceps. 
The supratemporal is remarkably large, about $4.4 \mathrm{~mm}$ wide and a little more than twice the width of that restored for $M$. longiceps, and has an extensive contact with the postorbital; nothing has been known of the supratemporal in Mycterosaurus until now; Romer and Price (1940, p. 21) restored it in dotted outline. This wide supratemporal seems to corroborate the opinion of Romer and Price that Mycterosaurus is related to the caseids: the supratemporal is wide in Casea and Cotylorhynchus, and in Colobomycter pholeter, an eothyridid relative of the caseids (Vaughn, 1958b, p. 982).

The posteroventral corner of the cheek cannot be completely determined, but the rough outline preserved on the right side suggests that the posterior border of the cheek sloped downward and backward, that the articular end of the quadrate was nearly in line with the maxillary tooth row, and that there was no pronounced concavity of the border of the cheek between the marginal dentition and the quadrate; all these features are in $M$. longiceps. The presumably long snout has not been preserved; therefore, the inclusion or exclusion of the lacrimal from the narial border cannot be determined: in $M$. longiceps, Colobomycter pholeter, and in advanced sphenacodontids it is excluded, probably as a result of the enlargement of maxillary "canine" teeth. The maxilla in $M$. smithae enters the orbital margin as in $M$. longiceps and prevents a contact between lacrimal and jugal. This lack of contact is a rare condition in pelycosaurs but is found also in Casea, Cotylorhynchus (Romer and Price, 1940, figs. 3-7, pl. 20), and the related Eothyris (Vaughn, 1958b) : this common condition is further evidence of affinity between Mycterosaurus and the caseids.

The temporal fenestra is much smaller in $M$. smithae ( $8 \mathrm{~mm}$ deep by $5 \mathrm{~mm}$ long) than in $M$. longiceps (14 $\mathrm{mm}$ deep by $10 \mathrm{~mm}$ long), but the shape of the fenestra, a vertical ellipse, is the same in the two species. The postorbital bar is about $3 \mathrm{~mm}$ thick in both species, the smaller size of the fenestra in $M$. smithae being associated with a thicker zygomatic arch and a greater postfenestral width of the squamosal. The smaller fenestra probably is a more primitive character than is the larger fenestra; it is likely that fenestral expansion in Mycterosaurus took place by thinning of the zygomatic arch and reduction of the postfenestral area of the squamosal.

There is no appreciable difference in the structure of the lower jaw as compared with that of $M$. longiceps. The lower jaw is rather shallow anteriorly, is deep in the region of the coronoid elevation, and tapers rapidly to be shallow again in the articular region in both species. The figures in this report would give the impression of a lower jaw more shallow in the coronoid region than that of $M$. longiceps, but this appearance results from the separation of a fragment from the jaw. This fragmentary film of bone with a backing of matrix fits perfectly into place over the rest of the jaw and shows that the depth of the lower jaw near the coronoid elevation is about $12 \mathrm{~mm}$ in both species. The lower jaw is not well enough preserved to permit discussion of its individual elements.

Only a small part of the dentition is preserved; most of this can be seen in the figure. A longitudinal section through a tooth in the right maxilla about a quarter of the way back in the length of the orbit shows that this tooth projected $4 \mathrm{~mm}$ beyond its socket. This projection is almost twice as long as the tooth figured in the same region of $M$. longiceps as reconstructed by Romer and Price (1940, pl. 21), but the teeth in this region of the type of $M$. longiceps are not completely preserved; from an inspection of their thickness at the lines of breakage, they seem to have been $4 \mathrm{~mm}$ long-or longer. A right maxillary tooth $15.7 \mathrm{~mm}$ in front of the anterior border of the orbit in MCZ 2985 projected at least $3.5 \mathrm{~mm}$ beyond its socket; the tip of this tooth was broken away, and the tooth may have been as much as 5 $\mathrm{mm}$ long. This is the region of greatest elongation of the teeth in $M$. longiceps (in which the longest tooth has an estimated length of $6.5 \mathrm{~mm}$, according to Romer and Price, 1940, pl. 21; the tips of the teeth are lacking in this region in the holotype). The bases of the maxillary teeth of $M$. smithae (about $2 \mathrm{~mm}$ ) are thinner than those of $M$. longiceps (about $3 \mathrm{~mm}$ ) some $15.7 \mathrm{~mm}$ in front of the orbit.

The considerable battery of palatal teeth is shown in the figure. Palatal teeth are not exposed on the holotype of $M$. longiceps, but Broom $(1930$, p. 3$)$ noted that "the pterygoids show a considerable number of small pointed teeth in both the anterior and middle parts" of the type of Eumatthevia bolli (AMNH 7002). We conclude that the upper dentitions in $M$. smithae and $M$. longiceps are similar but thicker and probably longer in M. longiceps.

Several lower teeth are preserved on the left side near the anterior border of the orbit, and on the right side a short distance in front of the orbit; the longest on the better preserved left side are $4 \mathrm{~mm}$ in length and about $1.2 \mathrm{~mm}$ thick at their bases. They taper toward their bluntly pointed tips and are gently recurved. Two associated small fragments of bone having teeth of similar shape are included in the type, but these fragments cannot be fitted onto the rest of the skull. The dentition of the lower jaw is not known in $M$. longiceps.

The remains of the postcranial skeleton are so poorly preserved that nothing significant can be added to the comments already given. There is no evidence in these 
materials to indieate that Romer and Price have not correctly assigned the postcranial elements in their reconstruction of Mycterosaurus longiceps. It must be noted that although the skull of MCZ 2985 was not found in actual articulation with the postcranial remains, all the parts were found in the same nodule, with the skull lying at a right angle to the vertebral column and about a centimeter away from it.

\section{Mycterosaurus smithae Lewis and Vaughn, referred specimen}

The first vertebrate fossil found in the Cutler Formation at Placerville (USNM 22098 from loc. 5), a string of seven or more poorly preserved posterior dorsal vertebrae, a partial left femur, and fragments of other bones, is referred to the new pelycosaurian species Mycterosaurus smithae Lewis and Vaughn because of the similar size of the vertebrae, shape and dimensions of the femur, and the occurrence in the same formation and area as the type. The length of one vertebral centrum is about $8.5 \mathrm{~mm}$ compared to central lengths of about $6.8 \mathrm{~mm}$ in an ?anterior dorsal vertebra of the type of $M$. smithae, about $6.0 \mathrm{~mm}$ in an anterior dorsal vertebra of the type of M. longiceps (CNHM UC 692), and about $8.5 \mathrm{~mm}$ in posterior dorsal vertebrae of another specimen referred to $M$. longiceps (CNHM UC 169). The preservation of the vertebrae is not good enough to permit further comparisons.

The femur is fairly well preserved in its proximal part, and is of exactly the same dimensions and proportions as in the type of $M$. longiceps. Part of the shaft of the femur is preserved; it has the same dimensions and shape as the corresponding parts of the femora of $M$. longiceps (CNHM UC 169). The length of the femur probably was about equal to that of one femur of $M$. longiceps $(49 \mathrm{~mm})$ measured by Romer and Price (1940, table 4) ; they record a length of $55 \mathrm{~mm}$ for another such femur. No further comparisons can be made.

\section{Order PELYCOSAURIA}

Incertae sedis

Several additional specimens from the Cutler Formation of the Placerville area probably represent pelycosaurs, but it has not been possible to assign these materials to definite suborders.

Two recognizable fragments and several poor scraps (MCZ 2978 from loc. 2) include a fair impression of what seems to be the posterior part of a pterygoid and three of the teeth of the transverse row and a large part of the quadrate process. Another fragment may be part of the shaft of an epipodial of a pelycosaur of the same size. These fragments seem to represent a pelycosaur about the size of Dimetrodon limbatus.

Two fragments of an interclavicle (MCZ 2988 from loc. 13) consist of the anterior part (the bowl and part of the shaft) and the posterior part (of the shaft). The medial part is missing so that the total length is not known, but it was at least $77 \mathrm{~mm}$ long from the center of the bowl to the distal end of the shaft. The bowl is about $18 \mathrm{~mm}$ long and about $47 \mathrm{~mm}$ wide. The shaft is $8 \mathrm{~mm}$ wide, is elliptical in cross section, and has a thickness of about $3 \mathrm{~mm}$. The distal end of the shaft is tapered and forked, having two prongs. The proportions of the bowl suggest that this interclavicle may have belonged to an ophiacodont.

A left tibia of pelycosaurian aspect (MCZ 2986 from loc. 12) is about $63 \mathrm{~mm}$ long, $18 \mathrm{~mm}$ wide at its proximal end, $12.5 \mathrm{~mm}$ wide at its distal end, and $5 \mathrm{~mm}$ wide at the narrowest part of the shaft. The proximal end is not well preserved. This tibia resembles the tibiae of several kinds of pelycosaurs (Romer and Price, 1940, fig. 38 ) in its proportions, but we are unable to suggest a more definite identification.

The incomplete distal end of a femur (MCZ-no number) found 50 feet below the seymouriid vertebra (MCZ 2983 from loc. 9) must have been at least $35 \mathrm{~mm}$ wide, and seems referable to a small pelycosaur.

\section{Indeterminate remains}

A small, poorly preserved lower jaw having both rami was found at the same locality as the vertebrae (MCZ 2977 from loc. 1) identified as Ophiacodon sp. These vertebrae suggest a pelycosaur about equal in size to a mature specimen of Ophiacodon navajovicus; this jaw is much too small to have belonged to the same skeleton as the vertebrae. The jaw bears many small, conical teeth and tapers towards the symphysis; it may not be complete posteriorly, but is about $41 \mathrm{~mm}$ long as preserved. The depth $5 \mathrm{~mm}$ behind the anterior end of the jaw is about $4 \mathrm{~mm}$, but in the coronoid region is about $7 \mathrm{~mm}$. The best preserved tooth, some $8.5 \mathrm{~mm}$ posterior to the anterior end of the jaw, is about $1 \mathrm{~mm}$ long from alveolar border to tip. A section through one of these teeth shows no sign of labyrinthodonty. This jaw is too small to warrant even tentative assignment to Mycterosaurus smithae, but is probably reptilian, possibly pelycosaurian, and must remain indeterminate until better specimens of the same animal are known.

One poor, unidentifiable fragment of bone (MCZ 2990 from loc. 15) probably is part of a dermal skull roof.

Several other scraps of bone were found with the distal part of the probably pelycosaurian femur described in the last section. One scrap is probably part of a dermal skull roof. Two others are fragments of either one or two vertebrae that indicate a centrum about 15 $\mathrm{mm}$ wide and a neural arch in which the lateralmost 
points on the postzygapophyses are about $23 \mathrm{~mm}$ apart. This vertebra may be that of a captorinomorph cotylosaur.

\section{AGE AND CORRELATION OF THE FAUNA}

\section{COMPARISON WITH EARLY PERMIAN FAUNAS OF} NORTH AMERICA

Analysis of the significance of the several faunal elements from the Cutler Formation of the Placerville area and consideration of the fauna as a whole make possible the correlation of the upper part of the Cutler of Colorado with other stratigraphic units in the United States beyond much reasonable doubt.

The presence of Eryops cf. E. grandis in the fauna of the Cutler at Placerville is of no great help in precise correlation: although the specimen corresponds most closely to E. grandis of the Cutler of New Mexico, the genus is known to have existed from early Conemaugh time to late Arroyo time (Vaughn, 1958a). The most that can be said is that specific differences in this genus are based largely on size differences, and the specimens from the Cutler, both of Colorado and New Mexico, tend to be smaller than those from the Wichita and Clear Fork Groups of Texas.

The monotypic genus Platyhystrix has been unknown until this time from anywhere except the Cutler Formation outcrops near Arroyo de Agua, Rio Arriba County, N. Mex., and from the Halgaito Tongue in San Juan County, Utah (Platyhystrix ef. P. mugosus, Vaughn, 1962, p. 534-535). Langston (1953, p. 409411 ) concluded that the vertebrate fauna from the Cutler near Arroyo de Agua is equivalent in age to the faunas from the Moran and Admiral Formations of the Wichita Group of north-central Texas, which are the continental equivalents of the uper part of the marine Wolfcamp to the west and southwest. Vaughn (1962, p. 538) believes that the Halgaito Tongue also is of Wolfcamp age. The presence of $P$. rugosus in the Cutler at Placerville is excellent evidence of a late Wolfcamp age.

We believe that the new but unnamed seymouriid from the Cutler of the Placerville area represents a morphologically more primitive genus than Seymouria, probably of about the same age as that of the faunas of the lower to middle part of the Wichita Group of Texas. This unnamed seymouriid has been compared to the somewhat younger Seymouria baylorensis of the Clear Fork Group of Texas, but not to the inadequately known Seymouria of the Moran, Putnam, and Admiral Formations in the Wichita Group.

Diadectes sanmiguelensis is not the first diadectid to be reported from Colorado: one was found in the Sangre de Cristo Formation in Fremont County (Brill,
1952 , p. 834). The known diadectids from the Cutler (formerly designated "Abo") Formation of northern New Mexico are Diadectes lentus and Diasparactus zenos. The immaturity of the type makes Diadectes sanmiguelensis of little value in stratigraphic correlation because of the uncertainty of its taxonomic affinities; its resemblance in some respects to Desmatodon might suggest the possibility of an age near the Pennsylvanian-Permian boundary. But Diadectes sensu stricto is restricted to Early Permian time, and there is no cogent reason to suggest that $D$. sanmiguelensis is pre-Permian in age, older than the Cutler of $\mathrm{New}$ Mexico.

We have named and described Limnoscelops longifemur as a member of the Limnoscelidae, a family otherwise known only from the Cutler of northern New Mexico, the Halgaito Tongue of southeastern Utah, and from the Dunkard Group of the Ohio-PennsylvaniaWest Virginia area of the Eastern United States. $L$. longifemur seems to indicate an Early Permian age and a stratigraphic position that corresponds to that of the Cutler Formation of New Mexico, whence comes Limnoscelis, and the Dunkard Group of West Virginia where the new limnoscelid's nearest known relative, Limnosceloides dunkardensis, was found (Romer, 1952, p. 88-92, 99-100). Both the Cutler of New Mexico and the Dunkard correlated with the lower to middle parts of the Wichita Group of Texas.

The captorhinomorph cotylosaur of undetermined genus and species belongs to a suborder that ranges from Upper Pennsylvanian to middle Permian rocks in North America. If it is a member of the captorhinid family, as we believe, then it belongs to a family that ranges from Lower to middle Permian in North America; it most closely resembles Captorhinikos chozaensis, a species from the upper part of the Clear Fork Group of Texas. Therefore its age probably is Early Permian.

Ophiacodontids, in the form of Clepsydrops, first appeared in Late Pennsylvanian time (Romer, 1961, p. 1, 4; Romer and Price, 1940, p. 212; Peabody, 1957, p. 947 ), but Ophiacodon apparently was restricted to the time of deposition of the Cutler Formation in Colorado and New Mexico, and of the Wichita Group of Texas. The vertebrae of Ophiacodon from the Cutler at Placerville, insofar as their size and morphology are concerned, agree with those of $O$. navajovicus and are very similar to those of O. mirus, both from the Cutler of New Mexico. Ophiacodon uniformis, the Texas species most closely related to $O$. navajovicus and $O$. mimus, ranges from the Putnam Formation to the Clyde Formation of the Wichita Group (Romer and Price, 1940, p. 242). Accordingly, the Ophiacodon in the Cutler Formation at Placerville is still another item of evidence for cor- 
relating the upper part of the Cutler of Colorado with the Cutler of New Mexico and the middle part of the Wichita Group of Texas.

The nearest relatives of Cutleria wilmarthi are the species of Haptodus from the European Autunian and Rotliegende. Because the new genus and species from the Cutler of the Placerville area of Colorado represent the first-recorded non-European haptodontine, this specimen offers no chance for direct comparisons with other North American faunal elements. Sphenacodon, known only from the Cutler of New Mexico, is very similar to the short-bodied species of Dimetrodon from the lower to middle part of the Wichita Group of Texas (to which they are restricted; the more advanced species of this genus are known only from younger formations of Texas) except for the much less elongate neural spines and the slightly less specialized dentition of Sphenacodon. The morphological evolutionary sequence leading to the more advanced species of Dimetrodon probably paralleled the stages shown by the series of contemporaries Cutleria of the Cutler of Colorado to Sphenacodon of the Cutler of New Mexico to Dimetrodon of the Wichita of Texas.

Mycterosaurus smithae, the new species from the Cutler at Placerville, seems to be more primitive than its nearest relative $M$. longiceps from the Clyde Formation of Texas, whose thicker teeth and larger temporal fenestra may reasonably be considered as more advanced. This evidence, although inconclusive, does suggest a somewhat older age than that of the Clyde, and, once more, possible equivalence with the Moran and Admiral Formations of Texas.

Brill (1952, p. 834, 870) reported the discovery of Diadectes sp. and pelycosaurs in the Sangre de Cristo Formation in westernmost Fremont County, Colo., about 120 miles eastward from the Placerville area across the old Uncompahgre highland area of Early Permian time. It is entirely probable that the two faunas and those parts of the Cutler and Sangre de Cristo Formations in which they occur are virtually contemporaneous.

The area of outcrop of the vertebrate-bearing Permian formations of Texas has been the classic collecting ground for what are perhaps the best known Permian vertebrate faunas in the United States. Just as Marsh is remembered for having pioneered in research on the Baldwin collection from the New Mexican Permian red beds, Cope is remembered for having pioneered in research on the Boll collection from the Texas red beds, and both continued their researches for some two decades. We have known of these faunas for some 85 years because of these rival pioneers, each having first published reports on the Permian age and the paleontol- ogy of these respective areas of interest in the same year (1878). Case $(1908,1911 \mathrm{a}, 1911 \mathrm{~b})$ and Williston (1911a, 1911b, 1912) both collected and studied Permian vertebrates after the deaths of Marsh and Cope. Williston's successor at the University of Chicago, Romer, and the latter's students both at Chicago and Harvard, have devoted many years to extremely informative and useful work on the American Permian vertebrate faunas and related subjects.

We have made frequent reference to faunal elements of the Texas Permian red beds. The general information on the geology (Moore, 1949) and paleontology (Romer, 1958) of these rocks has been so well summarized by others that only an outline, and some of the more pertinent details, need be repeated here.

Moore (1949) considered that the Pueblo, Moran, Putnam, Admiral (these four of Wolfcamp age), Belle Plains, Clyde, and Lueders (these three of Leonard? age) make up the Wichita Group, and that the Arroyo Formation is at the base of the Clear Fork Group; this is the usage now accepted and used by us in this report.

So recently as 1935 , Romer (1935, fig. 2, p. 1604, and fig. 5, p. 1654) considered that the Wichita Group (including the Moran, Putnam, Admiral, and Belle Plains Formations) marked the top of the Pennsylvanian, and the Clear Fork Group (including the Clyde, Lueders, Arroyo, Vale, and Choza Formations) the base of the Permian. Romer and Price (1940, p. 23) showed the definitely "Pennsylvanian" Cisco Group as including the Pueblo Formation, overlain by the "Permian or Pennsylvanian" Moran, Putnam, Admiral, and Belle Plains Formations to make up the Wichita Group, overlain by the definitely "Permian" Clear Fork Group including the Clyde and Arroyo Formations in northcentral Texas.

Olson (1955, p. 226) believed the Permian sequence involved to be, in ascending order, as follows: the Moran, Putnam, Admiral, Belle Plains, and Clyde Formations making up the Wichita Group; the Lueders, Arroyo, Vale, and Choza Formations, the Clear Fork Group. Seltin's interpretation (1959, p. 498) of these Permian stratigraphic divisions is, in ascending order, as follows: the Early Permian Admiral, Belle Plains, and Clyde Formations comprising the Wichita Group; the Leuders [sic], Arroyo, Vale, and Choza Formations, the Clear Fork Group.

Omitting those genera which offer no basis for correlation, what faunal elements of the upper Paleozoic red beds of Texas are pertinent for comparison with the fauna of the Cutler Formation in the Placerville area of Colorado? Of a score of amphibians, only Eryops is common to the Cutler of Placerville and the Wichita and Clear Fork of Texas; we have already pointed out 
that this genus ranges throughout the Wichita and Clear Fork, and that the smaller individuals that tend to occur in the lower parts of the Wichita are closer to the Cutler specimen than are those from the upper part of the Wichita and from the Clear Fork. The Cutler seymouriid seems more primitive than seymouria baylorensis of the Clear Fork; we have not had the opportunity to compare it with the inadequately known Seymouria from the Wichita. The immature Diadectes sanmiguelensis, though smaller, more closely resembles $D$. lentus from the Cutler of New Mexico than it does any of the even larger adults of the two Texan species, $D$. sideropelicus and $D$. tenuitectus, with which meaningful comparisons of stratigraphic implication cannot be made bceause of the immaturity of the specimen.

Limnoscelops longifemur is nearer to the limnoscelids-especially to Limnosceloides - than any other captorhinomorphs; Limnosceloides of the Dunkard and Limnoscelis of the New Mexican Cutler are of Wolfcamp age. The femur of Limnoscelops does, however, show a morphological approach to that of Captorhinus, a genus that appears in the middle part of the Wichita. The captorhinomorph of undetermined genus and species from the Cutler at Placerville most closely resembles Captorhinitos of the Vale and Choza Formations of the Clear Fork Group, but we are not certain that it belongs to the same family.

The Ophiacodon is closest to O. uniformis if compared to the Texan species of this typically Wichita genus (Romer and Price, 1940, p. 230); O. uniformis first appears in the Putnam Formation.

Mycterosaurus smithae from the Cutler at Placerville seems to be more primitive than its nearest relative, $M$. longiceps of the Clyde Formation; this feature suggests an age for $M$. smithae equivalent to that of the Moran or Admiral Formations.

After weighing all this evidence, we conclude that the upper part of the Cutler Formation, exposed in the Placerville area of Colorado, probably is equivalent in age and stratigraphic position to the Moran, Putnam, and Admiral Formations of Texas.

The fauna of the Cutler at Placerville is not comparable to that of the Hennesey and other formations of Oklahoma which seem without exception to be of Clear Fork age (Romer and Price, 1940, p. 28).

Marsh $(1878$, p. 409) was the pioneer who placed the Cutler of New Mexico in the Permian, but opinion has varied. Williston and Case $(1912$, p. 4,12$)$ believed it to be "in part at least of upper Pennsylvanian age." Darton (1928, p. 158, pl. 37) stated that the age is Permian and published a reconnaissance geologic map that shows the chief areas of outcrop of the vertebratebearing Cutler of New Mexico. Not many years ago,
Romer (1935, p. 1629, 1633-1635, 1650-1653) believed the Cutler of New Mexico to be Pennsylvanian, even lower than the Wichita Group of Texas, which he referred to the top of the Pennsylvanian. Romer and Price (1940, p. 23-24, 28-30, 33-34) placed the Pennsylvanian-Permian boundary "between lower and upper Wichita" and correlated all the Cutler of New Mexico with the Wichita except for the Cutler at El Cobre Canyon which they considered provisionally to be Upper Pennsylvanian. Romer (1946, p. 186) continued to believe that the El Cobre Canyon fauna "may well be of uppermost Pennsylvanian rather than lower Permian." Later he (Romer, 1958, p. 164) stated: "It has been frequently assumed that the base of the Permian in Texas was the base of the Wichita Group, although some workers, as the writer on occasion (1935), have advocated a higher position $* * *$ the whole question of the boundary is as yet unsettled."

A different opinion was held by Langston (1953, p. 409-410, 412), who considered that the evidence from most of the fish, amphibian, and reptilian faunas of the New Mexican Cutler indicated an age about the same as the comparable faunas "from the lower and middle Wichita (Moran-Admiral) beds of Texas," and that there was little value in assigning the El Cobre Canyon fauna of the Cutler to the Pennsylvanian on morphological grounds alone, the conservative course being to consider it also as Permian. But the senior writer joined Romer only a few years ago (in Bush and otherrs, 1959, p. 313) when the fossils had "not been completely removed from the rock matrix and fully prepared," to make a tentative correlation of the Cutler at Placerville with that ("Abo") at El Cobre Canyon. They pointed out the moot question of the position of the Wichita Group, and reached the tentative conclusion that the Cutler at Placerville might be either very low Permian or uppermost Pennsylvanian. But the present, more detailed study after the fossils have all been fully prepared has necessitated considerable revision of the 1959 faunal list, and has convinced us that the age is Early Permian beyond all reasonable doubt, equivalent to that of the Moran, Putnam, and Admiral Formations of Texas.

We reached the same conclusion with regard to the Cutler of El Cobre Canyon, N. Mex. One of us (Vaughn, 1963, p. 286) has now made further collections there and, after studying all the old and new evidence, concluded once more that it "would seem to demonstrate equivalence in age of the El Cobre and the Arroyo de Agua beds $* * *$ to the lower and middle parts of the Wichita Group *** (Wolfcampian) $* * *$ Early Permian." 
The basic similarity of the Cutler faunal assemblages from Placerville and New Mexico is to be expected when we consider their apparent equivalence in age, their proximity, and their similar paleogeographic situations: both assemblages lived during about the same time near the southwestern edge of the ancient Uncompahgre highland (Baker, Dane, and Reeside, 1933, p. $975)$. Erosion of this highland yielded the clastic sediments of the continental area where these land-dwelling vertebrates lived in Early Permian time.

To a somewhat lesser degree, a similar situation obtains in the more distant Monument Valley area of northeastern Arizona and southeastern Utah, where Baker $(1936$, p. $29,30,35)$ reported the discovery of fragmentary remains of fossil vertebrates in the Cutler Formation, where it is divided into subordinate units named (in ascending order) the Halgaito Tongue, the Cedar Mesa Sandstone Member, the Organ Rock Tongue, the De Chelly Sandstone Member, and the Hoskinnini Tongue. The Halgaito and Organ Rock 'Tongues yielded Baker's very fragmentary fossil vertebrates, determined by Case to be of Permian age; they were Ophiacodon? ["Ephiacodon" (sic)] or Sphenacodon? of the Halgaito, Diadectes? ["Notodon" (sic)] and Sphenacodon? of the Organ Rock. Fossil plants from the Organ Rock Tongue were also determined to be of Permian age by White. No vertebrate fossils were reported from the typical sandstone members.

Recently, Vaughn (1962, p. 532-538) reported the discovery of much better material from the Halgaito Tongue, including Eryops sp., Platyhystrix cf. $P$. rugosus, Diadectes sp., a limnoscelid that may be specifically identical to Limnoscelops longifemur, Ophiacodon cf. O. navajovicus, and a sphenacodontid pelycosaur close to if not generically identical to Sphenacodon. On the basis of this faunal evidence, he believes "the Halgaito Tongue *** in the vicinity of Mexican Hat, Utah is Wolfcampian in age $* * *$ clearly $* * *$ of Early Permian age, but greater in age than the Clear Fork Group of northcentral Texas." This is the same conclusion that we have reached about the upper part of the Cutler Formation where it crops out in the Placerville area of Colorado. Moreover, our faunal list from the latter, when compared to Vaughn's faunal list from the Halgaito Tongue of the Cutler, and with the probable Diadectes ["Notodon" (sic)] and "Sphenacodon?" reported by Baker (1936, p. 35) from the Organ Rock Tongue, an association characteristic of the Cutler of New Mexico, clearly indicates virtual contemporaneity.

It has been shown that Diadectes sanmiguelensis, although having some points in common with Desmatodon hollandi of the Conemaugh, is nevertheless prob- ably referable to Diadectes and closest to the Early Permian species D. lentus of the Cutler of New Mexico. Limnoscelops longifemur, however, has as its nearest demonstrable relative Limnosceloides dunkardensis from the Dunkard of West Virginia, a group of rocks that has also yielded an Ophiacodon-like animal (Romer, 1952, p. 88, 96). Ophiacodon is a genus typical of the Wichita Group of Texas and of the Cutler Formation of New Mexico. Romer (1952, p. 100) concluded that "the Dunkard, as a whole, is essentially comparable to the Wichita Group of Texas" in spite of the difference in faunal facies. We agree with Romer, and believe that the ages of the faunas from the Cutler of Placerville, Colo., the New Mexican Cutler, the lower and middle parts of the Wichita of Texas, and the Dunkard of the Ohio River valley are virtually the same.

The most recent report on the fauna of the red beds of Prince Edward Island, Canada, is by Langston (1963), who lists: two genera of fish; Eryops megacephalus; a brachyopid; a small Seymouria sp.; a very small diadectid; a Diadectes sp. similar to the diadectid of the species of the Admiral Formation; an ophiacodont; the sphenacodontid Bathygnathus borealis; a nitosaurid close to Mycterosaurus; and the caseid Trichasaurus sp. The fauna shows relationship to the Cutler, Wichita, and early Clear Fork faunas and to the Autunian-Rotliegende faunas, which is not surprising when we consider that Prince Edward Island is about midway between these other occurrences. These Early Permian faunal assemblages probably had a fairly continuous holarctic distribution.

\section{COMPARISON WITH EUROPEAN EARLY PERMIAN FAUNAS}

Cutleria wilmarthi is the first haptodontine pelycosaur to be described from North America. Haptodus, of the Autunian of France and the lower Roliegende of Germany, is closely comparable to the new genus from the Cutler except for the shape of the temporal fenestra. Cutleria, like Haptodus, is a morphologically primitive sphenacodontid that differs from the more advanced but contemporary sphenacodontines in the lack of a "step" in the upper jaw, in the lack of development of "canines," and in the short neural spines of the vertebrae.

Cutleria, very close in morphology and stage of evolution-and therefore also very close in age-to Haptodus of the Lower Permian Autunian and Rotliegende of western Europe, is the newest link in the chain of evidence that shows the virtual contemporaneity of these two European stratigraphic units to the Cutler, Moran, Putnam, and Admiral Formations. As they are becoming better known, it becomes increasingly clear that 
the Early Permian European and North American vertebrate faunas were much alike. Among the reptiles, we may cite the similarity of the following North American and European genera respectively : the captorhinids Captorhinikos and Gecatogomphius, the areaeoscelids A raeoscelis and Kadaliosaurus, the diadectids Diadectes and Phanerosaurus, the pelycosaurs Cotylorhynchus and Ennatosaurus, Edaphosaurus novomexicanus and E. credneri, Cutleria and Haptodus. The plants, fish and amphibians show comparable resemblances.

The Autunian and lower part of the Rotliegende of Europe (Gignoux, 1960, p. 174-176, 244-252), the Dunkard of Ohio and West Virginia, the Cutler and Sangre de Cristo of Colorado and New Mexico, the Pueblo, Moran, Putnam, and Admiral of Texas, and their correlatives in nearby States are continental facies and age equivalents of the marine Wolfcamp of Texas and the Sakmarian Stage of Russia.

\section{PALEOGEOGRAPHIC CONSIDERATIONS}

The geologic and paleogeographic environments of the western and central European areas where Lower: Permian continental vertebrate-bearing rocks crop out are so similar to those of comparable North American rocks that they lead to an inescapable conclusion: the Early Permian fish, amphibians, and reptiles lived in remarkably similar environments in these two parts of the world.

The Early Permian animals and plants of what is now the Placerville area of Colorado lived in a-for those times-fairly typical continental environment, just south of the ancient Uncompahgre highlands of Precambrian crystalline rocks. The erosion of these rocks, under climatic conditions of at least seasonal aridity, produced highly arkosic sediments. The Cutler Formation increases in thickness from the type locality on Cutler Creek (about 2,000 ft) to the Placerville area (about $4,000 \mathrm{ft}$ ) 20 miles to the west. Some 60 miles farther west-northwest, in the Paradox Basin, the Cutler Formation ranges from 0 to 8,000 feet in thickness near the Uncompahgre front. "In late Paleozoic time the Uncompahgre uplift $* * *$ was bordered on the southwest by the deep Paradox Basin *** About 16,000 feet of Pennsylvania, Permian, and Lower to Middle(?) Triassic strata fill the trough and pinch out abruptly against the Uncompahgre front" (Elston, Shoemaker, and Landis, 1962, p. 1858, 1861).

The Early Permian uplands and highlands of Colorado (Uncompahgre and Front Range), New Mexico (Bravo, Defiance, Pedernal, Sierra Grande, and Zuni), Arizona (Defiance), and Texas (Amarillo, Cimarron, Matador, and Wichita) are all ancient positive areas of Precambrian crystalline rocks, across some of which Pennsylvanian or older Paleozoic rocks overlap. Early
Permian detritus from these high areas flooded into the basins and troughs that flank them to become the Lower Permian fanglomerates, arkosic and other continental clastic rocks that reflect increasing semiaridity and aridity. The occasional transgressions of shallow arms of the seas that lay to the south and west were of limited extent and duration before regression; they probably took place first in one area, then in another, and so on, never flooding more than a part of some of the basins or troughs at any one time. But the paleogeographic and paleotectonic situation was probably such that many land-dwelling vertebrate genera and species were able to migrate from one region to another. The supposed Early Permian sea often postulated (for example, Hills, 1942, fig. 3) as a continuous barrier between the "fourcorners" area and the north-central Texas area probably never existed.

Gilluly (1963, p. 143-144, fig. 7) recently outlined the Pennsylvanian and Permian structural evolution that produced this paleogeographic environment in the Rocky Mountain area:

The best known of the $* * *$ orogenies took place in Colorado and Wyoming, where the former shelf area was broken by huge normal faults and block uplifts to form the Ancestral Rockies *** Most of these tilted horsts and trap-door uplifts exposed Pre-Cambrian plutonic bodies from the beginning, and some of those that originally had thin carapaces of Paleozoic sedimentary rocks were soon denuded. From the uplifts huge volumes of coarse arkose spilled into the bordering lowlands, to form deposits, partly continental, partly marine $* * *$ In some of the deeper basins the total thickness, which includes an unknown thickness of Permian beds, is as much as 13,000 ft $* * *$ The uplifts began in Early Pennsylvanian times and continued through Early Permian times, at different rates in different places.

In western and central Europe, there were several large dry-land areas of older rocks formed by Variscan and Sudetian folding during Carboniferous time. They were flanked by basins and troughs into which poured the detritus eroded from the uplands and highlands of ancient rocks. These areas of dry land, having Precambrian rocks at their cores, existed in France (Massif Central and Vosges), Germany (Black Forest, Rhenish Massif, Fichtelgebirge, Erzgebirge, and Schiefergebirge), and Czechoslovakia (Sudeten Mountains and Bohemian Massif). The flanking troughs were continental geosynclinal areas formed by the coalescence of Stephanian basins. Brinkmann (1954, p. 125) has pointed out that the noteworthy Autun and Creusot troughs of the Massif Central area can be traced to the upper Rhine, along both sides of the Black Forest and Vosges Massifs, and onward into central Bohemia. The Autunian (France) and lower Rotliegende (Germany) sediments flooded into the troughs as piedmont, flood-plain, and littoral deposits; the isostatic response 
to the weight of these deposits permitted their accumulation to thicknesses as much as 2,000 m during Early Permian time, when the sea transgressed southward during only a short interval and never extended farther than the North German Basin.

Increasing aridity, indicated by the record in the rocks, progressed from Stephanian (Late Carboniferous) time through Autunian (Early Permian) and became intense in Saxonian (middle Permian) time when the upper part of the Rotliegende accumulated to thicknesses of as much as $800 \mathrm{~m}$. Early in the Permian, deposition of some carbonaceous clastic sediment and a few thin coal seams, as well as brown and red arkosic sediments, shows that there was some alternation between times of humid, semiarid, and arid climate.

The Indo-Gangetic alluvial area of India today may show us analogous environmental situations where previously existing seaways have been silted up in the not very remote past. Near the coast, the Lower Permian probably was deposited in an environment most closely paralleled today in the Kathiawar-Cutch area with its monsoon climate:

Some 46,000 sq mls between the Rann of Cutch and the Gulf of Cambay is a world apart $* * *$ The Rann is a vast expanse of naked tidal mudflats *** here and there the banks of dead creeks are picked out in a white skeletal outline of salt or scum. To the $\mathrm{N}$ the desert of mud and the desert of sand in the Thar merge almost imperceptibly. The normal dendritic pattern of the creeks has been interrupted by earthquakes $* * *$ prolonged silting by the mainland rivers and tectonic uplift have attached it to the mainland *** The old channel (doubtless tidal or seasonal) joining the Little Rann $* * *$ and the Gulf of Cambay is marked by the lakes and marshes of the Nal depression *** Physically it is an alternation of little *** plateaus $* * *$ and tiny alluvial basins $* * *$ The environment is generally arid enough, but *** there is some climate variation. Cutch averages 12-15 ins., and as little as 1.4 have been recorded; from the air, the arid aspect of its erosional features is striking. The Kathiawar coastlands, except in the SE, receive 15-20 ins., but the highland centre and the Cambay coast have over 25 and Junagadh $* * *$ about $40 * * *$ The natural cover of most of the region is $* * *$ very open and stunted $* * *$ almost desert in places (Spate, 1954, p. 595-598).

The more inland areas could have resembled more inland parts of the Indus or Ganges-Brahmaputra Valleys:

The western valley section $* * *$ of Sind $* * *$ is probably an old Indus course; it expands in the $S$ into the marshy Lake Manchar, which when full covers some $200 \mathrm{sq} \mathrm{mls}$ and is then the largest fresh-water lake in India. It is alternately fed and drained by the Aral, a stream reversible as the Indus is high or low. At low water Manchar covers only $14 \mathrm{sq} \mathrm{mls} \mathrm{***}$

The Assam or Brahmaputra Valley is an extension of the Indo-Gangetic trough $* * *$ extends for over $400 \mathrm{mls} * * *$ most of this great area is formed of the detrital terraces of the Brahmaputra and its numerous tributaries $* * *$ The channel is of course braided and shifting $* * *$ The climate shows some slight modification of the standard monsoonal type *** Large areas are covered with sal forest and with tall reed-jungle in the swamps and jhils of the immense floodplain (Spate, 1954, p. 551-553).

Similar conditions are found today in the Orinoco and Amazon Basins.

Given these paleogeographic similarities, it is no accident that there are striking stratigraphic, paleontologic, and paleobotanic resemblances between not only the American and European continental Permian, but also Lower and Upper Triassic, the time of deposition of which saw a continuation of similar environments on both continents.

\section{SELECTED REFERENCES}

Baker, A. A., 1936, Geology of the Monument Valley-Navajo Mountain region, San Juan County, Utah: U.S. Geol. Survey Bull. 865, $106 \mathrm{p}$.

Baker, A. A., and Reeside, J. B., Jr., 1929, Correlation of the Permian of southern Utah, northern Arizona, northwestern New Mexico, and southwestern Colorado: Am. Assoc. Petroleum Geologists Bull., v. 13, p. 1413-1448.

Baker, A. A., Dane, C. H., and Reeside, J. B., Jr., 1933, Paradox formation of eastern Utah and western Colorado: Am. Assoc. Petroleum Geologists Bull., v. 17, p. 963-980.

Brill, K. G., Jr., 1952, Stratigraphy in the Permo-Pennsylvanian zeugogeosyncline of Colorado and northern New Mexico: Geol. Soc. America Bull., v. 63, no. 8, p. 809-880.

Brinkmann, Roland, 1954, Abriss der Geologie : 7th ed., Stuttgart, F. Enke, v. 2, 359 p.

Broom, Robert, 1930, On a new primitive theromorph (Eumatthevia bolli) : Am. Mus. Novitates, no. 446, p. 1-4.

Brown, R. W., 1956, Palmlike plants from the Dolores formation (Triassic), southwestern Colorado: U.S. Geol. Survey Prof. Paper 274-H, p. 205-209.

Burbank, W. A., 1930, Revision of geologic structure and stratigraphy in the Ouray district of Colorado, and its bearing on ore deposition: Colorado Sci. Soc. Proc., v. 12, p. 151-232.

Bush, A. L., Bromfield, O. S., and Pierson, C. T., 1959, Areal geology of the Placerville quadrangle, Colorado: U.S. Geol. Survey Bull. 1072-E, p. 299-384, pls. 4-8, figs. 13-16.

Bush, A. L., Marsh, O. T., and Taylor, R. B., 1960, Areal geology of the Little Cone quadrangle, Colorado: U.S. Geol. Survey Bull. 1082-G, p. $423-492$, pls. 18-19, figs. 42-46.

Case, E. C., 1907, Revision of the Pelycosauria of North America : Carnegie Inst. Washington Pub. 55, 176 p.

- 1908, Description of vertebrate fossils from the vicinity of Pittsburgh, Pennsylvania: Carnegie Mus. Annals, v. 4, p. 234-241.

1910, New or little known reptiles and amphibians from the Permian(?) of Texas: Am. Mus. Nat. Hist. Bull., v. 28, p. 163-181.

1911a, A revision of the Cotylosauria of North America : Carnegie Inst. Washington Pub. 145, p. 1-122.

1911b, Revision of the Amphibia and Pisces of the Permian of North America: Carnegie Inst. Washington Pub. 146, $p$. 1-179.

Case, E. C., and Williston, S. W., 1912, A description of the skulls of Diadectes lentus and Animasaurus carinatus: Am. Jour. Sci. v. 33 , p. 339-348.

1913, Description of a nearly complete skeleton of Diasparactus zenos Case, in Case, E. C., and others, Permo-Carbon- 
iferous vertebrates from New Mexico: Carnegie Inst. Washington Pub. 181, p. 17-35.

Cope, E. D., 1878, Descriptions of extinct Batrachia and Reptiles from the Permian formation of Texas : Am. Philos. Soc. Proc., v. 17 , p. 505-530.

1881, The Permian formations of New Mexico: Am. Naturalist, v. 15, p. 1020-1021.

Cross, Whitman, 1899, Description of the Telluride quadrangle [Colo.] : U.S. Geol. Survey Geol. Atlas, folio 57, p. 1-15.

Cross, Whitman, and Howe, Ernest, 1905, Geography and generall geology of the [Silverton] quadrangle: U.S. Geol. Survey Geol. Atlas, folio 120, p. 1-25.

Cross, Whitman, and Larsen, E. S., Jr., 1935, A brief review of: the geology of the San Juan region of southwestern Colorado: U.S. Geol. Survey Bull. 843, p. 1-138.

Darton, N. H., 1928, "Red Beds" and associated formations in New Mexico, with an outline of the geology of the State: U.S. Geol. Survey Bull. 794, 356 p.

Elston, D. P., Shoemaker, E. M., and Landis, E. R., 1962, Uncompahgre Front and salt anticline region of Paradox Basin, Colorado and Utah: Am. Assoc. Petroleum Geologists Bull., v. 46, p. 1857-1878.

Gignoux, Maurice, 1960, Geologie Stratigraphique : 5th ed., Paris, Masson, $759 \mathrm{p}$.

Gilluly, James, 1963, The tectonic evolution of the western United States : Geol. Soc. London Quart. Jour. v. 119, p. 133174.

Gregory, H. E., 1917, Geology of the Navajo country ; a reconnaissance of parts of Arizona, New Mexico, and Utah: U.S. Geol. Survey Prof. Paper 93, 161 p.

Gregory, J. T., 1950, Tetrapods of the Pennsylvanian nodules from Mazon Creek, Illinois: Am. Jour. Sci., v. 248, No. 12, p. 833-873.

Hills, J. M., 1942, Rhythm of Permian seas-a paleogeographic study: Am. Assoc. Petroleum Geologists Bull., v. 26, No. 2, p. 217-255.

Holmes, W. H., 1877a, Report of William H. Holmes, geologist of the San Juan Division: U.S. Geol. and Geog. Survey Terr. (Hayden) 9th Ann. Rept., p. 237-276.

Holmes, W. H., 1877b. In Hayden, F. V. (in charge), Geological and geographical atlas of Colorado and portions of adjacent territory: U.S. Geol. and Geog. Survey Terr. (Hayden), sheets 14, 15.

Holmes, W. H., 1878, Report on the geology of the Sierra Abajo and west San Miguel Mountains : U.S. Geol. and Geog. Survey Terr. (Hayden) 10th Ann. Rept., p. 187-195.

Langston, Wann Jr., 1953, Permian amphibians from New Mexi-co: California Univ. Pubs. in Geol. Sci., v. 29, p. 349-416.

-1963 , Fossil vertebrates and the late Palaeozoic red beds of Prince Edward Island: Natl. Mus. Canada Bull. 187, Geol. Ser. 56, p. 1-36.

Larsen, E. S., Jr., and Cross, Whitman, 1956, Geology and petrology of the San Juan region, southwestern Colorado: U.S. Geol. Survey Prof. Paper 258, p. 1-303.

Lee, W. T., 1909, Stratigraphy of the Manzano group of the Rio. Grande Valley, New Mexico : U.S. Geol. Survey Bull. 389, 141 p.

Luedke, R. G., and Burbank, W. S., 1962, Geology of the Ouray Quadrangle Colorado: U.S. Geol. Survey Geol. Quad. Map GQ152

Marçou, Jules, 1856, Resumé and field notes, with a translation by W. P. Blake [Whipple's reconnaissance near the thirty-fifth parellel], in U.S. War Dept., Reports of explorations and surveys to ascertain the most practicable and economical route for a railroad from the Mississippi River to the Pacific Ocean : v. 3 , pt. 4, p. 121-164.

Marsh, O. C., 1878, Notice of new fossil reptiles: Am. Jour. Sci., ser. 3, v. 15, p. 409-411.

Moore, R. C., 1949, Rocks of Permian(?) age in the Colorado River Valley, north-central Texas: U.S. Geol. Survey Oil and Gas Inv. Prelim. Map 80, (2 sheets), scale 1 inch to 1 mile.

Olson, E. C., 1947, The family Diadectidae and its bearing on the classification of reptiles: Fieldiana, Geology, v. 11, p. 1-53.

1950, The temporal region of the Permian reptile Diadectes: Fieldiana, Geology, v. 10, p. 63-77.

1954, Fauna of the Vale and Choza: 7, Pelycosauria: Family Caseidae: Fieldiana, Geology, v. 10, p. 193-204.

1955, Fauna of the Vale and Choza: 10, Trimerorhachisincluding a revision of the pre-Vale species : Fieldiana, Geology, v. 10, p. 225-274.

Parrington, F. R., 1958, The problem of the classification of reptiles: Jour. Linnaean Soc. London, Zoology, v. 44, and Botany, v. 56, p. 99-115.

Peabody, F. E., 1957, Pennsylvanian reptiles of Garnett, Kansas : edaphosaurs: Jour. Paleontology, v. 31, p. 947-949.

Romer, A. S., 1935, Early history of Texas red-beds vertebrates : Geol. Soc. America Bull., v. 46, p. 1597-1658.

-1944, The Permian cotylosaur Diadectes tenuitectus: Am. Jour. Sci., v. 242, p. 139-144.

1946, The primitive reptile Limnoscelis restudied: Am. Jour. Sci., v. 244, p. 149-188.

1947, Review of the Labyrinthodontia: Mus. Comp. Zool. Bull., v. 99, p. 1-368.

1948, Relative growth in pelycosaurian reptiles: Roy. Sci. South Africa Spec. Pub., Robert Broom Comm. Vol., p. 45-55. 1952, Late Pennsylvanian and Early Permian vertebrates of the Pittsburgh-West Virginia region: Carnegie Mus. Annals v. 33, p. 47-113.

1956, Osteology of the Reptiles: Chicago Univ. Pressis, 772 p.

-1958, The Texas Permian red beds and their vertebrate fauna, in Westoll, T. S., ed., Studies on fossil vertebrates. Essays presented to D. M. S. Watson : London, Athlone, p. 157179.

1961, A large ophiacodont pelycosaur from the Pennsylvanian of the Pittsburgh region: Mus. Comp. Zool. Brev., no. $144,7 \mathrm{p}$.

Romer, A. S., and Price, L. I., 1940, Review of the Pelycosauria : Geol. Soc. America Spec. Paper 28, 538 p.

Scott, W. B., 1907, An introduction to geology : 2d ed., New York, MacMillan, $816 \mathrm{p}$.

Seltin, R. J., 1959, A review of the Family Captorhinidae: Fieldiana, Geology, v. 10, p. 461-509.

Spate, O. K. H., 1954, India and Pakistan: New York, Dutton, $827 \mathrm{p}$.

Stevenson, J. J., 1906, Carboniferous of the Appalachian basin : Geol. Soc. America Bull., v. 17, p. 65-228.

Tomlinson, C. W., 1916, The origin of the red beds; a study of the conditions of origin of the Permo-Carboniferous and Triassic red beds of the western United States: Jour. Geology, v. 24, p. $153-179,238-253$.

Vaughn, P. P., 1958a, On the geologic range of the labyrinthodont amphibian Eryops: Jour. Paleontology, v. 32, p. 918-922.

$-1958 \mathrm{~b}$, On a new pelycosaur from the Lower Permian of Oklahoma, and on the origin of the family Caseidae: Jour. Paleontology, v. 32, p. 981-991. 
Vaughn, P. P., 1962, Vertebrates from the Halgaito tongue of the Cutler formation, Permian of San Juan County, Utah: Jour. Paleontology, v. 36, p. 529-539.

1963, The age and locality of the late Paleozoic vertebrates from El Cobre Canyon, Rio Arriba County, New Mexico: Jour. Paleontology, v. 37, p. 283-286.

Watson, D. M. S., 1954, On Bolosaurus and the origin and classification of reptiles: Mus. Comp. Zoology Bull., v. 111, p. 297449.

Welles, S. P., 1941, The mandible of a diadectid cotylosaur : California Univ. Pub., Geol. Sci. Bull., v. 25, p. $423-432$.
White, T. E., 1939, Osteology of Seymouria baylorensis Broili : Bull. Mus. Comp. Zoology, v. 85, p. 325-409.

Williston, S. W., 1911a, A new family of reptiles from the Permian of New Mexico: Am. Jour. Sci., v. 31, p. 378-398.

1911b, American Permian Vertebrates: Chicago Univ. Press, $145 \mathrm{p}$.

1912, Restoration of Limnoscelis, a cotylosaur reptile from New Mexico : Am. Jour. Sci., v. 34, p. 457-468.

1915, A new genus and species of American Theromorpha, Mycterosaurus longiceps: Jour. Geology, v. 23, p. 554-559.

Williston, S. W., and Case, E. C., 1912, the Permo-Carboniferous of northern New Mexico: Jour. Geology, v. 20, p. 1-12. 


\title{
FOOTPRINTS FROM THE CUTLER FORMATION
}

\author{
By Donald BaIRd ${ }^{2}$
}

\begin{abstract}
Footprints occur in the Lower Permian Cutler Formation near Placerville, Colo. Limnopus cutlerensis n. sp., a small species similar to the Late Pennsylvanian L. vagus of Kansas, is ascribed to an eryopoid labyrinthodont. A korynichniid pes imprint similar to that of Brachydactylopus represents a small diadectid cotylosaur. Early Permian red beds ichnofaunas are quite different from contemporaneous dune-sand ichnofaunas; the latter represent tetrapod faunas of which skeletal records are lacking.

Three specimens of fossil footprints in the Museum of Comparative Zoology provide supplementary information on the tetrapod fauna of the Cutler Formation. I am indebted to George Edward Lewis, Peter Paul Vaughn, and Alfred S. Romer for the opportunity to study these specimens, and to Albert E. Wood and Joseph T. Gregory for access to comparative material at Amherst and Yale.
\end{abstract}

\section{SYSTEMATIC DESCRIPTIONS}

Genus LrMNoPUs Marsh, 1894

Limnopus cutlerensis Baird, n. sp.

Figure $14 B, C$

Type.-A trackway of five manus-pes sets on a channeled surface of reddish-brown micaceous siltstone; trackway preserved as a natural mold; MCZ 233.

Source.-Cutler Formation, Lower Permian. Locality 20, 80 feet above road level, north of mouth of Fall Creek, Mrs. Stockton Smith property, San Miguel County, Colo. Collected by S. J. Olsen, 1953.

The form-genus Limnopus as redefined (Baird, 1952) differs from Cursipes in having shorter digits and a prominent rounded pad at the base of digit $I$ in manus and pes. In pes structure Limnopus resembles Saurichnites salamandroides Geinitz from the Rotliegende of Bohemia, but the manus of Saurichnites is pentadactyl rather than tetradactyl (cf. a topotypic specimen at Yale, YPM 3764). As text figure 14 demonstrates, Limnopus cutlerensis shows close affinities with the type species, L. vagus Marsh, from the Upper Pennsylvanian (Virgil Series) of Kansas. Although the differencessmaller size, disproportionately smaller manus, more turned-out manus and pes, more posterior position of pes digit $V$ in L. cutlerensis-are not great, they justify

a Princeton University, Princeton, New Jersey. a specific distinction. Measurements of the type trackway are as follows:

Stride : $55-75 \mathrm{~mm}$; mean of six, $62 \mathrm{~mm}$.

Pace of manus : $38-44 \mathrm{~mm}$; mean of four, $41 \mathrm{~mm}$.

Pace of pes : 41-54 mm; mean of four, $49 \mathrm{~mm}$.

Trackway width : $55-57 \mathrm{~mm}$.

Pace angulation between pedes: $75^{\circ}-91^{\circ}$; mean of three, $79^{\circ}$

The trackmaker had a gleno-acetabular length (or "wheelbase") of about $48 \mathrm{~mm}$-slightly more than half that of the type individual of Limnopus vagus - and a total length estimated at $140 \mathrm{~mm}$. By its morphology and proportions the trackmaker seems to have been a small temnospondylous amphibian, probably an eryopoid rhachitome.

The known distribution of Limnopus footprints, last summarized in 1952, is enlarged by this and other additional records. A slab at Amherst (Hitchcock colln. 26/14) demonstrates that Thenaropus heterodactylus King (1845) from the Conemaugh Group (early Virgil?) near Greensburg, Pa., is a valid species of Limnopus and closest in form to L. littoralis (Marsh) from the Virgil of Kansas. The earliest known occurrence of the genus is in an equivalent of the Cow Run Sandstone of Stevenson (1906) (Conemaugh Group, Missouri) in Jefferson County, Ohio, where my field party found trackways of Limnopus heterodactylus (MCZ 253) in 1955.

Of course, we cannot determine how many amphibian genera are represented by the various Limnopus trackways, or whether these genera formed a natural taxonomic group. The ichnological record tells us only that trackmakers of varied size but of similar foot structure and body proportions ranged from Colorado east to Pennsylvania and persisted from Late Pennsylvanian into Early Permian time, that is, from the Missouri into the Wolfcamp.

Genus indet., cf. BRACHYDACTYLOPUS Toepelman and Rodeck, 1936

Figure $14 D$

Material.-Isolated imprint of right pes, preserved as a natural mold; MCZ 231. 

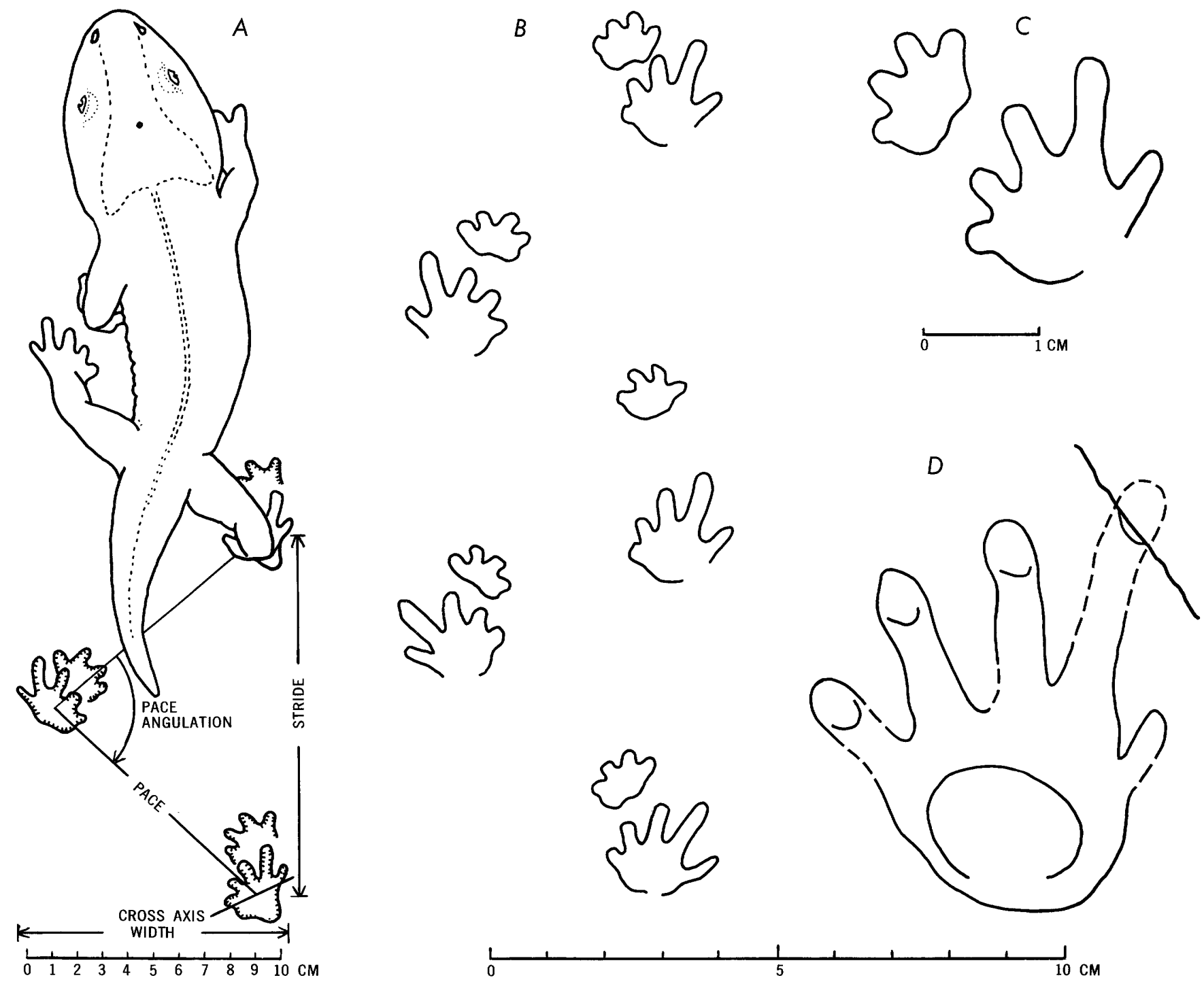

FIGURE 14.-A, Limnopus vagus Marsh, trackway with hypothetical reconstruction of trackmaker in walking pose (from Baird, 1952). B, Limnopus cutlerensis n. sp. (type trackway, $\mathrm{MCZ} 233$ ) ; footprint outlines restored. C. L. cutlerensis, composite restoration of right manus-pes set, enlarged. $D$, korynichniid right pes imprint, ef. Brachydactylopus (MCZ 231).

Source.-Micaceous reddish-brown siltstone near top of Cutler Formation. Locality 21, west side of the second side-canyon east of Placerville, a quarter of a mile south of San Miguel River, San Miguel County, Colo. Collected by A. D. Lewis, 1953.

This footprint, although too indistinct for generic identification, is evidently referable to the form-family Korynichniidae, a widely distributed group of Permian and Carboniferous footprint genera. The pes is pentadactyl with digits I to IV forming a sequence of increasing length; digit $\mathrm{V}$ is small and set well back on the lateral margin of the foot. The digit tips made deep oval impressions and there is no evidence of claws. The tarsal area is marked by the deep impression of an ovoid plantar pad, the long axis of which is somewhat obliquely inclined toward the direction of motion and forms a right angle with the axis of digit IV. Such a pad is characteristic of korynichniid footprints.

The small size and posterior, offset position of digit V distinguish this footprint from Ichniotherium and Korynichnium of the German Rotliegende and the English Lower Permian. (See Korn, 1933, and works cited in Korn.) Megabaropus from the Upper Pennsylvanian (Benwood Limestone Member, Monongahela Formation, Virgil) of Ohio (Baird, 1952, p. 839) has a similar fifth digit but differs from the Cutler footprint in its heavy, splayed digits and reniform tarsal pad. Closer comparisons can be made with Brachydactylopus 
fontis Toepelman and Rodeck (1936) from the Permian and Pennsylvanian Fountain Formation of the Colorado Front Range. Another similar form is Tridentichnus supaiensis (Gilmore (1927) (with which I synonymize Ammobatrachus turbatans Gilmore, 1928), from the Supai Formation of the Grand Canyon, Ariz. Another species of korynichniid footprints, left undescribed at the untimely death of Frank E. Peabody, occurs in the Upper Pennsylvanian (Rock Lake Shale Member, Stanton Limestone, Virgil) of Garnett, Kans. All the American forms just listed are here referred for the first time to the form-family Korynichniidae. Until they can be comprehensively restudied, and until better material of the Cutler species is available, further comparisons are unprofitable.

Korynichniid footprints have been correlated with diadectid cotylosaurs by Nopesa (1923) and Lotze (1928), although Korn (1933) believed the affinities of Korynichnium to lie with the procolophonids rather than the diadectids. (See, however, the recent summary by Schmidt, 1959, p. 116.) In my opinion the direct correspondence of korynichniid manus imprints to the articulated manus of Diadectes described in the preceding section, and the long-known similarity of the pes imprints to the pes of Diadectes as described by Romer and Byrne (1931), leave little doubt that the korynichniid footprints are of diadectid origin. The conspicuous imprint of a tarsal pad in all korynichniid pes tracks correlates well with the massive diadectid astragalus (cf. Schaeffer, 1941, p. 431). The isochronous distribution of korynichniid footprints and diadectid skeletons is supporting evidence.

A third footprint specimen from the Cutler (MCZ 232 ), found near locality 6 by G. E. Lewis in 1953, consists of an arc of four round digit-tip impressions which measures $75 \mathrm{~mm}$ in span. This footprint may be that of a korynichniid but it might equally well have been made by an amphibian such as Eryops.

Some hundreds of footprints from the Cutler ("Abo") Formation of New Mexico were collected for the University of Missouri in 1946 by Carl C. Branson (Branson and Branson, 1946). I have not, unfortunately, had the opportunity to accept Dr. Branson's generous invitation to examine this noteworthy collection and to make comparisons with the Cutler specimens described above.

\section{PROSPECTUS AND PROBLEMS}

Except for a few piecemeal descriptions of species, footprints from red beds facies of the Lower Permian have been little studied in recent years. The classic ichnofaunas from North American red beds-those of the Supai and Hermit Formations in the Grand Canyon of Arizona (Gilmore, 1926-1928) and the Clear Fork Group at Castle Peak, Tex. (Moodie, 1929, 1930) -were gravely misunderstood by their describers and need extensive redescription and taxonomic revision before they can be compared fruitfully with contemporary footprints and skeletal material. (I have assembled, in the form of latex molds, the material for such a study.)

In Europe the situation is somewhat better. The Rotliegende ichnofauna of Central Europe has been exhaustively studied by Pabst (1908 and earlier) and reinterpreted by subsequent authors, although its nomenclature is still confused through Pabst's arbitrary use of a pseudo-Linnaean system of names. This Rotliegende fauna also occurs near Birmingham, England (Hardaker, 1912). There is thus a useful European standard of comparison for further work on the ichnology of Permian red beds in this country. Another major task is the tracing of Permian footprint genera back into the Pennsylvanian; much undescribed Pennsylvanian material awaits study and nearly all the described forms need restudy.

Quite a different set of problems are presented by the trackways recorded in Permian beach and dune sands. Footprints made in this environment-for example, those from the Coconino Sandstone, the De Chelly Sandstone Member of the Cutler Formation of Arizona, and the Lyons Sandstone of Colorado-are quite unlike those from Cutler and other contemporary red beds; their affinities lie rather with Permian dune-sand footprints from Great Britain (reviewed by Hickling, 1909) and the Cornberger Sandstein of Germany (Schmidt, 1959). Footprints made in sloping sand are much more difficult to interpret than those made on mudflats, but so far as I can see the ichnofaunas of red beds and dune sands have nothing in common. To add to our diffculties, the dune-sand environment rarely preserved skeletal remains. Thus one contribution of ichnology to Permian faunistics is to remind the student-of-bones that an evolving facies-fauna quite different from his familiar red beds fauna was lurking offstage, so to speak, ready to supply taxonomic novelties whenever changing conditions in the red beds area favored their introduction.

\section{REFERENCES CITED}

Baird, Donald, 1952, Revision of the Pennsylvanian and Permian footprints Limnopus, Allopus and Baropus: Jour. Paleontology, v. 26, no. 5, p. 832-840, pls. 122-124, 4 text figs.

Branson, E. B., and Branson, C. C., 1946, Footprints from the Abo formation of New Mexico [abs.]: Geol. Soc. America Bull., v. 57, p. 1181. 
Gilmore, C. W., 1926, Fossil footprints from the Grand Canyon: Smithsonian Misc. Colln., v. 77, no. 9, 41 p., 12 pls., 23 text figs.

1927, Fossil footprints from the Grand Canyon: second contribution: Smithsonian Misc. Colln., v. 80, no. 3, 78 p., 21 pls., 37 text figs.

1928, Fossil footprints from the Grand Canyon: third contribution: Smithsonian Misc. Colln., v. 80, no. 8, 16 p., 5 pls., 7 text figs.

Hardaker, W. H., 1912, On the discovery of a fossil-bearing horizon in the 'Permian' rocks of Hamstead Quarries, near Birmingham: Geol. Soc. London Quart. Jour., v. 68, pt. 4, p. 639-681, 30 text figs.

Hickling, George, 1909, British Permian footprints: Manchester Lit. Philos. Mem., v. 53, pt. 3, no. 22, 31 p., 4 pls.

King, A. T., 1845, Description of fossil footmarks, found in the Carboniferous series in Westmoreland County, Pennsylvania : Am. Jour. Sci., v. 48, no. 2, p. 343-352, 9 text figs.

Korn, Hermann, 1933, Eine für die Kenntnis der Cotylosaurier des deutschen Perms bedeutsame Schwimmfährte von Tambach [A significant trackway from Tambach for knowledge of the Cotylosauria of the German Permian]: Palaeobiologica, v. 5, no. 2, p. 169-200, pl. 15, 4 text figs.

Lotze, F., 1928, Die Tambacher Sphaerodactylum-Fährten [The Sphaerodactylum tracks from Tambach] : Paläont. Zeitschr., v. 9, p. 170-175.
Marsh, O. C., 1894, Footprints of vertebrates in the Coal Measures of Kansas: Am. Jour. Sci., ser. 3, v. 48, p. 81-84, pls. 2-3. Moodie, R. L., 1929, Vertebrate footprints from the Red Beds of Texas: Am. Jour. Sci., ser. 5, v. 17, p. 352-368, 9 text figs. 1930, Vertebrate footprints from the Red Beds of Texas, II : Jour. Geology, v. 38, p. 548-565, 16 text figs.

Nopesa, Franz, 1923, Die Familien der Reptilien [The families of the Reptilia]: Geologie u. Paläontologie Fortschr., no. 2, 210 p., 6 pls.

Pabst, Wilheim, 1908, Die Tierfährten in dem Rotliegenden "Deutschlands": Acad. Leop.-Carol. Nova Acta, v. 89, no. 2, p. $313-481,35$ pls., 36 text figs.

Romer, A. S., and Byrne, Frank, 1931, The pes of Diadectes: Notes on the primitive tetrapod limb: Palaeobiologica, v. 4, p. 25-48, 9 text figs.

Schaeffer, Bobb, 1941, The morphological and functional evolution of the tarsus in amphibians and reptiles: Am. Mus. Nat. History Bull., v. 78, art. 6, p. 395-472, 21 text figs.

Schmidt, Hermann, 1959, Die Cornberger Fährten im Rahmen der Vierfüssler-Entwicklung [The trackways from Cornberg in the frame of the evolution of the tetrapods] : Hessisches Landesamt für Bodenforschung Abh., no. 28, 137 p., 9 pls., 57 text figs.

Toepelman, W. C., and Rodeck, H. G., 1936, Footprints in Late Paleozoic red beds near Boulder, Colorado: Jour. Paleontology, v. 10, no. 7, p. 660-662, 2 text figs. 